
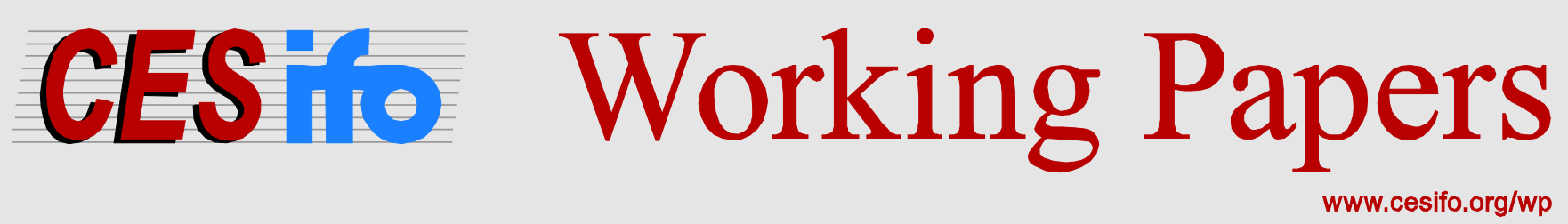

\title{
What Do We Know About the Global Financial Safety Net? A New Comprehensive Data Set
}

\author{
Beatrice Scheubel \\ Livio Stracca
}

CESIFO WORKING PAPER NO. 6184

CATEgory 6: Fiscal Policy, MaCROECONOMICS AND GROWTH

NOVEMBER 2016

An electronic version of the paper may be downloaded

- from the SSRN website: Www.SSRN.com

- from the RePEc website: $\quad$ www.RePEc.org

- from the CESifo website: www.CESifo-group.org/wp 


\title{
What Do We Know About the Global Financial Safety Net? A New Comprehensive Data Set
}

\begin{abstract}
This paper critically reviews the theoretical basis for the provision of the global financial safety net (GFSN) and provide a comprehensive database covering four elements of the GFSN (foreign exchange reserves, IMF financing, central bank swap lines and regional financing arrangements) for over 150 countries in the sample period 1960-2015. This paper also presents some key stylised facts regarding the provision of GFSN financing and compares macroeconomic outcomes in capital flow reversal episodes depending on how much GFSN financing was available to countries. Finally, this paper concludes with some avenues for further research on the possible evolution of the GFSN.
\end{abstract}

JEL-Codes: F320, F330, F340, G010, H870.

Keywords: global financial safety net, financial integration, financial globalisation, IMF.

Beatrice Scheubel

European Central Bank

Frankfurt / Germany

beatrice.scheubel@ecb.europa.eu
Livio Stracca

European Central Bank

Frankfurt / Germany

livio.stracca@ecb.europa.eu

November 9, 2016

This paper is based on previous work with Risto Herrala. We thank Donata Faccia, Katja Jakobs, Sandra Rhouma and Irina Andone for data support. We also thank Arnaud Mehl, Regine Wölfnger, Michael Sturm and Benjamin Vonessen for useful suggestions. The views expressed belong to the authors and are not necessarily shared by the ECB. The data set for this paper can be downloaded at

https://www.ecb.europa.eu/pub/research/occasional-papers/html/index.en.html with Occasional Paper No. 177. 


\section{Introduction}

The global financial safety net (GFSN) - a set of institutions and mechanisms which provide financial support to countries hit by a financial crisis (often currency, banking or sovereign crisis) - is widely considered to be an essential element of the international financial architecture and a necessary infrastructure to support financial integration and globalisation. Foreign exchange reserves, central bank swap and repo lines, funding by international institutions and regional financing arrangements are considered the key elements of the GFSN. At the same time, the GFSN is still far from being a coherent construction. In fact, an adjective that often accompanies the description of the GFSN is 'patchy'. However, the GFSN has not been established with one coherent design. A benevolent social planner, internalising all of the externalities, is certainly not behind the current design. ${ }^{2}$ The elements of the GFSN are diverse, have different origins, follow different rules and incentives, and help in addressing different types of crises. Consequently, they do not reflect a widely shared consensus at the international level. Instead, they are the result of the accumulation and stratification of different forms of financial insurance, often influenced by domestic rather than global interests.

An evaluation of the current design of the GFSN is often hampered by the lack of a coherent description of its elements and the absence of data availability. Against this backdrop, the purpose of this paper is fourfold. First, this paper provides a detailed description of the current configuration of the GFSN, including in particular its four main elements: (i) own foreign exchange reserves, (ii) IMF loan facilities, (iii) regional financing arrangements (RFAs) and (iv) central bank swap lines. As it is argued at length in the paper, one important dividing line between different forms of insurance is whether there is conditionality attached or not. Broadly speaking, own reserves and central bank swap lines do not involve conditionality; IMF and RFA lending do. Second, this paper provides the reader with a concise yet reasonably comprehensive overview of the existing literature on the GFSN, including about its theoretical underpinnings, from which a lack of consensus on the optimal design of the GFSN is clearly visible, which is to

\footnotetext{
${ }^{2}$ Reviewing the international financial architecture, including the GFSN, is one of the objectives of the Chinese Presidency of the G20 this year.
} 
some extent rather unsettling. Third, this paper provides an annual database for over 150 countries, available online from the ECB website, of the existing access to the GFSN, together with a comprehensive list of variables that may be useful to understand financial integration and the role of the GFSN in supporting it. In fact, any serious discussion on the GFSN should start from an understanding of the facts and solid empirical work, and the database will hopefully provide an impetus to this kind of analysis and to a more informed discussion at the policy level. Fourth and finally, the potential of the database is illustrated by providing some key stylised facts about the availability of the GFSN. This paper also provides evidence on the usefulness of the GFSN for individual countries, in particular when faced with capital flow reversals. This analysis finds positive results with regard to the effect of (actual or potential) access to the GFSN on the severity of sudden stop episodes. While there is some evidence that a higher GFSN coverage cushions the impact of such episodes, the effects are not always economically large. Clearly, this is an area where further research is needed. The paper is organised as follows. In Section 2 the theoretical and practical arguments involved in the discussion on the optimal set-up of international safety nets are outlined in order to highlight key open issues which warrant closer analysis. Section 3 describes the four key elements of the GFSN and how they are captured in the database. Section 4 provides some stylised facts regarding the provision of GFSN financing to illustrate the key variables of the database and how the database can be used to analyse pertinent research questions. Section 5 concludes.

\section{Global financial safety nets}

\subsection{The rationale for GFSN}

This section provides a broad yet reasonably concise overview of the issues associated with the provision of the GFSN. The purpose of this section is to highlight many interesting unanswered questions concerning the GFSN which require more extensive empirical analysis, to which the database can contribute. The reader who is familiar with the GFSN debate may go directly to Section 3 for more innovative content, in particular on the GFSN database, which is the central contribution. 


\subsubsection{Why is there a safety net at all?}

From an economic point of view, the main rationale for the existence of safety nets, in particular publicly provided ones, is the existence of negative externalities. The analysis by Stiglitz and Orszag (2002) of the optimal size of fire departments is a useful parable for the existence of externalities in crisis prevention and resolution in that fires can spread from home to home in the same way as crises may spread between different countries. Financial crises have a lot in common with fires in that they reflect both effort (good policies) and luck (exogenous shocks) that are difficult to disentangle. Moreover, contagion is a regular characteristic of crisis episodes. The presence of externalities makes private solutions in principle inefficient, and a global social planner may want to internalise the external effects of crisis episodes. For that reason, a certain amount of provision of financial safety nets is prima facie a sensible thing to have.

However, since financial safety nets are de facto a form of insurance, the provision of a safety net may cause moral hazard similar to any other form of insurance provision. In the Stiglitz and Orszag (2002) analogy, the presence of externalities affects the optimal size of the fire department. A higher probability of fires jumping from one home to the next implies a higher optimal size, but above a certain threshold a further increase may be counterproductive, because it may discourage households from investing in fire prevention (ex ante moral hazard). This moral hazard problem is larger if fire prevention effort is unobservable. Full insurance (a very large fire department) is optimal only for fires that arise for exogenous reasons and are not preventable with fire prevention effort. Similarly, the existence of a safety net for countries may induce them to invest less in good policymaking if the safety net is large and creditors can lend imprudently to vulnerable countries (thereby increasing their own vulnerability), in the expectation that support will be provided in the event of a crisis. Therefore, as in other domains of insurance, fire safety like global crisis insurance does not imply perfect insurance as an optimal solution, because of the moral hazard created by not being able to observe prevention efforts.

From a political point of view, the existence of options to provide financial support to a country hit by a crisis supports regional and global cohesion. As crises 
easily spread across borders, containing them fosters political agreement between neighbouring countries. Regional insurance mechanisms, in addition, provide fora for regional exchanges and thereby foster a regional dialogue to address economic challenges.

\subsubsection{What are the relevant lessons from the domestic lender of last resort function?}

As pointed out by several previous contributions (Fischer, 1999; Fernández-Arias and Levy-Yeyati, 2010), a useful starting point to discuss the functioning of the global financial safety net is the domestic lender of last resort (LOLR) function. ${ }^{3}$ The doctrine behind the domestic LOLR function is built on the need to prevent costly deleveraging driven by runs on financial intermediaries and their short-term debt liabilities. 'Illiquid but solvent' institutions should receive LOLR funds in the event of distress. If private interbank markets are not able to play that insurance role a public entity with 'deep pockets' has to provide LOLR financing. Because central banks sit at the top of the money hierarchy, they have been traditionally entrusted with the role of LOLR - indeed some of them, like the US Federal Reserve System (Fed), were created precisely with that objective in mind. At the same time, being able to produce money at will is a desirable characteristic of a lender of last resort but not a knock-out criterion, as pointed out by Fischer (1999).

Also in the domestic setting, the provision of LOLR financing is fundamentally associated with the risk of moral hazard because it may lead to higher financial fragility and risk. It is important to recognise that moral hazard is a problem without a perfect solution in real-world situations; the best that can be done is to manage the trade-off effectively (Fischer, 1999).

An important part of the domestic LOLR doctrine is the Bagehot precept to 'lend freely, against good collateral and at a penalty rate' (even if Bagehot himself did not use exactly those words). The requirement to have good collateral (though

\footnotetext{
${ }^{3}$ Although the LOLR literature is generally underdeveloped, some good surveys are available, for example Grossman and Rockoff (2014).

${ }^{4}$ Morris and Shin (2004) extend the same idea to lending relationships more generally. They assume that creditors of a distressed borrower face a coordination problem. Even if the fundamentals are sound, fear of premature foreclosure by others may lead to pre-emptive action, undermining the project.
} 
not as good as that accepted in normal operations or in the interbank market) not only protects the central bank balance sheet, but also prevents the build-up of further moral hazard.

The penalty rate is the least settled element of the Bagehot doctrine. Apart from the fact that it is not clear what Bagehot really meant by 'penalty' (Goodhart, 1999), the effect of a penalty rate is ambiguous. On the one hand, a penalty might discourage moral hazard by reducing the net present value of LOLR loans for intermediaries in distress; on the other hand, it would lower the effectiveness of the LOLR, which becomes particularly important if externalities are large. As a matter of fact, a penalty rate is not always applied in LOLR operations; in particular, this was generally not the case during the global financial crisis. ${ }^{5}$

In practice, the LOLR faces a difficult signal extraction problem, where it needs to decide whether a financial institution is in distress owing to a run or to its fundamental weakness. InRochet and Vives (2004), for example, runs may be driven by both 'sunspots' and fundamentals. While it is clearly a task for the LOLR authority to prevent deleveraging due to sunspots, runs that are the result of fundamentals should in principle not be prevented at all.

One dimension of considerable practical importance in the domestic provision of LOLR loans is the optimal degree of ex ante predictability. To be effective in preventing costly runs and provide beneficial insurance to the private sector (Holmstrom and Tirole, 1998), the provision of LOLR loans should ideally be automatic and based on ex ante eligibility. At the same time, automaticity may worsen moral hazard and encourage intermediaries to game the system. If the LOLR provider could perfectly discriminate between illiquidity (owing to exogenous shocks) and insolvency (owing to inadequate effort or policies), this point would be irrelevant, but if the extraction of the signal is imperfect or costly, it may be optimal not to ensure full automaticity. In fact, some authors have advocated constructive ambiguity (Freixas, 2000). This would, however, give rise to other problems, such as time inconsistency. It is in fact usually optimal to provide LOLR funding ex post (i.e. once a crisis is already under way), but not to commit ex ante (when it is not

\footnotetext{
${ }^{5}$ As in the international context, one important practical question is the seniority of LOLR claims vs. private sector claims and how this affects the optimal provision of LOLR financing. See among others Kahn and Santos (2005).
} 
known if a crisis will come), to prevent moral hazard; the resulting equilibrium may well be unsustainable.

\subsubsection{What is different in the international context?}

There are important similarities between the domestic and international provision of LOLR loans. Domestic runs are typically determined by the fragility of financial intermediaries and in particular by the presence of short-term debt on the liabilities side of their balance sheets. It makes conceptually little difference if short-term debt is foreign debt or if the debt is denominated in foreign currency; the fundamental objective and trade-off of the LOLR authority is largely the same, i.e. preventing inefficient deleveraging while being mindful of moral hazard.

There are, however, some important practical differences for the provision of LOLR financing in the international context. First, if external liabilities are denominated in foreign currency, the central bank may not have the 'deep pockets' required to provide LOLR loans effectively. In a sense, the run eventually becomes a run on the domestic central bank, which can only be prevented by an institution with deep pockets filled with foreign currency. Second, an international LOLR (public or private) has fewer means to influence the behaviour of borrowers and to require adequate collateral, for the simple reason that countries are sovereign and enforcement by international courts and laws is far more difficult. For example, one way to mitigate moral hazard in the domestic context is to regulate banks and possibly to impose sanctions on those who made mistakes, but this is typically not possible in the case of sovereigns. Third, in the absence of a truly global central bank any international LOLR is unlikely to have unlimited financial means.

A wider interpretation of a 'run' in the international context would include any sharp movements of foreign investors (or even domestic investors) out of domestic debt that imply downward pressure on the currency and cannot be adequately countered by the central bank using its foreign reserves. These may take the form of sudden stops, retrenchment or capital flight (Forbes and Warnock, 2012). In many cases the main concern, rather than abrupt deleveraging by itself, is a sharp and undesirable depreciation of the currency, possibly characterised by overshoot- 
ing. ${ }^{6}$ Indeed, currency and banking crises often come together (twin crises) as one vulnerability feeds the other in a negative feedback loop. Exposure to sudden stops is also a function of countries' financial openness. For that reason, capital controls, if substantial and effective, generally reduce the need for international insurance (Cordella and Levy-Yeyati, 2006).

It is useful here to draw a parallel again with the fire safety example. Shortterm foreign debt is susceptible to run-like behaviour (fire), which is costly. Runs (fires) depend on both fundamentals over which countries have some control (and on which they can expend some effort) and sunspots (say, the neighbouring country experiences a financial crisis or the neighbouring house goes on fire). In principle, fire safety (financial safety nets) should cater only for the second type of phenomena, but in reality they are difficult to tell apart. More externalities (more contagion or more spreading of fire) should lead to more safety nets (fire departments). Homeowners could hold large water reservoirs (foreign reserves) to put out fires (sudden stops), but this is costly and it would be globally more efficient to have a global LOLR to provide water (loans in foreign currency) only when needed. ${ }^{7}$

In the same way that private financial intermediaries can access LOLR loans in the event of distress, a global financial safety net implies that a central bank should be able to borrow foreign reserves in the event of distress at the country level (sudden stop or capital flight). And indeed there is quite some evidence that the availability of some form of insurance may be beneficial. Eichengreen et al. (2008) show that countries are less likely to experience sudden stops in capital flows in years following IMF programmes, in particular if they have strong fundamentals, while Papi et al. (2013) show that IMF lending programmes reduce the

\footnotetext{
${ }^{6}$ If preventing deleveraging was the only concern, it should in principle always be possible for the domestic central bank to prevent it, possibly by purchasing foreign currency in the foreign exchange market. See Blanchard et al. (2015) for a recent analysis of why capital flow reversals are costly for countries. More generally, the aim is to prevent an overshooting (of the depreciation), but this paper still do not know much about why an overshooting would happen or why it would be undesirable from a welfare perspective.

7 Of course, in practice in the case of the international LOLR, extinguishing the fire is ultimately the responsibility of national authorities (with their own incentives that may deviate from the maximisation of global welfare); the international LOLR can only facilitate their task to some extent. Preventing and extinguishing financial crises is much more difficult than extinguishing fires.
} 
probability of banking crises. Looking at the global financial crisis, Dominguez et al. (2012) find that countries with higher reserve holdings experienced higher real GDP growth in the crisis years. Goldberg et al. (2010) find that the dollar swap lines among central banks were effective at reducing the dollar funding pressures abroad and stresses in money markets. They also conclude that the central bank dollar swap facilities are an important part of a toolbox for dealing with systemic liquidity disruptions. Obstfeld et al. (2009) note that international reserve demand can be rationalised by a central bank's desire to backstop the broad money supply to avert the possibility of an internal/external 'double drain', i.e. a bank run combined with capital flight. They show that a country's reserve holdings just before the global financial crisis, relative to their predicted holdings based on financial motives, can significantly predict exchange rate movements of both emerging and advanced countries in 2008. Currencies of countries with larger reserve holdings did not depreciate, and some even appreciated. In fact, current account balances and short-term debt levels are not statistically significant predictors of depreciation once reserve levels are taken into account. Fernandez-Arias and Levy-Yeyati (2012) find that in the Lehman episode (an exogenous global shock) larger reserve holdings as a share of foreign debt predicted a lower increase in sovereign (EMBI) spreads over a cross section of emerging markets.

\subsubsection{Should there be conditionality in the international lender of last resort funtion and, if so, how much?}

Since financial safety nets are de facto a form of insurance, the provision of a safety net may cause moral hazard similar to any other form of insurance provision. First, it may induce ex ante moral hazard in that countries may invest less in good policymaking and creditors may lend imprudently to vulnerable countries (thereby increasing their own vulnerability), in the expectation that support will be provided in the event of a crisis. Second, it may promote ex post moral hazard in that it may induce crisis-hit countries to delay needed adjustment. Therefore, the GFSN needs to be designed in such a way as to encourage and support the implementation of sound domestic policies.

Jeanne and Zettelmeyer (2001) emphasise that especially ex ante conditionality is essential to prevent moral hazard. They have a broad interpretation of moral 
hazard, implying not only taking risks with the money of the global taxpayer but also with that of the domestic taxpayer, who can eventually foot the bill for bad policies. In other words, it should be avoided that the international community at large becomes the accomplice of bad domestic policies.

Therefore, one element which is often present in the international LOLR (ILOLR) but typically absent, at least explicitly, in the domestic setting is conditionality, implying that LOLR loans are provided under certain conditions 'with strings attached'. Conditionality can be ex ante (qualification to obtain LOLR loans) or ex post (LOLR loans are released only against evidence of compliance).

The IMF in particular provides its loans subject to conditionality, which has been refined since the introduction of the Stand-by Agreement (SBA) facility in 1952, to safeguard its resources in line with its Articles of Agreement. ${ }^{8}$ Ensuring that the Fund is paid back is obviously crucial owing to its nature of an international credit union, where its members are also its shareholders. To a certain extent, IMF conditionality may be seen as a form of collateral, the use of which is more difficult in an international context. A good overview of conditionality in IMF lending is provided by Dreher (2009). According to Jeanne et al. (2008), with the doctrine of conditionality the IMF has developed a 'lending technology' whereby it can elicit, more effectively than uncoordinated private investors, policy adjustments from crisis countries. The decision behind IMF lending is therefore not only or even not mainly of the 'illiquid or insolvent' type as is typical in the domestic provision of LOLR financing, but rather is one about whether countries are 'conditionally solvent', i.e. conditional on good policies.

Dreher and Vaubel (2004) and Dreher (2009), among others, raise fundamental concerns about IMF-style conditionality. Dreher and Vaubel (2004) find that the number of conditions attached by the IMF depends negatively on international reserves and positively on interest rates; this would suggest that conditionality is more stringent for countries with weaker outside options, rather than necessarily weaker fundamentals and hence more in need of emergency lending. Moreover,

\footnotetext{
${ }^{8}$ Bird (2007), among others, suggests that there have been strong signs of an "upward creep in conditionality" in IMF lending over time. Note that RFAs also typically resort to conditionality. There is a large body of literature on conditionality more generally; in this paper, the focus is only on those elements which are important in the provision of GFSN financing.
} 
they discuss several arguments against conditionality, including the fact that it may undermine democracy ${ }^{9}$; the weakness of structural conditionality (see also Radelet and Sachs, 1998); the poor implementation record, which together with the fact that the IMF is almost always paid back weakens the argument that conditionality is a form of collateral; that ex post conditionality is particularly ineffective in reducing moral hazard; and that consensus is often not possible on the best policies to pursue, and so it is unlikely that the IMF knows them.

Approaches to limit moral hazard in the provision of emergency liquidity in the international context differ among the elements of the GFSN, depending on their purpose and set-up. As IMF conditionality represents a unique institutional apparatus, some other elements of the GFSN, such as some RFAs, condition at least part of their lending on a country having in place an IMF programme simultaneously. At the same time, other RFAs lend to support infrastructure and regional cohesion, thus placing a lesser emphasis on containing moral hazard. The case for swap and repo lines is even more specific as they are provided under the mandate of the participating central banks and may, but need not, be granted under specific conditions.

Clearly, an understanding of the pros and cons of conditionality also has important implications for the optimal design (and the desirability of different forms) of the GFSN. In turn, the optimal set-up of conditionality also depends on the interaction between the different elements of the GFSN.

\subsubsection{Who is in the best position to provide ILOLR financing?}

During a capital flow reversal episode, the domestic central bank mostly needs foreign reserves, whereas during non-crisis episodes central bank money is the primary commodity of the domestic LOLR. One first important question is whether this insurance function is best performed by accumulating reserves individually (self-insurance) or by pooling (global insurance). Clearly, self-insurance may be more efficient as it involves less information asymmetries and other frictions, but it is also more costly and inefficient because diversification gains are not reaped. A pooled solution, by contrast, reaps economies of scale and the benefits of diversi-

\footnotetext{
9 Of course, one has to keep in mind here that IMF programmes are often approved by democratically elected governments.
} 
fication (at least as long as crises are to some extent idiosyncratic), but is fraught with a number of practical complications that could already be seen. A first-best solution may well therefore involve a combination of self and pooled insurance. In particular, some form of pooled insurance will generally be needed for truly global liquidity crunches; as noted by Fernandez-Arias and Levy-Yeyati (2012), in the event of a global negative shock only the issuer of reserve assets can perform an effective LOLR function. Until the global financial crisis, it was relatively uncontroversial that the IMF is the international LOLR. With the global financial crisis and the large dislocations in global capital flows, doubts have been raised about whether the IMF's pockets are sufficiently deep to provide ILOLR financing effectively. ${ }^{10}$ In parallel, major central banks (in particular the US Federal Reserve) provided large amounts of LOLR loans in the form of swap lines in the wake of the global financial crisis. This has led some authors such as Capie and Wood (1989) and Truman (2013) to argue that only central banks have the necessary balance sheet elasticity to be the ILOLR. Truman (2013) is particularly in favour of a more robust global financial safety net centred on central banks 'because that is where the money is'. ${ }^{11}$ Central banks are seen by some as ideally suited to handle in particular fast-developing crises with practically unlimited potential short-term liquidity needs (Truman, 2013; Papadia, 2013).

Another problem associated with IMF lending is the perceived stigma effect of IMF conditionality. Bird and Mandilaras (2011) find, for example, that IMF programmes have had a significant positive effect on subsequent reserve accumu-

\footnotetext{
10 The key question, more than the absolute size of IMF restheces, is one of elasticity in meeting potential financing needs. In the context of the present IMF governance, there is no mechanism to ensure that IMF restheces adequately match potential financing needs arising from, say, deepening financial globalisation other than its regular quinquennial quota reviews. As a consequence, to be able to react to exceptional resthece needs during the global financial crisis, the IMF bolstered its restheces by temporarily borrowing from some of its members.

11 Bordo et al. (2014) describe the early use of central bank swap lines by the Federal Reserve, which this paperre mostly used to prevent gold losses (potentially leading to a dollar depreciation) in the latter phase of the Bretton Woods system when the United States had very little foreign reserves. Swap lines with foreign (G10) central banks continued to be used in the 1970s after the collapse of Bretton Woods. Moreover, the United States had a swap line with Mexico from 1967 which was drawn upon in the Mexican crisis in the mid-1990s. The use of swap lines as a general tool to prevent runs towards the dollar did not happen before the global financial crisis. Bordo et al. (2014) also discuss the complex interaction with the US Treasury and Congress related to the use of swap lines by the Federal Reserve.
} 
lation, allowing for other determinants, and that this effect endures over time. This suggests (although it does not necessarily prove) that the cost of IMF conditionality pushes countries to self-insure excessively, which may have negative global repercussions (e.g. stoking the creation of global imbalances). Similar to a too high penalty rate in the Bagehot doctrine, IMF conditionality may result in a suboptimal insurance provision and may lead countries to either excessively self-insure or to under-insure, creating negative externalities. At the same time, if conditionality serves to limit IMF lending and exposure to countries with weak fundamentals, some degree of stigma is not necessarily suboptimal.

If the IMF faces limits in raising enough funds and if its conditionality doctrine is fraught with problems, should one support a shift towards a GFSN system based on central bank swap lines? Building the global financial safety net around central bank swap lines (or other types of financing) gives rise to significant problems. Central banks currently do not have the legal mandate to be the ILOLR and can only perform this function for overriding reasons of domestic interest, for example to prevent a financial crisis in a country with which their countries have strong trade and financial ties. They are not entrusted with a global mandate. In addition, they do not have the 'lending technology' of the IMF which has proved successful at least in terms of the repayment rate of LOLR loans and which is still widely considered to be irreplaceable in preventing excessive moral hazard, despite the doubts raised in the academic literature. Moreover, the senior status of IMF loans may be important for the efficient provision of ILOLR funding (if only de facto and not de jure) and it is unclear how central bank loans could retain the same status. Finally, combining central bank swap lines (deeper pockets) with IMF conditionality (more efficient lending technology as LOLR), as suggested by Cordella and Levy-Yeyati (2006) and others, is also not unproblematic. It can be argued that IMF conditionality is only effective if the Fund maintains some 'skin in the game' and it is not clear how conditionality could really be delegated. ${ }^{12}$ At a minimum, this would raise complex institutional issues that would have to be dealt with effectively.

\footnotetext{
12 The authors thank Susan Schadler for suggesting this to them.
} 


\subsection{The recent debate on the GFSN}

\subsubsection{Is the current GFSN large enough?}

An important part of the policy debate about the GFSN concerns the issue of whether it is sufficient in terms of its size and coverage to safeguard global financial stability. Cordella and Levy-Yeyati (2006), Pickford (2011) and Truman (2013), among others, maintain that the GFSN does not command sufficient funds to properly safeguard global financial stability. Truman (2013), in particular, points out that the financial crises of the past decades show that financial integration has increased markedly and, subsequently, financial stability has become more dependent on global financial conditions. In his view, the IMF and RFAs are not nearly big enough to safeguard global financial stability. A viable option to address this issue is central bank coordination, perhaps in the form of a central bank swap network, since central banks are in his view the only players with sufficient financial leverage to credibly address future threats.

In a related vein, Fernández-Arias and Levy-Yeyati (2010) and Shafik (2015) argue that the GFSN is too patchy, in particular as regards its ability to address problems in the poorer countries. Rajan (2014) calls for the global community to better identify those countries that do not have their own bilateral, regional or multilateral liquidity arrangements to fall back on, and to work to improve their situation. In his view, there is a strong interest also for developed countries to internalise the possible negative spillovers of emerging market economy (EME) vulnerabilities which, in part, reflect the expansionary monetary policies in the developed world during the recent past.

Destais (2014) and Hawkins et al. (2014) argue that the prominent role of temporary arrangements in the GFSN such as swap lines create the problem of unpredictability. Destais (2014) proposes that the swap arrangements between central banks should be transparent and stable over time so that they could be useful in the sound management of banks' foreign currency liquidity risks. Hawkins et al. (2014) propose that to convince markets that global financial stability will be preserved; sufficient funds should be committed, preferably by the IMF.

It is difficult to assess empirically the sufficiency of the GFSN, and the existing evidence is somewhat mixed. In the debate, one indicator that has been 
used as being indicative of the insufficiency of the GFSN is the frequency and severity of financial crises in the world (Truman, 2013). This view is consistent with the earlier study by Jeanne and Zettelmeyer (2001) who attempt to quantify the potential liquidity needs of an international LOLR in the context of a theoretical model. They conclude that, to safeguard global financial stability, an international LOLR would need to stand ready to provide virtually unbounded amounts of liquidity, thereby making the central banks the only viable option. It is also consistent with the prediction by Herrala (2001) that voluntary cooperation on liquidity provision leads to insufficient insurance cover. However, in a recent study, Denbee et al. (2016) use stress-testing techniques to show that the GFSN at present appears capable of dealing with severe crisis scenarios. Only in unlikely, severe crisis events involving a large number of countries would the existing GFSN coverage be insufficient.

Another important strand of the recent debate concerns the institutional structure, the appropriate roles of the various parties, and governance of the GFSN. In the debate about the appropriate role of the various parts of the GFSN, the IMF is credited as having broad and often superior crisis resolution expertise, the ability to impose conditionality, and a global pooling of funds (Henning, 2015; Rhee et al., 2013; Eichengreen, 2012). Its weaknesses include limited access to funding and the perceived stigma associated with its involvement (Rhee et al., 2013). While the strengths of RFAs vary across schemes (McKay et al., 2011), their potential advantages include additional funding, novel insights about the specific economic and institutional circumstances, and the strengthening of ownership of funded projects based on regional economic objectives IMF (2013).

Various authors have pointed out that the presence of multiple overlapping agents in the provision of the GFSN can cause severe coordination problems (Henning, 2011; Lombardi, 2010; Kawai and Lombardi, 2012; Rhee et al., 2013) and conflict (Eichengreen, 2012). (Henning, 2013, 2011) proposes a set of principles to foster cooperation: ex ante competence building, specialisation of the IMF and RFAs in areas of comparative advantage, the prohibition of competition in selected areas, and transparency. ${ }^{13}$

\footnotetext{
13 In November 2011 the leaders of the Group of Twenty (G20) endorsed six principles for cooperation between the IMF and RFAs: (1) cooperation should foster rigorous and even-handed
} 


\subsubsection{Institutional structure and governance}

To promote crisis resolution, Rhee et al. (2013) further suggest that the IMF Articles of Agreement should be changed to allow direct lending to RFAs. The legal basis and operational principles of RFAs should be improved to allow the RFAs to better cooperate with the IMF. Following further discussions in the course of 2013, there has been no consensus among G20 members on the need to revise the 2011 principles, with a large majority of members seeing little value added in revising the principles. However, according to some authors, the lack of more specific guidelines makes the present cooperation framework non-transparent and susceptible to criticism about unequal treatment (Rajan, 2014; Rhee et al., 2013; Eichengreen, 2012). Worries about IMF bias in favour of advanced economies are exacerbated by the slow pace of IMF governance reform. Some authors furthermore worry that the lack of transparent rules on cooperation may endanger efficient crisis resolution (Eichengreen, 2012; Volz and Marino, 2012).

Other authors also propose a division of labour so that the RFAs would focus on smaller, contained events, while IMF involvement would be needed during larger global crises (Sussangkarn, 2011; Jeanne, 2010). According to Miyoshi et al. (2013), the IMF falls short of taking a strong explicit stand on how to develop cooperation with RFAs, possibly in part due to the fact that the issue appears to currently be a low priority item for the IMF. The Fund shows some preference for fine-tuning the current flexible approach to address the most significant issues regarding transparency, rather than establishing overarching and detailed structural procedures. The latter approach is at present challenged by the complex economic and institutional issues that surround IMF-RFA cooperation.

surveillance and promote the common goals of regional and global financial and monetary stability; (2) cooperation should respect the roles, independence and decision-making processes of each institution, taking into account regional specificities; (3) while cooperation between RFAs and the IMF may be triggered by a crisis, ongoing collaboration should be promoted as a way to build regional capacity for crisis prevention; (4) cooperation should commence as early as possible and include open sharing of information and joint missions where necessary; (5) consistency of lending conditions should be sought to the extent possible; and (6) RFAs must respect the preferred creditor status of the IMF. IMF engagement with RFAs has thus far been conducted largely on an ad hoc basis reflecting, inter alia, the specifics of the crisis and the regional institutional setting (IMF, 2013). The six general principles for cooperation between the IMF and RFAs endorsed by the G20 Finance Ministers and Central Bank Governors in 2011 represent non-binding guidelines and thus leave room for a flexible approach. 


\section{The database on the elements of the global financial safety net}

\subsection{An overview}

The database provides data on the four elements which are considered key layers of the GFSN: foreign currency reserves, swap lines, IMF support and RFAs. The database does not cover central bank repo agreements or hedging instruments.

The GFSN database builds on the country and country group classification systems used in the World Bank and the IMF World Economic Outlook (WEO) databases. In total, 198 countries are included. They are identified by a unique three-letter and two-letter ISO code, a three-digit IFS (International Financial Statistics) country code, and a country name. In addition, geographical areas (such as the euro area) are additionally indicated. The dataset covers at a maximum the years 1960-2014. Some series are available for a shorter sample, as indicated by the Coverage column in Table 1 .

The data described in the separate sections are summarised in Table 1. The variables are primarily expressed as percent of GDP or as a binary indicator (dummy).

\subsection{Foreign currency and international reserves}

Foreign currency reserves comprise external assets generally controlled by national monetary authorities, while other international reserves include claims on international financial institutions (IFIs) that can be rapidly converted into foreign currency reserves, for example claims on the IMF or special drawing right (SDR) holdings at the IMF. This makes international reserves a readily available, prepaid and highly liquid resource controlled by the national authority. These properties also contribute to the signalling value of reserves, which can help to prevent sudden capital flow reversals. Consequently, reserves are different from the other layers of the GFSN in that they do not require an agreement with other parties and can be considered a means of self-insurance. Moreover, the usefulness of reserves depends on country-specific factors, such as the degree of openness or the foreign currency funding of the economy. Therefore, some institutions, particularly the IMF, have 
developed country-specific metrics of an appropriate level of reserve holdings.

The dataset provides both data on reserve levels and a simple metric of reserve adequacy. Data on foreign currency reserves are taken from the World Bank and from the IMF's International Financial Statistics (IFS) database, comprising holdings of monetary gold, SDRs, reserves of IMF members held at the IMF, and holdings of foreign exchange under the control of monetary authorities (hence holdings by sovereign wealth funds, or SWFs, are not included). They are expressed both as a proportion of GDP (ReservestoGDP) and as a proportion of external debt (ReservestoDebt). In addition, the database contains an aggregate measure of reserve adequacy (reserve_adequacy), which is based on IFS data. It builds on the traditional reserve adequacy benchmarks of import coverage, short-term external debt and the broad money stock in the economy. ${ }^{14}$ The reserve_adequacy indicator groups these three rules of thumb together in one simple indicator, which is the equally weighted average of the three measures. A reserve adequacy ratio higher than one indicates that the country's foreign exchange reserves are more than the average amount implied by the most used benchmarks (i.e. one month of imports plus $100 \%$ of short-term debt plus $20 \%$ of M2).

As it is not clear how to deal with reserve holdings by euro area countries in view of the single monetary policy and authority, this paper includes an additional variable: ReservestoGDP2, based on World Bank data, which considers euro area reserves as aggregated at the euro area level (reported as missing for individual euro area countries). The measures ReservestoGDP and ReservestoDebt consider all reserves as country-held, but this may not be completely correct for the euro area where some reserves are held by the national central banks and some reserves are held by the Eurosystem.

A separate question concerning the euro area is how to deal with Eurosystem TARGET2 balances which, according to some, play the same role as foreign exchange reserves. ${ }^{15}$ This variable is not included in the database as this should be

\footnotetext{
14 Three months of imports and $100 \%$ short-term debt coverage provide indicators of vulnerability against an external finance shortage. The M2 coverage ratio takes into account an internal drain on external financing which is driven by domestic investors. As a rule of thumb, $20 \%$ of domestic financial liabilities (M2) that could potentially be converted into foreign currency are used as a benchmark to assess the adequacy of the level of reserves.

15 Fagan and McNelis (2014) find that the availability of TARGET2 balances in the euro area
} 
seen as part and parcel of the domestic monetary policy function in the euro area, not as an element of the GFSN.

[Table 1 about here.]

\subsection{Access to IMF financial support}

With 189 member countries, the International Monetary Fund (IMF) is the most comprehensive and largest provider of liquidity insurance and crisis support. It has a special role with regard to the overall functioning of the GFSN enshrined in its Articles of Agreement, which set out the IMF's primary purpose as being to ensure the stability of the international monetary system. The IMF does so through various activities which help countries prevent and address crises, inter alia by providing financial assistance in a crisis subject to appropriate conditionality as necessary to overcome balance of payments (b.o.p.) problems and by preventing moral hazard through appropriate access requirements and conditionality.

The data on IMF activities in the database therefore mainly relate to its membership (quota) and to its lending activities (programmes). These data are compiled from the IFS, the IMF Monitoring of Fund Arrangements (MONA) database, the World Bank World Development Indicators (WDI) database, and IMF quota review reports.

The IMF's MONA database contains the most complete account of planned and implemented transactions with the Fund by arrangement. The variable $I M$ FArrangement provides information on the type of IMF arrangement. The variable IMFArrangementNumber gives the unique identifier number for a programme, as listed in the MONA database. As a programme may be cancelled during a year and immediately followed by a successor programme, the variable IMFNrofProgrammes gives the number of programmes during one year if there were multiple programmes during that year. The dummy variable IMFConcessional indicates whether a programme is concessional. The dummy variable IMFPrecautionary takes the value 1 if the arrangement is a Flexible Credit Line (FCL) or a Precautionary Credit

greatly mitigated the impact on income during sudden stops, relative to a regime in which such financing is not available. At the same time, they observe that the availability of such financing leads to moral hazard (overborrowing), increasing the likelihood of sudden stops. 
Line (PCL)/Precautionary and Liquidity Line (PLL) or a precautionary Stand-by Arrangement (SBA). The variable IMFAgreedTotaltoGDP provides the total programme envelope, which is the same for all years of a programme. By contrast, the variable IMFAgreedYeartoGDP gives the amount scheduled to be disbursed to a country within the calendar year. The variable IMFDrawtoGDP gives the actually drawn amount during a calendar year. As publicly available MONA data only go back to 1992, information on agreed and drawn amounts is complemented with IFS data and WDI data where available for years prior to 1992. Appendix A contains a detailed explanation of how these IMF variables were combined.

The variable IMFQuotatoGDP taken from the quota and governance reports indicates a country's quota. It is also provided in SDR (IMFquota_SDR)

\subsection{Regional financial arrangements (RFAs)}

Regional financing arrangements (RFAs) cover regional agreements to help members address crises. There are currently RFAs in several regions - East Asia, Europe, Latin America, the Middle East and Africa. Some RFAs have been in place for a long time, while others have been established only more recently in response to the global financial crisis. The Arab Monetary Fund (AMF), ${ }^{16}$ founded in 1976, and the Latin American Reserve Fund (FLAR), ${ }^{17}$ set up in 1988, have more than three decades of lending experience (e.g Ocampo and Titelman, 2009). The Chiang Mai Initiative (CMI), an agreement to provide bilateral swap lines, was set up in response to East Asia's perceived need to develop a regional mechanism after the 1997-98 financial crisis (e.g Sussangkarn, 2011). Other RFAs such as the CMI's successor agreement, the Chiang Mai Initiative Multilateralisation (CMIM) Agreement, ${ }^{18}$ and the European facilities (the temporary European Fi-

\footnotetext{
16 The Arab Monetary Fund is a small RFA whose aim is to assist its non-OPEC members. Members include Algeria, Bahrain, Comoros, Djibouti, Egypt, Iraq, Jordan, Kuwait, Lebanon, Libya, Mauritania, Morocco, Oman, Qatar, Saudi Arabia, Somalia, Sudan, Syria, Tunisia, the United Arab Emirates and Yemen.

17 FLAR was established as an extension of FAR (Andean Reserve Fund), which was set up in 1988. Members include Bolivia, Colombia, the Dominican Republic, Peru, Uruguay and Venezuela.

18 The CMIM is an East Asian regional financing arrangement covering Brunei Darussalam, Cambodia, China, Hong Kong, Indonesia, Japan, Korea, Laos, Malaysia, Myanmar, the Philippines, Singapore, Thailand and Vietnam (Sussangkarn, 2011), which succeeded and extended the
} 
nancial Stabilisation Mechanism, EFSM, and European Financial Stability Facility, EFSF, and the permanent European Stability Mechanism, ESM) have been set up more recently to boost resources for surveillance and crisis resolution.

The dataset covers the following RFAs: FOCEM (Central American Monetary Stabilization Fund), FLAR (Latin American Reserve Fund), FAR (Andean Reserve Fund), AMF (Arab Monetary Fund), CMI (Chiang Mai Initiative), CMIM (Chiang Mai Initiative Multilateralisation), EFSD (Eurasian Fund for Stabilization and Development), BOP (EU Balance of Payments Assistance Facility), North American Framework Agreement (NAFA), EFSM (European Financial Stabilisation Mechanism), EFSF (European Financial Stability Facility) and ESM (European Stability Mechanism). ${ }^{19}$ The recently established BRICS contingent reserve arrangement is not yet included since the system was officially approved only in 2015. The data are collected primarily from the homepages of the respective institutions, except for the data on the CMI and CMIM which are from the Bank of Japan's website. Three variables are included: an indicator variable (RFAIndicator) regarding membership, a string variable (RFAName) identifying the respective RFA, and total loans drawn from the RFAs (RFALoanstoGDP). The latter indicates broadly the loans drawn during a year in gross terms, without diluting loan repayments. Since it is based on the information given on the respective websites, it is not completely harmonised and should therefore be interpreted as an approximation.

\subsection{Swap lines}

Bilateral swap lines between central banks technically provide the receiving central bank with short-term access to foreign currency liquidity in exchange for its domestic currency. These kinds of arrangements have been part of the policy toolkit of central banks for a long time and have been used for a multitude of purposes like supporting foreign exchange rate policies, managing assets and liabilities, promoting the international use of currencies, facilitating the functioning of financial markets and ensuring financial stability.

The database includes information on the swap lines of five major central banks:

Chiang Mai Initiative (CMI).

19 In cases of membership of multiple schemes, such as with the EFSF and the ESM, all schemes are listed, separated by commas. 
the Federal Reserve (Fed), the Bank of England (BoE), the European Central Bank (ECB), the Bank of Japan (BoJ) and the People's Bank of China (PBoC). The data have been collected from the respective central banks and from other central bank sources. ${ }^{20}$ Six dummy variables (SwapIndicator, FEDSwapIndicator, ECBSwapIndicator, BOJSwapIndicator, BOESwapIndicator and PBOCSwapIndicator) show the countries which have a bilateral swap line from the respective central banks, including also the bilateral swap lines related to the NAFA and the CMI/CMIM. An indicator variable (FedUnlimitedSwap) indicates whether a swap line from the Federal Reserve is unlimited; the Federal Reserve is the only central bank which makes this information publicly available. One quantitative variable (SwapLimittoGDP) indicates the sum of all limited swap lines for which data are available. ${ }^{21}$ Only the Federal Reserve makes publicly available the amounts drawn from its swap lines, measured as the balance of the swap line account at the yearend (FEDDrawtoGDP).

\subsection{Capital flows}

As the analysis of the GFSN, its role of providing insurance against crises and the interaction between its elements depends on identifying crisis episodes, particularly balance of payments crises, this paper provides a new measure of private capital flows and a selected number of measures for capital flow reversals. One important element of the dataset is that in contrast to most earlier work on capital flow reversals, this paper focuses on private capital flows. Given that the goal of any analysis of the GFSN must be to separate the impact of public flows, as measured by the GFSN, from that of private flows, it is essential that this paper does not include financial flows resulting from the triggering of the GFSN. It follows the literature which has either focused on private flows or on public flows in only selecting specific elements from the balance of payments for the aggregate measure of private flows.

Appendix B details how these elements are measured and how the measure

\footnotetext{
20 The authors thank Owen Humpage for providing historical data for the Federal Reserve swap lines.

21 Whenever there is no limit (unlimited access), the observation is treated as missing.
} 
of private flows compares with previous analyses. ${ }^{22}$ The capital flows data are from IMF b.o.p. statistics. Owing to data availability issues mainly for developing countries, this paper only provides capital flows data for 72 selected countries. ${ }^{23}$ The variables CapFloOutPrutoGDP and CapFloInPrvtoGDP are the preferred measures of private capital outflows and inflows. The variables CapFloOuttoGDP and CapFloIntoGDP denote total capital outflows and inflows.

Regarding the best way of identifying capital flow reversals, the literature has developed several approaches. The starting point of the more recent literature is Calvo et al. (2006), who pinpoint capital flow reversals which are accompanied by sharp increases in aggregate spreads by looking at a year-on-year capital flow fall at least two standard deviations below the sample mean. This starting point highlights that the definitions for capital flow reversals used both in the literature focusing on net flows and in the literature focusing on gross flows reflect the need for a parsimonious measure which can easily be applied. The literature usually defines a capital flow reversal as a deviation, usually by one or two standard deviations, from a benchmark. These benchmarks are often defined in terms of the capital flows themselves (e.g Forbes and Warnock, 2012), albeit with different definitions. Others combine such benchmarks with conditions on the size of capital flows in terms of GDP (e.g Agosin and Huaita, 2012; Furceri et al., 2012) or with conditions on the level of inflows, outflows or net flows (Cavallo et al., 2015). In addition, some authors use only the size in terms of GDP as the benchmark (e.g Levchenko and Mauro, 2007). A more recent approach is to smooth out capital flow series by using a cumulative measure which is standardised with its own standard deviation (Alberola et al., 2016, e.g). However, the Calvo et al. (2004) approach or a version of it that does not look at spreads and restricts the sample mean

\footnotetext{
${ }^{22}$ In short, this paper relies on a distinction between public entities and private entities in the b.o.p. data. Similar to previous studies (e.g Alfaro et al., 2014)(e.g. Alfaro et al., 2014, 2008), this paper always considers foreign direct investment (FDI) flows as private flows. The other components of the b.o.p. financial account - portfolio investment, financial derivatives (other than reserves and employee stock options), and other investment - are accounted for separately for the central bank/monetary authorities, general government, deposit-taking corporations and other sectors. This paper uses this differentiation provided in the b.o.p. to exclude all flows from and to central banks and general government, which should be broadly accurate as long as "other sectors" do not include de facto public sector entities.

${ }^{23}$ A list is provided in Appendix B.
} 
(Forbes and Warnock, 2012) is still the most commonly used one (e.g Korinek and Mendoza, 2014). One factor that is common across the sudden stop literature is to use at least quarterly data; However, some authors (e.g Calvo et al., 2004; Forbes and Warnock, 2012; Cavallo et al., 2015) deliberately annualise the data to avoid seasonality effects. As this paper does not have information on reserve holdings, swap lines and foreign exchange reserves on a monthly basis, this paper also uses annual data for deriving the capital flow reversal measures provided in the dataset.

To be able to compare results derived with this database with previous research, the database provides a classification of capital flow reversal episodes as defined by Forbes and Warnock (2012), which distinguishes between episodes which are triggered by a sharp change in inflows and episodes which are triggered by a sharp change in outflows. Note that these classifications are adjusted for annual data ${ }^{24}$ and that in contrast to Forbes and Warnock (2012), only private capital flows are used to identify the episodes. Forbes and Warnock (2012) define the following episodes related to capital inflows or outflows: Let $c_{t}^{x}$ denote capital flows, with $x \in i, o$ indicating inflows or outflows, and $\Delta c_{t}^{x}=c_{t}^{x}-c_{t-1}^{x}$ denote the annual year-over-year change in inflows or outflows with $t=1,2, \ldots, N$. In addition, let $m_{4}^{\Delta c_{t}^{x}}=\frac{\sum_{h=1}^{4} \Delta c_{t-h}^{x}}{4}$ denote the four-year moving average of the change in inflows or outflows ${ }^{25}$ and let $s d_{4}^{\Delta c_{t}^{x}}=\frac{\sum_{h=1}^{4} s d\left(\Delta c_{t-h}^{x}\right)}{4}$ denote the average standard deviation during those four years. Then, in the spirit of Forbes and Warnock (2012), define capital flow episodes along the lines of Table 2. For the illustrative analysis in this paper, only reversals of foreign capital flows into the domestic economy are considered; in the taxonomy of Table 2 this would be a sudden stop. The corresponding measures in the dataset are labelled surge, stop, flight and retrenchment.

[Table 2 about here.]

\footnotetext{
24 As some data on the elements of the GFSN is only available annually, the other variables which are available at a higher frequency are adjusted accordingly.

25 Forbes and Warnock (2012) look at the last 20 quarters. It is possible to also compute the episodes based on quarterly data, applying the methodology as outlined in Forbes and Warnock (2012).
} 


\subsection{Additional variables}

A crisis can be of domestic or external origin and it can take many different forms: a balance of payments crisis occurs when a nation is unable to pay for essential imports or service its external debt repayments. In some cases, balance of payments problems can be compounded by a sharp exchange rate depreciation and a currency crisis. Financial crises stem from insolvent or illiquid financial institutions, and fiscal crises are caused by excessive fiscal deficits and debt.

The literature review in Section 2 has shown that in addition to capital flow reversals indicating a balance of payments crisis, analysing the GFSN in the context of other types of crises may also be of interest. Hence, the database also includes the banking crisis start (bcstart) and currency crisis start (ccstart) dummies from Laeven and Valencia (2012) and an indicator of whether a country has sovereign loans in default (sovdefault) from the Bank of Canada, as well as the Chinn-Ito index for capital account openness (ChinnIto) (Chinn and Ito., 2012) and an overall capital flow restrictions index ( $k a)$ (Fernández-Arias et al., 2015). In addition, the database offers a set of regional dummies for euro area $(E A), \mathrm{EU}(E U)$ and OECD $(O E C D)$ membership in 2014 and in changing composition as well as G20 (G20) membership. In terms of macroeconomic variables, the database contains nominal GDP $(G D P)$, GDP growth $(d G D P)$, the share of the country in world GDP (GDPShare), exports (XtoGDP) and imports (MtoGDP), gross fixed capital formation $(G F C t o G D P)$, the official foreign exchange rate $(F X)$, the current account balance (CAtoGDP), the unemployment rate $(U)$, population $(P O P)$ as well as the VIX index as a proxy for financial market volatility. Moreover, the database includes World Bank governance indicators (VoiceandAccountability, RuleofLaw, RegulatoryQuality, PoliticalStability, GovEffectiveness) and an indicator concerning the voting patterns of the countries relative to the United States in the United Nations General Assembly (UNGAvotewithUSA), which has often been used as an instrument for IMF programmes. 


\section{Some stylised facts}

Having described the database, this section now turns to describing the set-up of the GFSN with the data. It provides key summary statistics and present different possible approaches to developing an aggregate measure of GFSN access. Finally, this paper also illustrates the correlation of GFSN access with capital flow reversal episodes, aiming to highlight a set of stylised facts on which future research may build.

\subsection{Summary statistics and general evidence on the GFSN}

\subsubsection{Summary statistics}

The data availability for reserves to GDP is roughly two-thirds of all available observations (one third is therefore missing), and that of reserves to debt is $39 \%$. On average, countries had a reserves-to-GDP ratio of about $14 \%$. The highest reserve levels relative to GDP are observed in Libya in 2011 (318\%): its reserves had been boosted by oil income, while its GDP was in steep decline owing to the onset of the Arab Spring. In absolute terms, the largest reserves are held by China, which has a reserves-to-GDP ratio of about $40 \%$.

Throughout the periods for which there is data, about one in five countries belonged to a regional financing arrangement. A typical loan drawn from an RFA is small (3.7\% of GDP). The largest loans are observed in the EU, where they peak at $55 \%$ of GDP (Greece). The negative draw from one scheme is related to a rearrangement of the euro area RFAs in which, for one country, there is a negative draw from one scheme (the EFSF) and a positive draw from another (the ESM).

About one-quarter (26\%) of countries / periods had a swap line from the central banks provided in the dataset during periods when there are data. With the exception of swap lines from the Federal Reserve, data coverage starts around 1999. The average limit size of the limited swap lines is around $37 \%$ of GDP. The maximum limit size of 25 times GDP is for Hong Kong, an important financial hub in Asia, which functions as a clearing house for offshore Chinese renminbi transactions and has a large swap line from the People's Bank of China (PBoC). 


\subsubsection{Coverage of GFSN across countries and over time}

Reserve assets held by the monetary authorities have increased markedly during the past decades (Figure 1), with some interruption in the trend only during the recent years. The rising trend has been linked by previous studies to increased openness of countries to the international economy and the subsequent need to better safeguard against external shocks (Obstfeld et al., 2009; Bussière et al., 2013). Own reserves have also been found to contribute to the ability of countries to influence the exchange rate Dominguez et al. (2012).

[Figure 1 about here.]

During the past decade, the number of countries with a swap line from one of the large central banks has increased markedly, mainly driven by the expansion of the PBoC swap line network (Figure 2). As a result, the geographical coverage of access to such swap lines is at present quite broad across all populated parts of the world, with the exception of Africa and some parts of Latin America (Figure 2). Not much is publicly known about the actual use of such swap lines, since only the Federal Reserve publishes such information. However, previous studies indicate that swap lines, in line with own reserves, can be effective in reducing exchange rate pressures (Goldberg et al., 2010).

[Figure 2 about here.]

[Figure 3 about here.]

The use of IMF financial support peaked sharply around financial crisis events and reached record levels during the recent global financial crisis (Figure 3). The use of RFA loans also peaked during the global financial crisis. Of the RFAs, by far the most active during the crisis period were the European schemes (the EFSF, EFSM and ESM), with an average loan size of about $8 \%$ of GDP among borrowing members, and maximum levels of over $50 \%$ of GDP. FLAR averages a loan size of about $1 \%$ of GDP among its borrowing members, and the AMF about $0.4 \%$. Of the multilateral RFAs, the CMIM and the EFSD do not report any lending activity. There has been a large geographical increase in RFA membership during the past decades (Figure 4). 
[Figure 4 about here.]

[Figure 5 about here.]

\subsection{A proxy for aggregate access to the GFSN}

It is generally difficult to obtain an aggregate measure of access to the GFSN, in part owing to the need to combine cardinal (e.g. the foreign reserves-to-GDP ratio) and binary (e.g. whether or not a country has an unlimited swap line with the Federal Reserve) information. Among the GFSN types, there is cardinal information on foreign reserves and IMF access to some extent (ex post access under programme conditionality, as well as the disbursed amounts); for RFAs there is more limited cardinal information (mainly granted amounts, but only for some of the RFAs and not consistently); and finally for swap lines there is cardinal information on drawn amounts and limits for the Federal Reserve, and limits for three other central banks if the swap is limited (Bank of Japan, European Central Bank, People's Bank of China). Apart from for the Federal Reserve, there is only binary information for central bank swap lines without limits and for RFA membership. An additional complication is that access to liquidity from some parts of the GFSN (mainly IMF and RFA loans) is strongly conditional, while in other cases (own reserves, swaps) conditionality is weak or non-existent, thereby implying differences in ease of access. Finally, in the case of the euro area, swap lines and own reserves are to a large extent controlled by the Eurosystem and therefore not directly accessible at the national level.

\subsubsection{Aggregate indicators based on past GFSN access}

Based on this situation, for each type of GFSN we build a cardinal measure, GFSN_CARD, which sums access to all of the GFSN sources for which we have cardinal information as a share of domestic GDP. In other words, GFSN_CARD sums available reserves, ${ }^{26}$ IMF disbursements during a year from an IMF programme, RFA disbursements during a year for those RFA loans for which there is

\footnotetext{
26 For the euro area, aggregate reserves at the euro area level are used.
} 
data, and the limit to a swap line if a country has a limited swap line. ${ }^{27}$

Consequently, GFSN_CARD gives information on the size of real-time access to the GFSN for past points in time. In addition, this paper provides an ordinal measure of past GFSN access for which the GFSN sources available at each point in time in the past are counted to construct the variable GFSN_COUNT. For example, a country which had access to, say, an ECB swap line and which received an RFA loan would receive 2 for this variable. For this measure having access to an IMF programme counts as 1 . Reserves count as 1 if the level of reserves is above the cross-country average in the same year .The measure GFSN_COUNT_NONPREC only counts those GFSN elements with a non-precautionary purpose, i.e. nonprecautionary IMF programme and RFA loans. The measure GFSN_COUNT_PREC counts access to GFSN elements which can be assumed to be precautionary, i.e. without or with only limited conditionality (foreign reserves, swap lines and IMF precautionary facilities).

\subsubsection{Aggregate indicators based on potential GFSN access}

Finally, this paper develops three measures of potential GFSN access. The first measure, GFSN_COUNT_IMF1, is equivalent to GFSN_COUNT, except that it (i) counts RFA membership instead of the receipt of an RFA loan and (ii) counts potential IMF access measured as having had an above-average number of IMF programmes in the past instead of counting a current IMF programme. The second measure, GFSN_COUNT_IMF2, is equivalent to GFSN_COUNT_IMF1 except that it counts potential IMF access as having an above-average quota.

[Table 3 about here.]

The third measure, GFSN_OVERALL, takes the concept of potential access one step further in that it is constructed like GFSN_COUNT_IMF2, but for swap lines it only contains an indicator of unlimited access to a swap line from the Federal Reserve. For example, a country with above-average foreign reserves, a small IMF quota and access to an unlimited swap line would receive a score for

${ }^{27}$ Note that this implies that unlimited swap lines from the Federal Reserve are not included in this measure. 
GFSN_OVERALL of $2(1+0+0+1)$. This approach gives us the closest approximation to potential GFSN access, based on the data.

Table 3 lists all indices. Note that because of the definitions described above, GFSN_CARD only includes information on swap lines with a limit, while GFSN_OVERALL only includes information on unlimited swap lines from the Federal Reserve. All GFSN_COUNT variables include all binary information on swap lines available in the data.

Clearly, these aggregate measures imply rather arbitrary assumptions, which need to be kept in mind when interpreting them. Nevertheless, they are a reasonable first attempt at measuring overall access to the GFSN for individual countries, allowing the implications for countries' performance and vulnerability to capital flow episodes to be studied.

\subsection{Correlates of GFSN access}

Table 4 reports correlations among the measures of (actual or potential) GFSN access. Two facts stand out. First, the cardinal and the ordinal measures are correlated, but the correlation is not particularly high. Ordinal measures of actual and potential access are more strongly positively correlated if unconditional access is considered. Second, the correlation between GFSN conditional and unconditional access is relatively low and negative. Therefore, to the extent that these two forms of insurance play different roles, it is important to look at both separately because one does not imply the other, empirically.

\section{[Table 4 about here.]}

Table 5 reports correlations between three measures of GFSN access (actual cardinal and ordinal access and overall potential access) with measures of country risk, indebtedness and size. Two stylised facts stand out here. First, actual GFSN access based on the ordinal measure is negatively correlated with the quality of institutions (Government Effectiveness) as well as a current account surplus, ceteris paribus. Moreover, GFSN access based on the cardinal measure is negatively correlated with size. While this may suggest lower use to the GFSN of 'stronger' countries, it should be noted that actual GFSN access based on the cardinal measure is positively correlated with a current account surplus. This suggests that 
'stronger' countries may have comparatively higher access to the GFSN. Second, while financial openness is negatively correlated with actual GFSN access based on the ordinal measure, more financially open countries have a higher potential access to the GFSN. The evidence for external debt is mixed. Clearly, it should be borne in mind that these are unconditional correlations, and this paper is silent on the direction of causality, which would require a much deeper econometric analysis. This paper can say, however, that prima facie the evidence does not seem to suggest an overwhelming role of moral hazard; countries with better access to the GFSN on the whole do not appear to be riskier or more indebted.

[Table 5 about here.]

\subsection{GFSN access and capital flow reversals: the case of sudden stops}

As a final element of the illustrative analysis, this section looks at whether countries are differently exposed to capital flow reversals depending on their access to the GFSN based on the aggregate measures. It focuses on the correlation between the occurrence of a sudden stop (a reversal in gross capital inflows) and the development of key macroeconomic variables after a reversal, depending on access to the GFSN. It should be emphasised that this analysis does not claim to be uncovering a causal relationship and do not deal with potential endogeneity (although GFSN access is considered with a lag in order to mitigate reverse causality).

The data suggest a limited impact of the availability of swap lines on the average number of sudden stops experienced by a country. When looking at the countries of which it is known that at some point between 1970 and 2014 they had agreed on a swap line, but never on an IMF programme or an RFA loan the minimum number of capital stops is 0 , while the maximum is 39 and the mean is 12.4. For those countries which also had available an RFA loan or an IMF programme, the minimum and maximum number of capital stops is the same, but the mean is lower at 9.9 .

Out of the countries which have ever tapped an RFA, the minimum number of sudden stops between 1970 and 2014 was 0, while the maximum number was 39 , with a mean of 6 sudden stops. Using IMF facilities and particular RFAs is 
associated with a significantly lower number of sudden stops. The minimum of 0 and maximum of 39 capital stops remain the same, but when conditioning on IMF use, the mean number of sudden stops is 9.1 while the mean number of sudden stops conditioning on RFA use is 6.3 .

[Table 6 about here.]

A simple analysis of pairwise correlations Table 6 indicates that the number of IMF programmes is negatively correlated with the number of sudden stops, but positively with the size of an RFA loan and the limit on a swap line. The positive correlation between the number of sudden stops and the size of an RFA loan is comparable to the positive correlation between the number of sudden stops and the limit on the Fed swap line.

Table 6 also indicates that some elements of the GFSN have a substitutive relationship, while others seem to be complementary. Foreign exchange reserves seem to be a complement for a (limited) swap line, but are substitutive to RFA loans and (albeit not significantly) the number of IMF programmes. It may be possible that IMF programme or RFA loans are required particularly when foreign exchange reserves are not available. RFA loans seem to be substitutive to the number of IMF programmes, a (limited) swap line and foreign exchange reserves. Moreover, a higher number of IMF programmes tends to be associated with a lower limit on a swap line.

[Figure 6 about here.]

Figure 6 gives an overview of the average duration of sudden stops and how it is associated with the GFSN. The left-hand side of 6 shows the correlation between the average duration of a sudden stop and the average level of foreign exchange reserves, the average size of RFA loans and the average limit of the limited swap lines as percentages of GDP. The right-hand side shows the correlation between the average duration of a sudden stop episode and the IMF programme envelope and actually drawn IMF amounts.

While there seems to be a positive association between the level of foreign exchange reserves and the duration of a sudden stop, Figure 6 suggests that the 
duration of a sudden stop may in fact be longer for some countries if they tap an RFA loan or agree on a (limited) swap line. Moreover, the right-hand side of Figure 6 seems to suggest that a higher IMF programme envelope may be associated with a shorter duration of sudden stops, while the amount actually drawn is if at all positively associated with the duration of a sudden stop. This may suggest that regarding private capital outflows, high buffers which enhance confidence may lead to lower outflows and lower outflows lead to a smaller reduction in FX reserves or a smaller need to ask for large IMF loans.

To gauge the macroeconomic effects of sudden stops, this section looks at their effect on real GDP growth, the current account balance, the foreign exchange rate and the unemployment rate around sudden stop episodes. The average development of the macroeconomic variables is calculated by using local projections in the spirit of Òscar Jordà (2005) for the four years after a sudden stop episode for each country in the sample. This means that one country can be represented more than once in the sample of sudden stop episodes. As the sample is restricted by the number of countries for which information on private capital flows are available, there are in total 1,962 time-year observations in the sample. The maximum number of years with sudden stops (of which some may also form an episode which is longer than one year) is nine.

The local projection method is a way of presenting impulse responses which puts fewer restrictions on these responses. Consider the model in equation (1). It shows a regression on the sudden stop of the dependent variable, such as GDP growth, at time horizons after the sudden stop. The local projection is defined as the coefficients $\beta_{-}(h)$ and $\theta_{-} h$ on the sudden stop:

$y_{i, t+h}=\alpha_{i}+\lambda_{t}+\beta_{h} s s_{i, t}+\varepsilon_{h} G F S N_{i, t-1}+\theta_{h} s s_{i, t}^{G} F S N_{t-1}+\gamma y_{i, t+h-1}+\delta z_{i, t+h}+\epsilon_{i, t+h}$

where $y_{i, t+h}$ is the macroeconomic outcome of interest in period $t+h$ with $h=1, \ldots, 4, s s_{i, t}$ is a dummy variable indicating a sudden stop during year $t$, $G F S N_{i, t-1}$ is GFSN availability in $t-1$ measured by one of the aggregate GFSN measures and $s s_{i, t}^{G} F S N_{t-1}=s s_{i, t} * G F S N_{i, t-1}$. In other words, $s s_{i, t}^{G} F S N_{t-1}$ indicates a sudden stop in year t interacted with one of the aggregate measures of 
GFSN coverage in $t-1 . y_{i, t+h-1}$ denotes the lagged value of the dependent variable prior to the sudden stop and $z_{i, t+h}$ denotes a vector of control variables.

[Figure 7 about here.]

Figure 7 shows the developments in four key macroeconomic indicators as an unconditional mean in the left panel (i.e. the coefficients $\beta_{h}$ and $\beta_{h}+\theta_{h}$ of equation (2)) and as a conditional mean (i.e. the coefficients $\beta_{h}$ and $\beta_{h}+\theta_{h}$ of equation (1)) in the right panel. The dashed line shows developments after a sudden stop for countries with no GFSN availability, i.e. $\beta_{h}$.

$$
y_{i, t+h}=\alpha_{i}+\lambda_{t}+\beta_{h} s s_{i, t}+\varepsilon_{h} G F S N_{i, t-1}+\theta_{h} s s_{i, t}^{G} F S N_{t-1}+\epsilon_{i, t+h}
$$

While it is obvious from the unconditional mean that developments in countries with at least some GFSN availability were more favourable after a sudden stop than developments in countries with no GFSN availability, the conditional mean in addition highlights that countries with GFSN availability seem to experience less volatility in key macroeconomic indicators and return more quickly to pre-crisis levels.

Table 7 shows the detailed local projections for four macroeconomic variables which are provided in the database. The top half of the table shows the coefficient $\beta_{h}$ of a conditional mean, using the ordinal measure of GFSN access GFSN_COUNT, for a local projection for the variables GDP, foreign exchange rate, current account balance and unemployment rate. The bottom half of the table shows the coefficient $\theta_{h}$.

Table 7 illustrates that - conditional on the level of the current account, GDP growth, in the preceding year, as well as on the foreign exchange rate, the unemployment rate, exports and debt as a share of GDP, the Chinn-Ito measure of capital account openness, the overall restrictions index by Fernández-Arias et al. (2015), a country's share in world GDP and the VIX index - economies which experience a sudden stop tend to also experience a significant drop in GDP during the year of the sudden stop and the year following the sudden stop. The foreign exchange rate significantly depreciates during the year of the sudden stop and the year after the sudden stop, but shows an (albeit insignificant) upward adjustment 
from year $t+2$. The current account balance increases during the year of the sudden stop and the following year. The unemployment rate is up to one percentage point higher for at least two years after the sudden stop.

[Table 7 about here.]

The bottom half of Table 7, illustrating effects of past GFSN availability based on an ordinal measure, suggests that effects of the sudden stop are mitigated particularly during the year of the sudden stop. GDP growth is higher and the exchange rate does not depreciate as much in countries with GFSN access. Interestingly, Table 7 also suggests that countries with GFSN access prior to a sudden stop experience a higher unemployment rate than countries without past GFSN access in years $t+2$ and $t+3$.

[Table 8 about here.]

Table 8 shows the same analysis as in Table 7 , albeit based on the measure GFSN_CARD. When defining the sample using the non-binary measures of past GFSN availability of which GFSN_CARD is composed, the local projections shown in the top half of the table suggest similar negative effects of a sudden stop on key macroeconomic variables as the local projections based on the ordinal GFSN measure in Table 7. However, the mitigating effect of GFSN access, as illustrated by the bottom half of Table 8 , is less pronounced than when using the ordinal GFSN measure. There is no significant difference in GDP growth between countries without and with GFSN access. The depreciation of the currency is significantly less strong in countries with GFSN access, but of limited economic significance. However, the local projections based on the cardinal measure of past GFSN access do not indicate a significantly higher unemployment rate among those countries with GFSN access. It seems that a higher GFSN coverage in the sense of a larger assistance package is mainly visible in differences in current account developments during $t+3$ and $t+4$.

[Table 9 about here.] 
Table 9 complements this picture with the same analysis, now based on GFSN_OVERALL, the measure of 'potential' GFSN coverage. The picture for the sample with low potential GFSN coverage is similar to the picture based on ordinal actual GFSN coverage: GDP first drops significantly during $\mathrm{t}$ and $t+1$ before rebounding again from $t+3$, while the foreign exchange rate first depreciates and then appreciates. Similarly, the unemployment rate rises first and then decreases from $t+3$. A significant difference for those countries with very high potential GFSN coverage appears only for the year of the sudden stop. GDP is significantly higher during the year of the sudden stop, while the foreign exchange rate depreciates significantly less. However, there is no significant difference in the unemployment rate.

\section{Conclusions}

This paper has focused on the global financial safety net (GFSN) seen as a unitary concept comprising four different types of safety nets, namely the accumulation of own foreign exchange reserves, financing from the IMF and regional financing arrangements, and central bank swap lines. Clearly, these elements are not coordinated or designed in a consistent manner, but rather reflect the accumulation and stratification of different forms of financial insurance often shaped by domestic rather than global interests. However, it is still interesting to understand their interplay and how they together form a necessary infrastructure for the global financial system.

The main contribution of this work is to provide an annual database of the GFSN for over 150 countries, available online from the ECB website. These data cover, in particular, the existing and potential access to the GFSN, together with a comprehensive list of variables that may be useful to understand financial integration and the role of the GFSN in it. In this way, this paper aims at providing a contribution to a rigorous debate on the role and design of the GFSN looking forward. This paper also distinguishes between forms of GFSN that are characterised by their precautionary purpose, and relatedly conditionality, and forms that are not, and discusses the theoretical underpinnings of conditionality. The potential of the database is illustrated by providing some interesting stylised facts about the availability of the GFSN across countries, although this paper is care- 
ful not to claim to be undertaking a causal analysis as it does not properly deal with endogeneity. It also provides evidence on the usefulness of the GFSN from the standpoint of individual countries, in particular when confronted with sudden stop episodes. Overall, the analysis obtains mixed results in this analysis. There is some evidence that a higher GFSN coverage cushions the impact of such episodes, but the evidence suggests effects to be limited to the first two years after such an episode and not always economically significant.

Hopefully the main contribution of this paper will be to spark further research on the GFSN. It reviews all the main theoretical and policy arguments surrounding the GFSN and presents, to the authors' knowledge, the only existing comprehensive database on the GFSN that is available. Future research will be essential to underpin the policy discussion on the GFSN and to arrive at a more consistent and globally desirable configuration of the GFSN going forward. 


\section{References}

Manuel R. Agosin and Franklin Huaita. Overreaction in capital flows to emerging markets: Booms and sudden stops. Journal of International Money and Finance, 31:1140-1155, 2012.

Enrique Alberola, Aitor Erce, and José Maria Serena. International reserves and gross capital flows dynamics. Journal of International Money and Finance, 60:151-171, 2016.

Laura Alfaro, Sebnem Kalemli-Ozcan, and Vadym Volosovych. Sovereigns, upstream capital flows, and global imbalances. Journal of the European Economic Association, 12:1240-1284, 2014.

Tamim A. Bayoumi, Joseph E. Gagnon, and Christian Saborowski. Official financial flows, capital mobility, and global imbalances. Journal of International Money and Finance, 52:146-174, 2015.

Graham Bird. The IMF: A bird's eye view of its role and operations. Journal of Economic Surveys, 21:683-745, 2007.

Graham Bird and Alex Mandilaras. Once bitten: The effect of IMF programs on subsequent reserve behaviour. Review of Development Economics, 15:264-278, 2011.

Michael D. Bordo, Owen Humpage, and Anna J. Schwarz. The evolution of the federal reserve swap lines since 1962. Working Paper 1414, Federal Reserve Bank of Cleveland, 2014.

Matthieu Bussière, Gong Cheng, Menwie D. Chinn, and Noémie Lisack. For a few dollars more: Reserves and growth in times of crises. Journal of International Money and Finance, 52:127-145, 2013.

Guillermo A. Calvo, Alejandro Izquierdo, and Luis-Fernando Mejía. On the empirics of sudden stops: The relevance of balance-sheet effects. IDB Publications (Working Papers) 6516, Inter-American Development Bank, 2004. 
Guillermo A. Calvo, Alejandro Izquierdo, and Ernesto Talvi. Sudden stops and phoenix miracles in emerging markets. American Economic Review, 96:405410, 2006.

Forrest Capie and Geoffrey E. Wood. Monetary Economics in the 1980s. Macmillan, London, 1989.

Eduardo Cavallo, Andrew Powell, Mathieu Pedemonte, and Pilar Tavella. A new taxonomy of sudden stops: Which sudden stops should countries be most concerned about? Journal of International Money and Finance, 51:47-70, 2015 .

Menzie Chinn and Hiro Ito. Notes on the Chinn-Ito Financial Openness index. Note, 2012.

Tito Cordella and Eduardo Levy-Yeyati. A (new) country insurance facility. International Finance, 9:1-36, 2006.

Dipak Dasgupta and Dilip Ratha. What factors appear to drive private capital flows to developing countries and how does official lending respond? Policy Research Working Paper 2392, World Bank, 2000.

Edd Denbee, Carsten Jung, and Francesco Paternò. Stitching together the global financial safety net. Bank of England Financial Stability Papers 36, 2016.

Christophe Destais. Central bank currency swaps and the international monetary system. Policy Brief 5, CEPII, 2014.

Kathryn M. E. Dominguez, Yuko Hashimoto, and Takatoshi Ito. International reserves and the global financial crisis. Journal of International Economics, 88:388-406, 2012.

Axel Dreher. IMF conditionality: theory and evidence. Public Choice, 141:233$267,2009$.

Axel Dreher and Roland Vaubel. The causes and consequences of IMF conditionality. Emerging Markets Finance and Trade, 40:26-54, 2004. 
Barry Eichengreen. Regional financial arrangements and the international monetary fund. Working Paper 394, ABDI, 2012.

Barry Eichengreen, Poonam Gupta, and Ashoka Mody. Sudden stops and IMFsupported programs. In Financial Markets Volatility and Performance in Emerging Markets, pages 219-266. National Bureau of Economic Research, Inc, 2008.

Gabriel Fagan and Paul McNelis. Target balances and macroeconomic adjustment to sudden stops in the euro area. The institute for international integration studies discussion paper series, IIIS, 2014.

Andrés Fernández-Arias and Eduardo Levy-Yeyati. Global financial safety nets: Where do we go from here? International Finance, 15(1):37-68, 2010.

Andrés Fernández-Arias, Michael W. Klein, Alessandro Rebucci, Martin Schindler, and Martín Uribe. Capital control measures: A new dataset. IDB Publications (Working Papers) 88195, Inter-American Development Bank, 2015.

Stanley Fischer. On the need for an international lender of last resort. The Journal of Economic Perspectives, 13:85-104, 1999.

Kristin J. Forbes and Francis Warnock. Capital flow waves: Surges, stops, flight, and retrenchment. Journal of International Economics, 88:235-251, 2012.

Xavier Freixas. Optimal bail out policy, conditionality and constructive ambiguity. DNB staff reports (discontinued), Netherlands Central Bank, 2000.

Davide Furceri, Stéphanie Guichard, and Elena Rusticelli. Episodes of large capital inflows, banking and currency crises, and sudden stops. International Finance, 15:1-35, 2012.

Linda S. Goldberg, Craig Kennedy, and Jason Miu. Central bank dollar swap lines and overseas dollar funding costs. NBER Working Papers 15763, National Bureau of Economic Research, Inc, 2010.

Charles Goodhart. Myths about the lender of last resort. International Finance, 2:339-360, 1999. 
Adam Hawkins, Jyoti Rahman, and Thomas Williamson. Is the global financial safety net at a tipping point to fragmentation? Economic Round-up, 1:1-20, 2014.

C. Randall Henning. Coordinating regional and multilateral financial institutions. Working Paper Series WP11-9, Peterson Institute for International Economics, 2011.

C. Randall Henning. Economic crises and regional institutions. Working Papers on Regional Economic Integration 81, Asian Development Bank, 2013.

C. Randall Henning. The global liquidity safety net institutional cooperation on precautionary facilities and central bank swaps, 2015.

Risto Herrala. An assessment of alternative lender of last resort schemes. Discussion Paper 1, 2001.

IMF. Stocktaking the fund's engagement with regional financing arrangements. Policy Paper 11.04.2013, IMF, 2013.

Olivier Jeanne. Dealing with volatile capital flows. Policy Briefs PB10-18, Peterson Institute for International Economics, 2010.

Olivier Jeanne and Jeromin Zettelmeyer. International bailouts, moral hazard and conditionality. Economic Policy, 16(33):407-432, 2001.

Olivier Jeanne, Jonathan D. Ostry, and Jeromin Zettelmeyer. A theory of international crisis lending and IMF conditionality. 2008.

Charles M. Kahn and Joao Santos. Allocating bank regulatory powers: Lender of last resort, deposit insurance and supervision. European Economic Review, 49:2107-2136, 2005.

Masahiro Kawai and Domenico Lombardi. Financial regionalism and the international monetary system. Brookings Institution Press, Washington DC, 2012. 
Anton Korinek and Enrique G. Mendoza. From sudden stops to Fisherian deflation: Quantitative theory and policy implications. Annual Review of Economics, 6: 299-332, 2014.

Luc Laeven and Fabián Valencia. Systemic banking crises database: An update. IMF Working Papers 12/163, IMF, 2012.

Philip Lane and Gian Maria Milesi-Ferretti. The external wealth of nations: measures of foreign assets and liabilities for industrial and developing countries. Journal of international Economics, 55:263-294, 2001.

Andrei Levchenko and Paolo Mauro. Do some forms of financial flows help protect against 'sudden stops'? The World Bank Economic Review, 21:389-411, 2007.

Domenico Lombardi. Financial regionalism: a review of the issues. Report, Global Economy and Development at Brookings Institution, 2010.

Julie McKay, Ulrich Volz, and Regine Wolfinger. Regional financial arrangements and the stability of the international monetary system. Journal of Globalization and Development, 2:1948-1837, 2011.

Giean-Maria Milesi-Ferretti and Cédric Tille. The great retrenchment: international capital flows during the global financial crisis. Economic Policy, 26: 285-342, 2011.

Toshiyuki Miyoshi, Stephanie Segal, Preya Sharma, and Anish Tailor. Stocktaking the fund's engagement with regional financing arrangements. Paper, IMF, 2013 .

Stephen Morris and Hyuan Son Shin. Coordination risk and the price of debt. European Economic Review, 48:133-153, 2004.

Maurice Obstfeld, J. C. Shambaugh, and A. M. Taylor. Financial instability, reserves, and central bank swap lines in the panic of 2008. American Economic Review, 99:480-486, 2009. 
José Antonio Ocampo and Daniel Titelman. Subregional financial cooperation: the south american experience. Journal of Post Keynesian Economics, 32: 249-268, 2009.

Òscar Jordà. Estimation and inference of impulse responses by local projections. American Economic Review, 95:161-182, 2005.

Francesco Papadia. Central bank cooperation during the great recession. Policy contribution, Bruegel, 2013.

Luca Papi, Andrea F. Presbitero, and Alberto Zazzaro. IMF lending and banking crises. Working Papers 80, Money and Finance Research group - Univ. Politecnica Marche, 2013.

Stephen Pickford. Global financial safety nets. Briefing paper, Chatham House, London, 2011.

Raghuram Rajan. Competitive monetary easing - is it yesterday once more? 2014.

Changyong Rhee, Lea Sumulong, and Shahin Vallée. Global and regional financial safety nets: lessons from Europe and Asia. Working Paper 801, Bruegel, 2013.

Jean-Charles Rochet and Xavier Vives. Coordination failures and the lender of last resort: was bagehot right after all? Journal of the European Economic Association, 2:1116-1147, 2004.

Minouche Shafik. Fixing the global financial safety net. Policy analysis and commentary, voxeu, 2015.

Joseph E. Stiglitz and Peter R. Orszag. Optimal fire departments: Evaluating public policy in the face of externalities. Research paper, Brookings, 2002.

Chalongphob Sussangkarn. Chiang mai initiative multilateralization: Origin, development, and outlook. Asian Economic Policy Review, 6:203-220, 2011.

Edwin Truman. Enhancing the global financial safety net through central bank cooperation. 2013. 
Ulrich Volz and Roberto Marino. A critical review of the IMF's tools for crisis prevention. Discussion Paper 4/2012, German Development Institute, 2012. 
Appendix A: tables and figures

Tables 


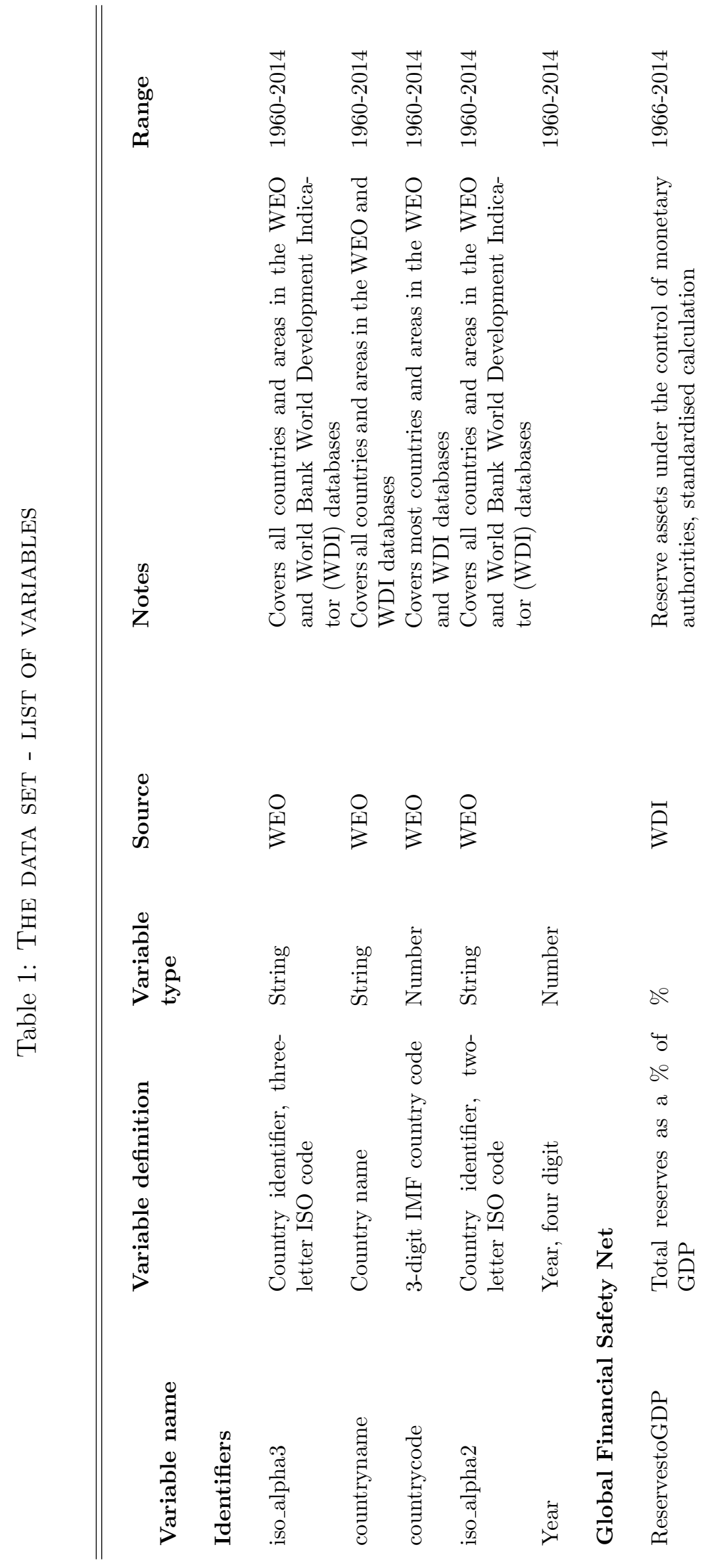




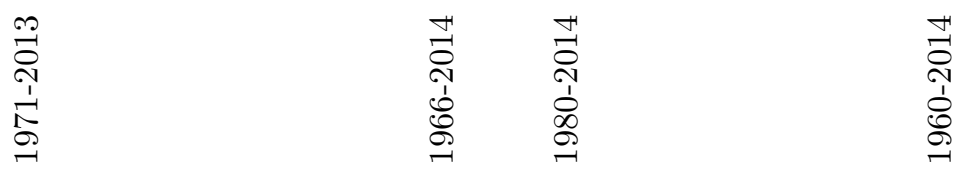

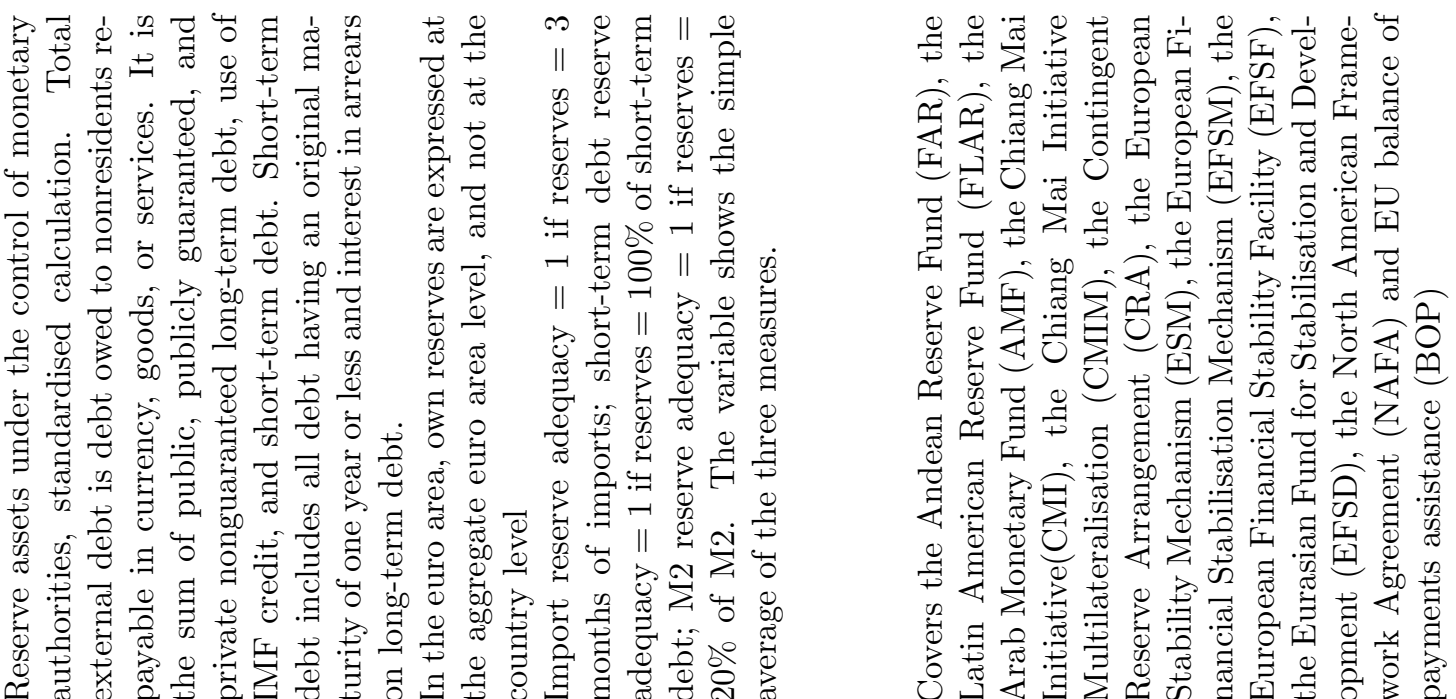

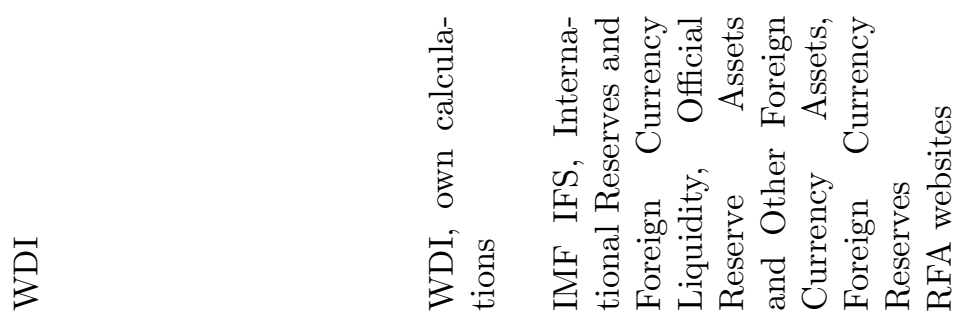

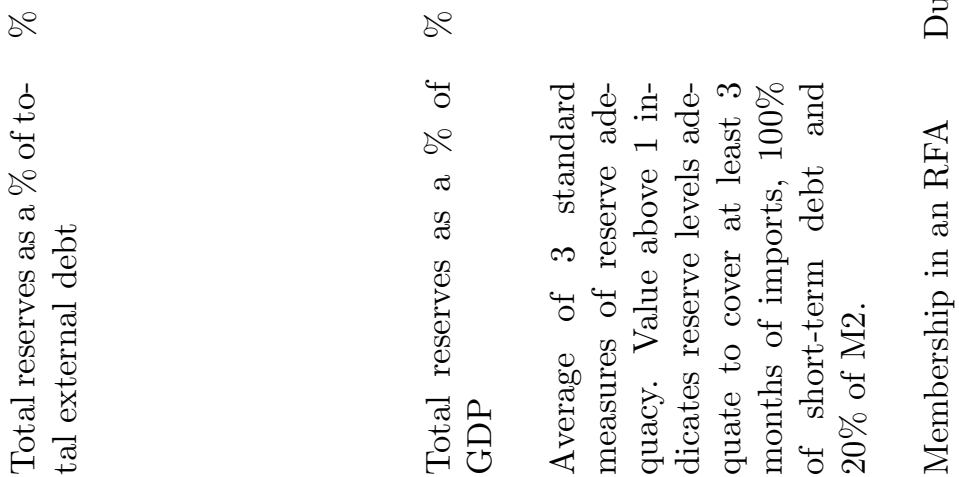

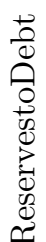

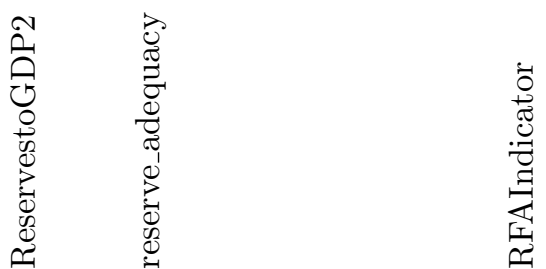




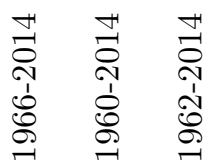

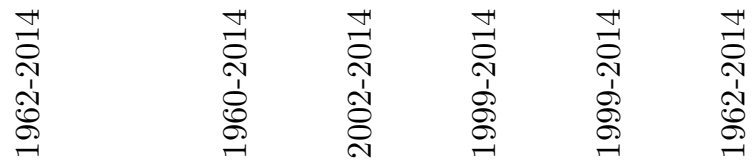

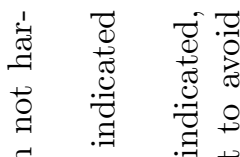

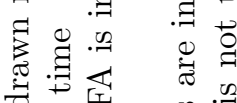

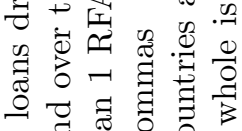

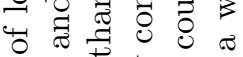

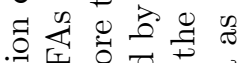

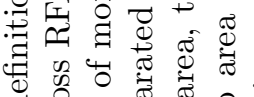

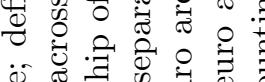

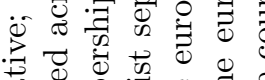

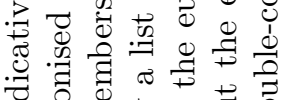

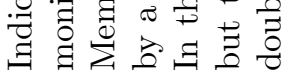

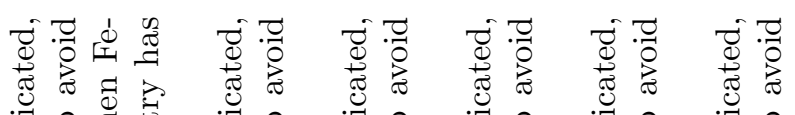

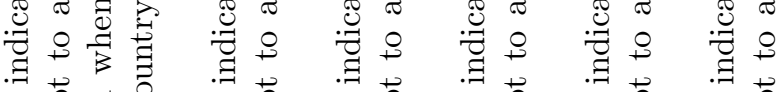

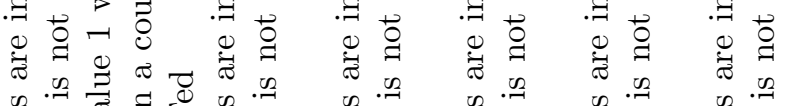

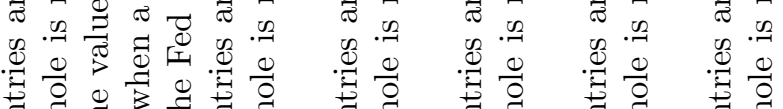

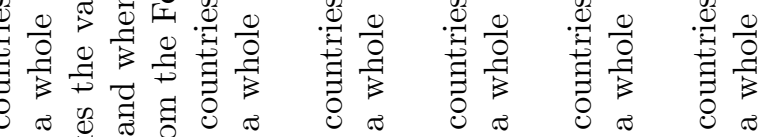
\% $\pi$ \%

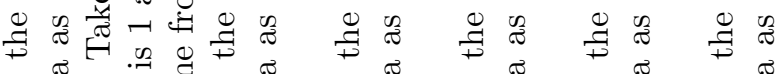

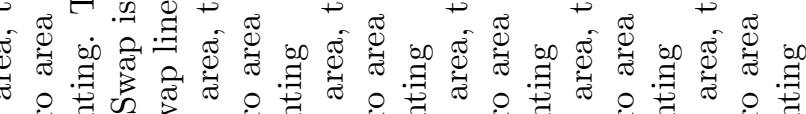

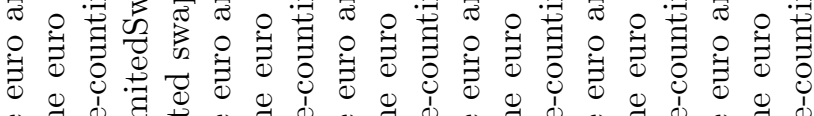

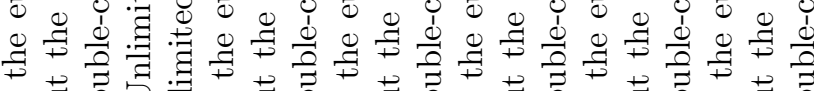

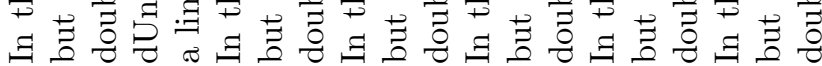

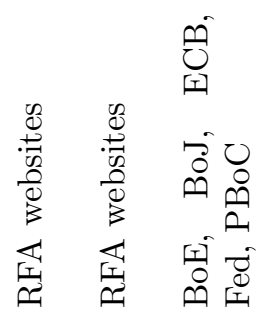

$\begin{array}{llll}0 & 0 & 0 & \\ 0 & 0 & 0 & 0 \\ 0 & 0 & 0\end{array}$

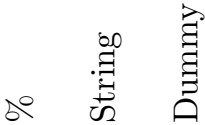

富

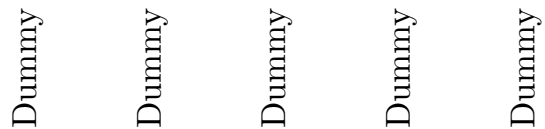

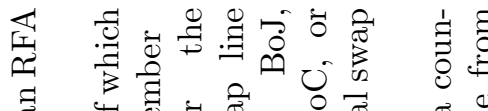

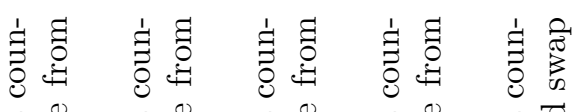

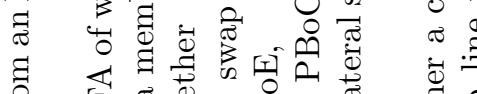

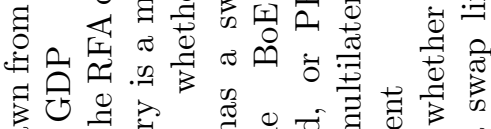

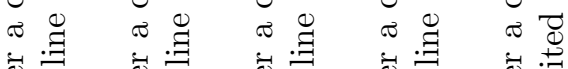

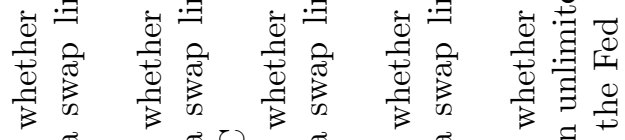

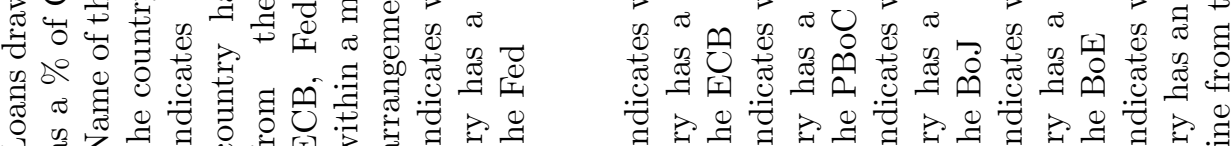

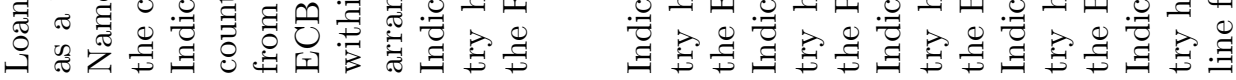

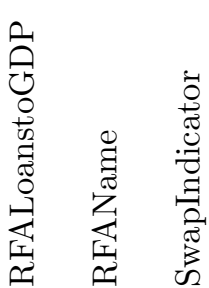

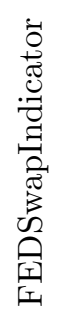

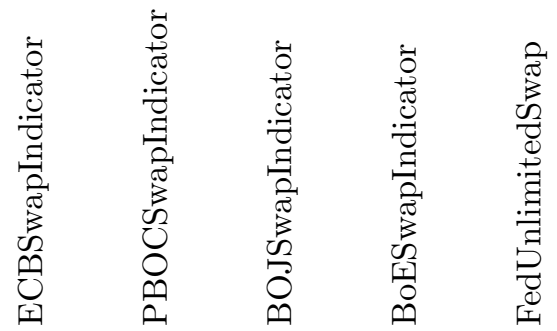




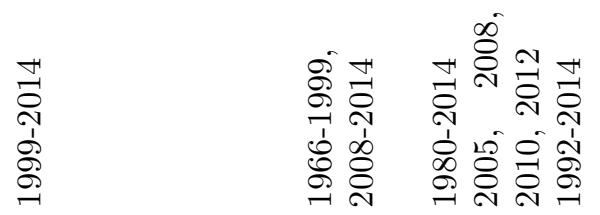

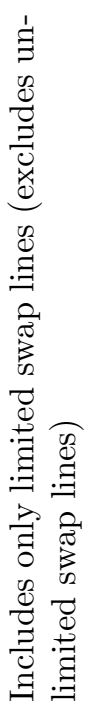

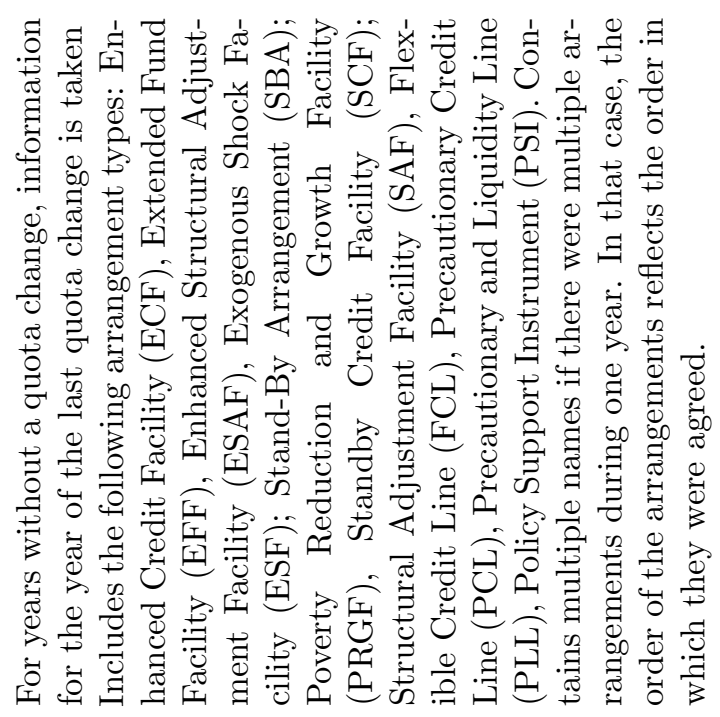

๑ْ่

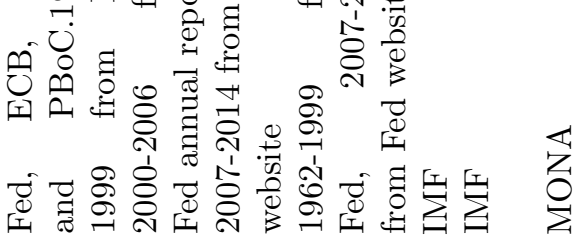

se

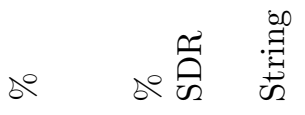

粂䁬岸

हี ซٔ

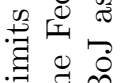

$\exists$

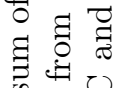

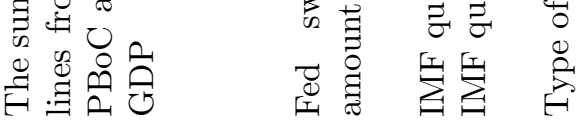

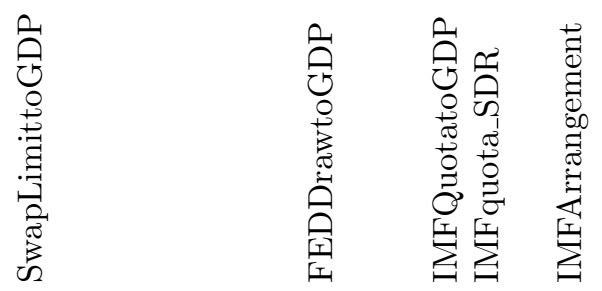




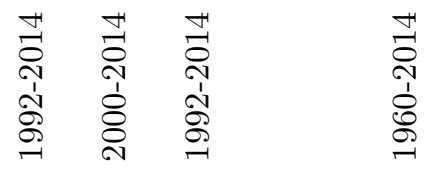

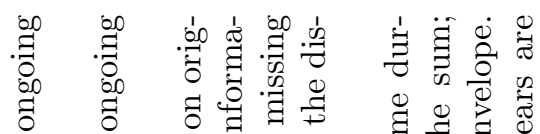

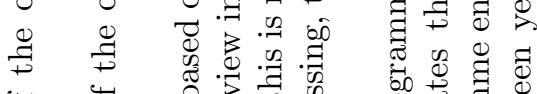

虫

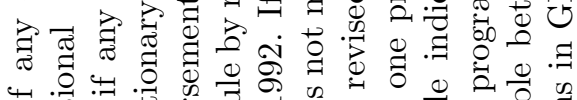

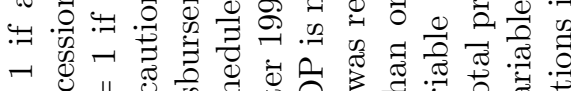

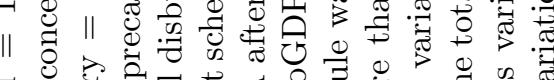

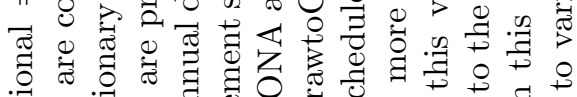

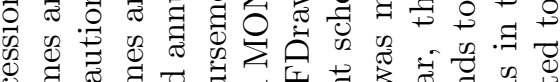

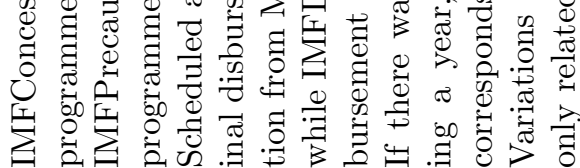

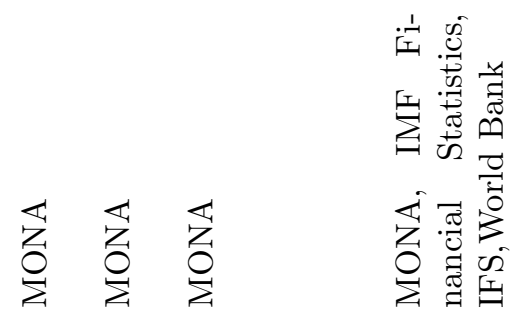

弯高

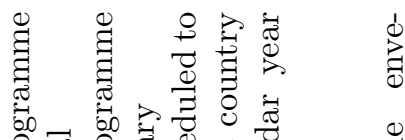

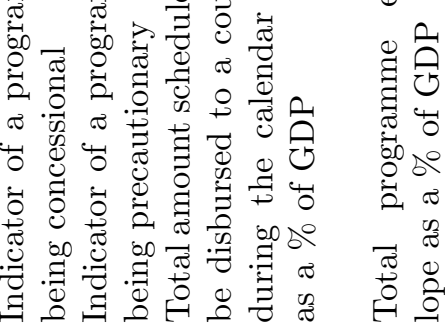

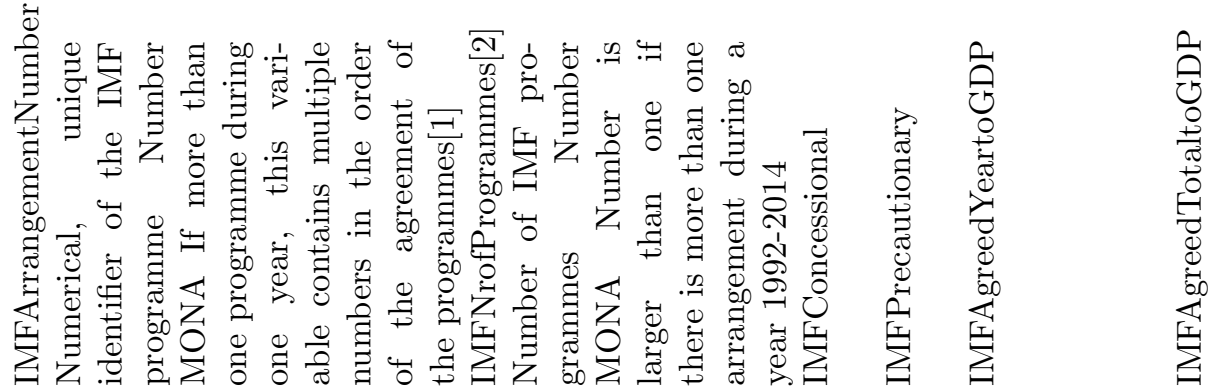




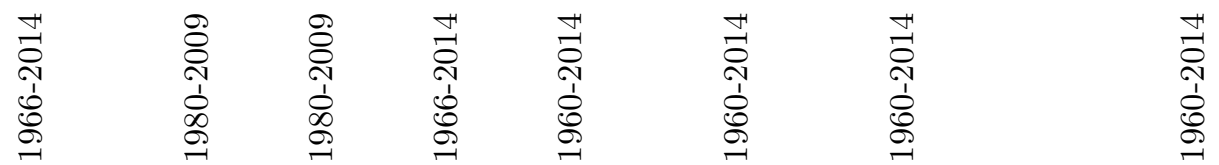

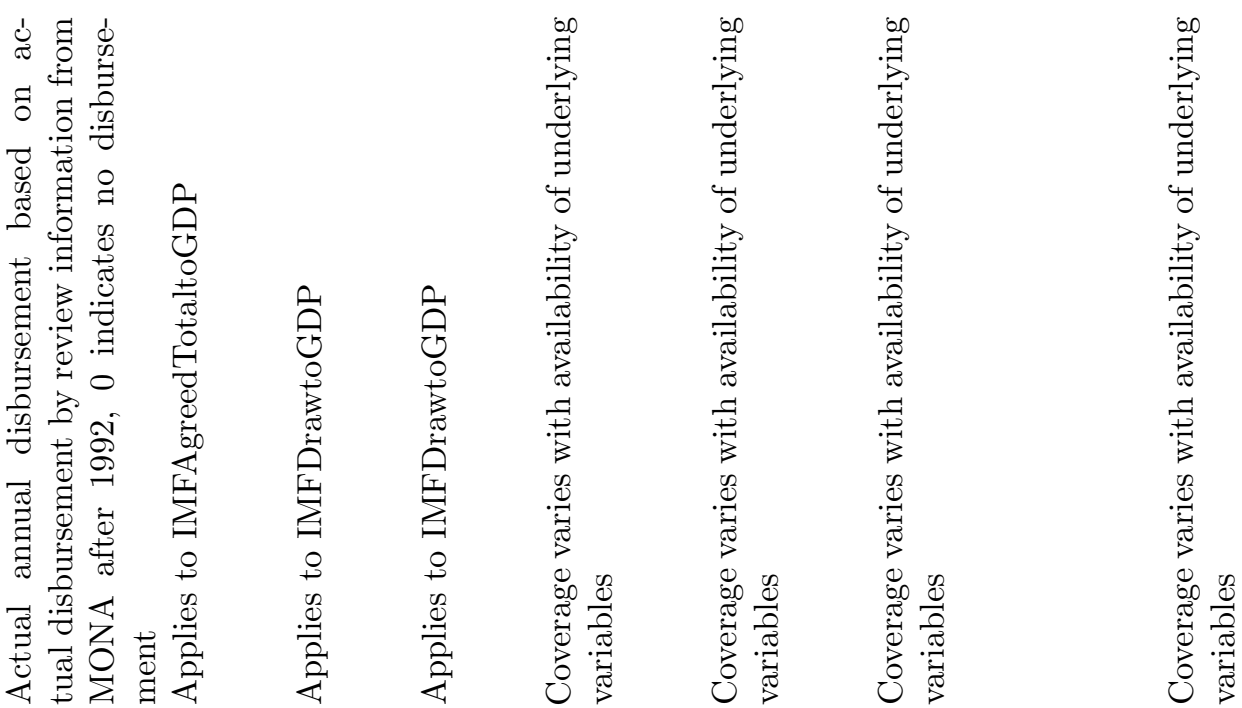

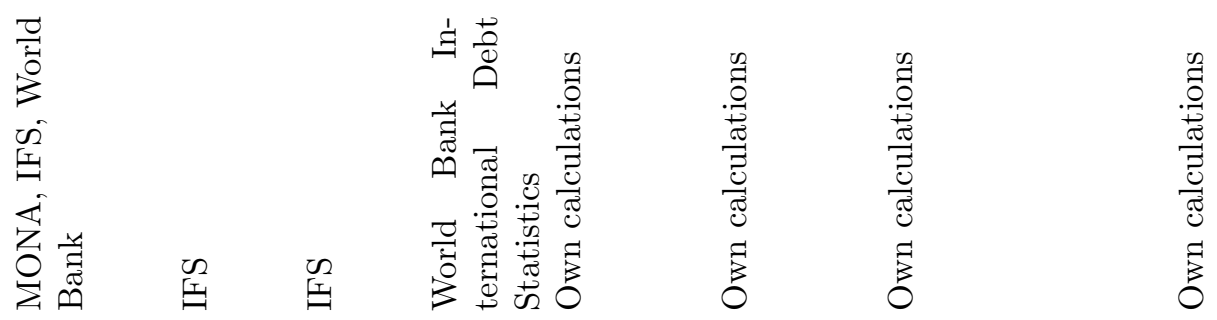

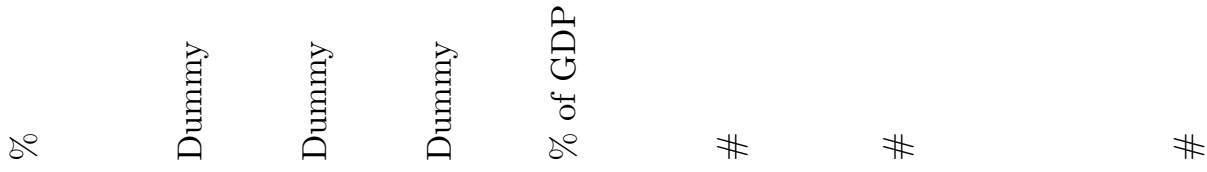

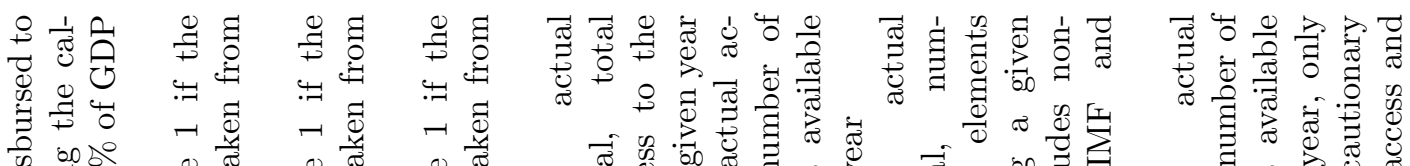

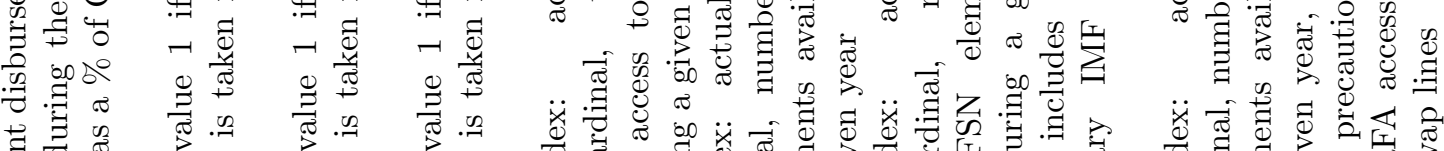

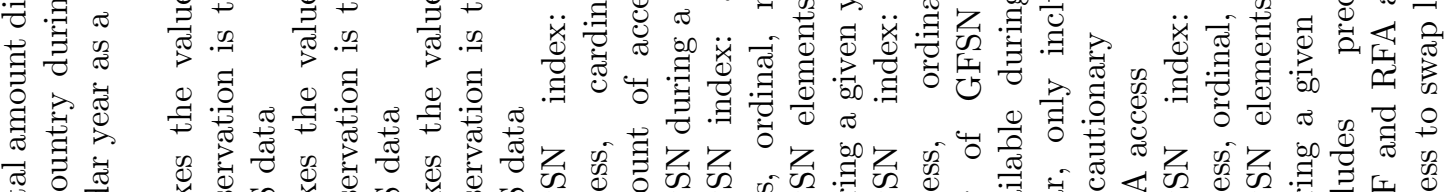

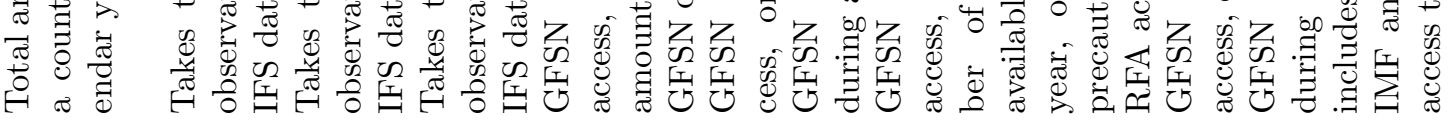

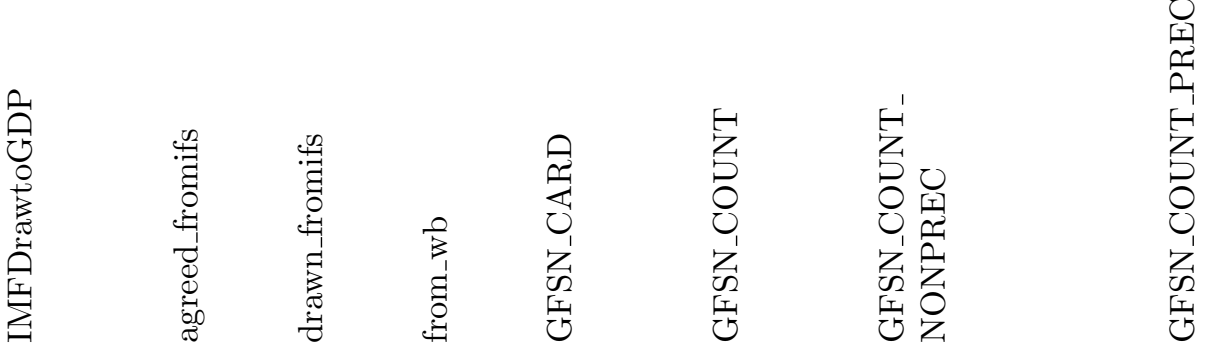




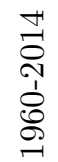

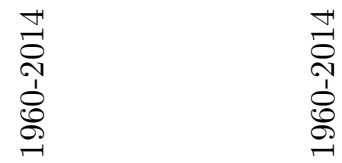

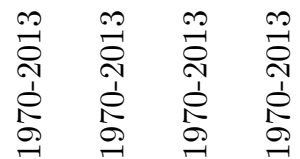

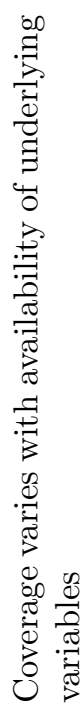

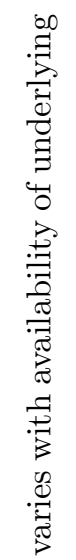

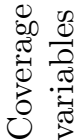

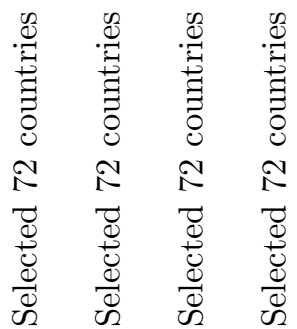

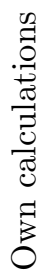

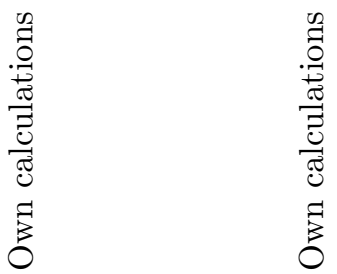

$\begin{array}{llll}\dot{0} & \dot{0} & \dot{0} & \dot{0} \\ \dot{0} & \dot{0} & \dot{0} & \dot{0}\end{array}$

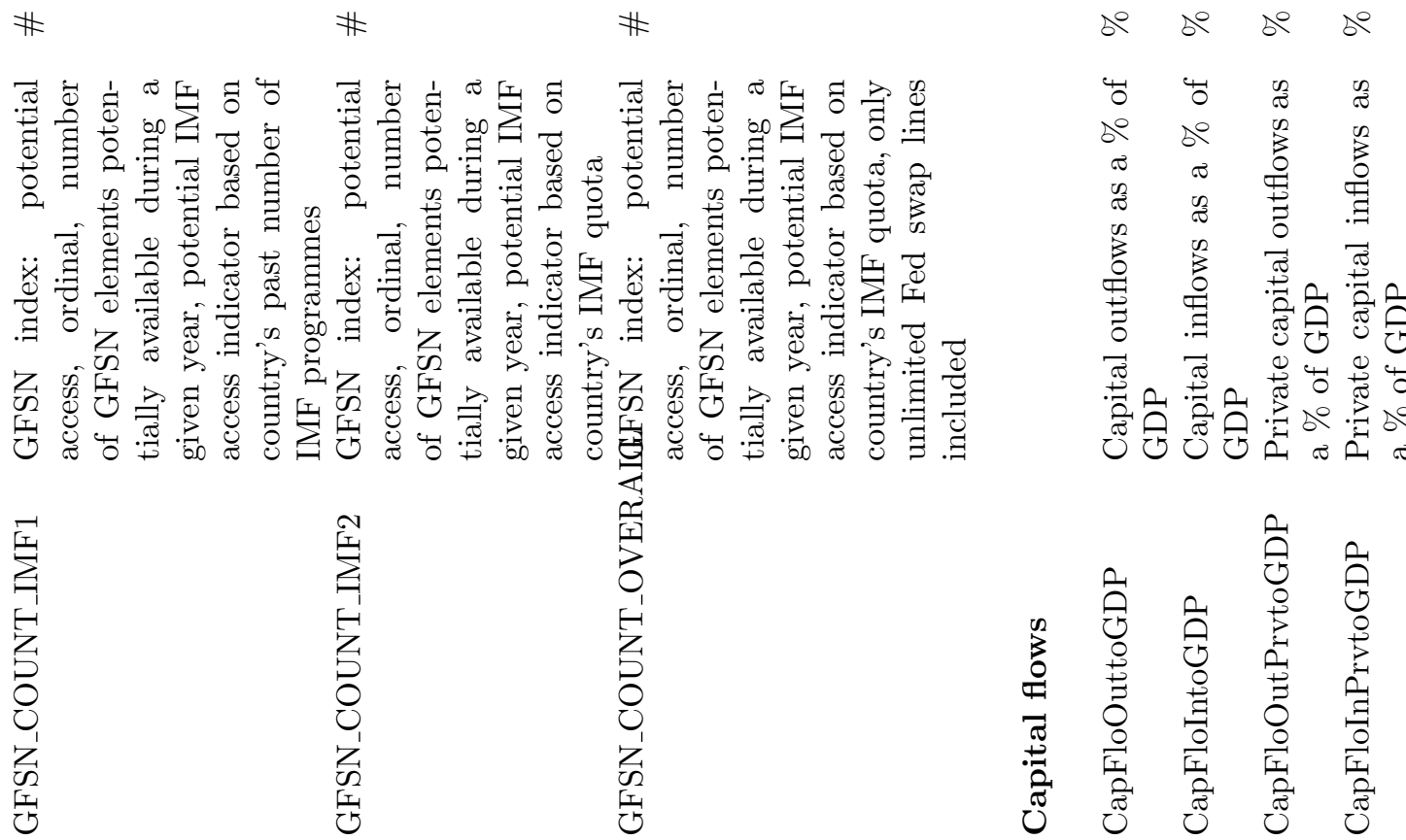




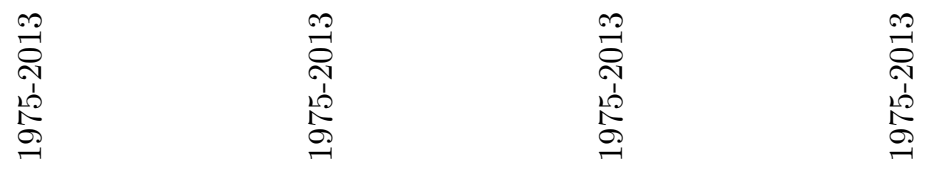

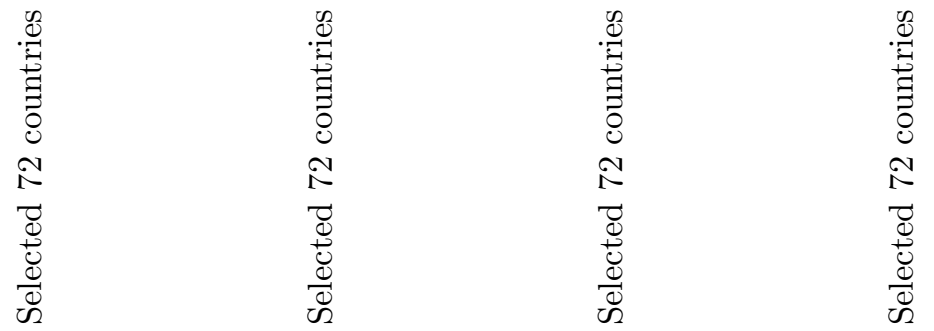

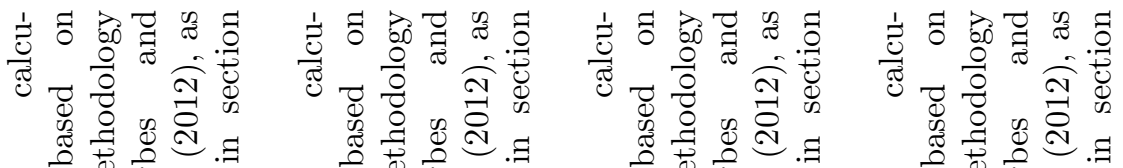

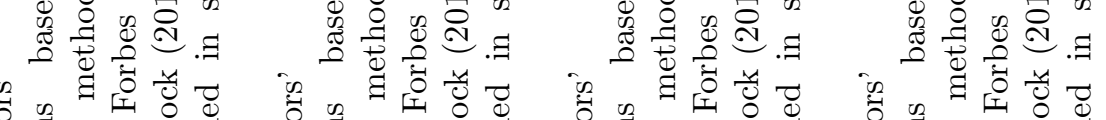

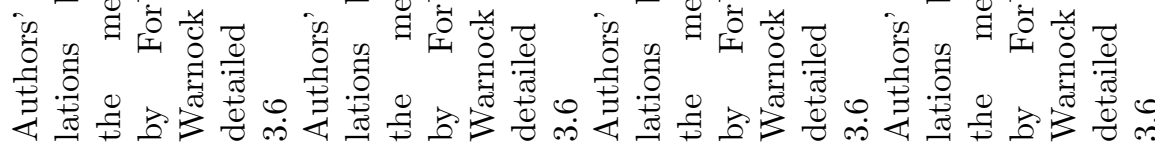

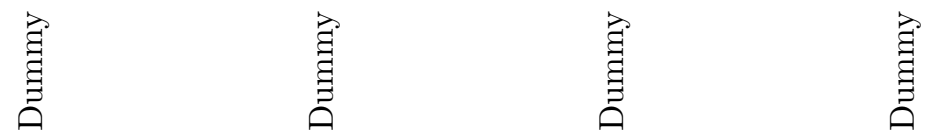

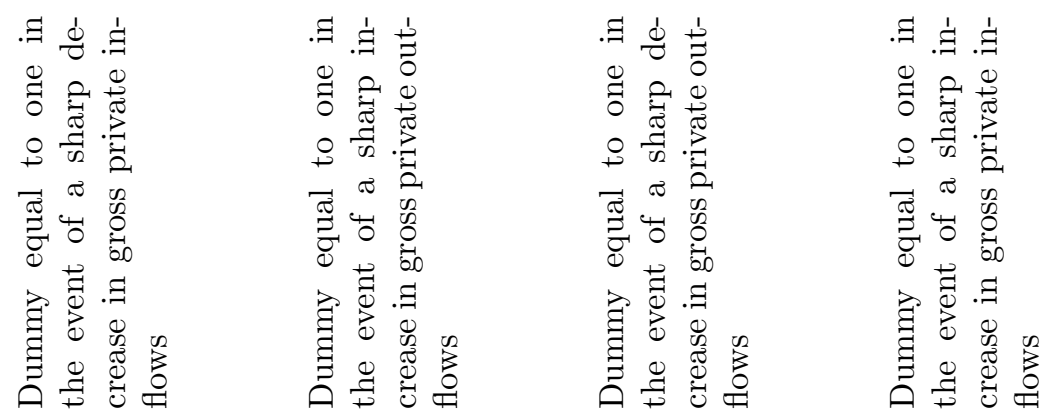

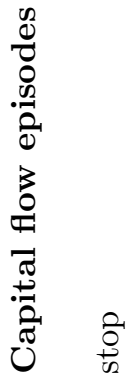

:
:
0
0
0
0
0

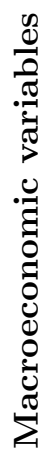




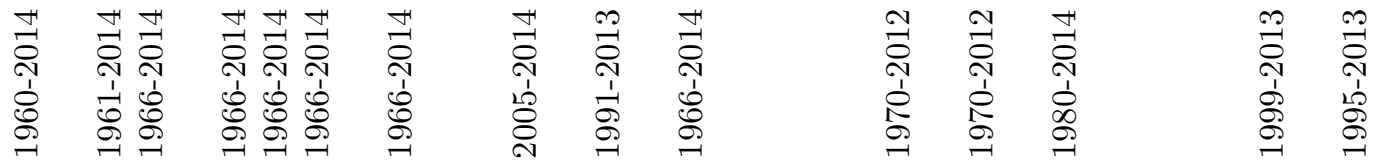

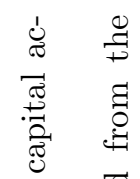

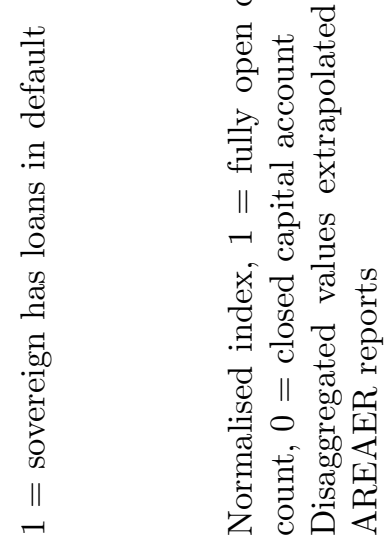

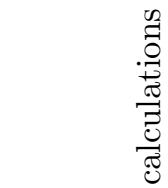

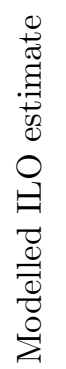

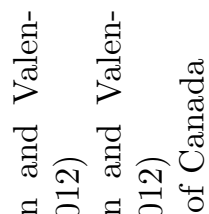

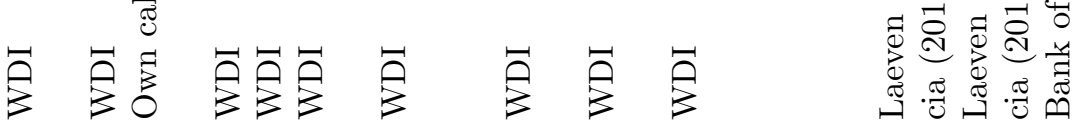

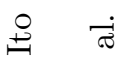

$\widetilde{\Xi}$

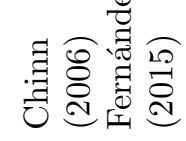

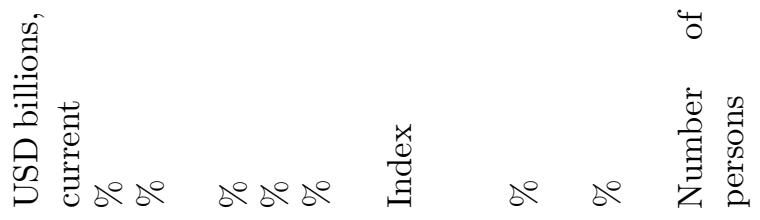

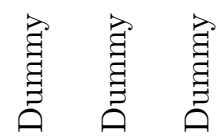

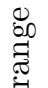

至

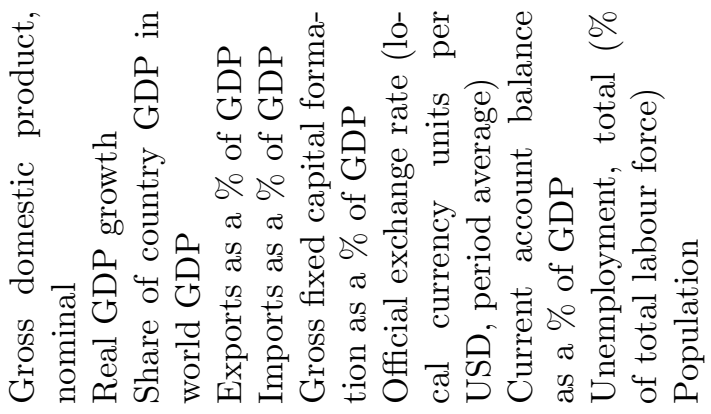

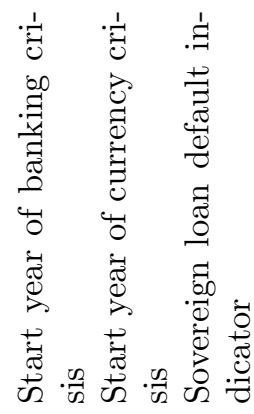

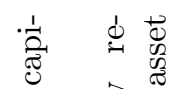

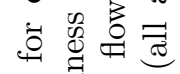

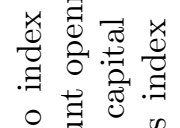

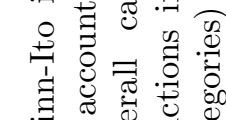

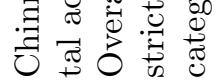

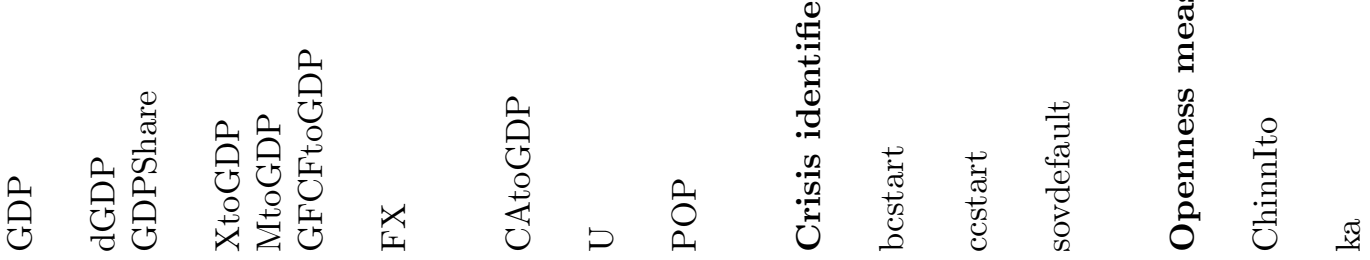




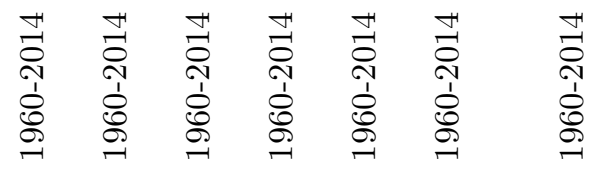

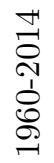

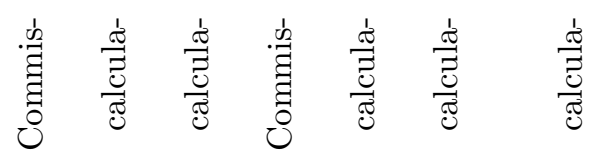

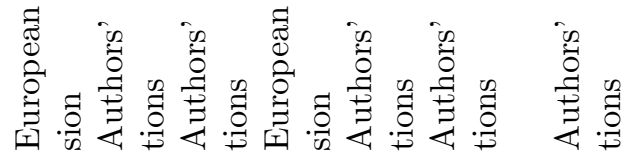

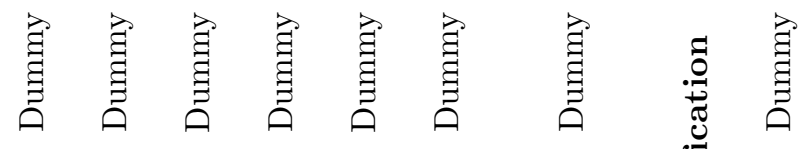

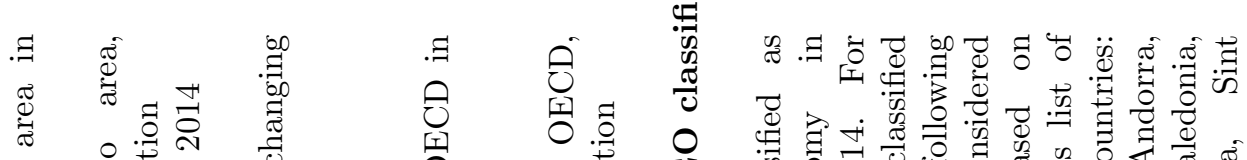

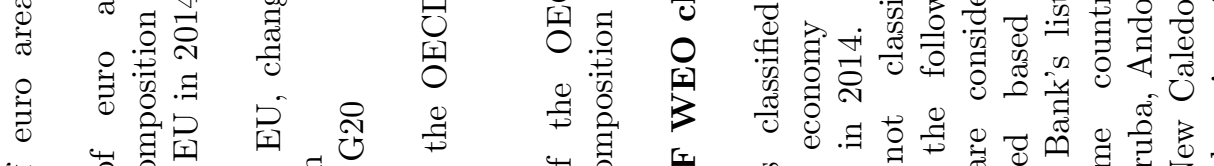

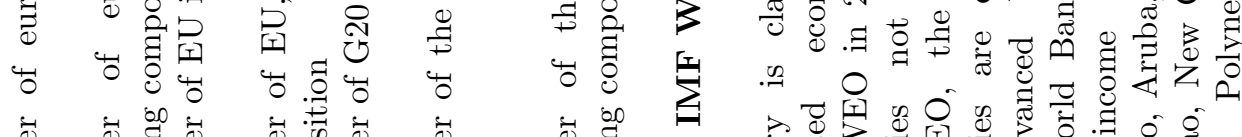

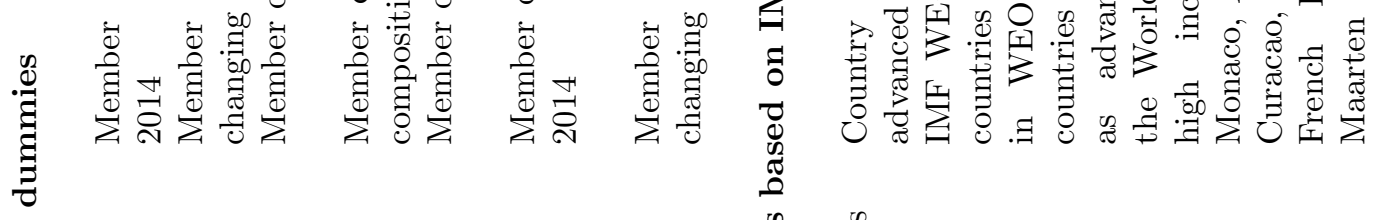

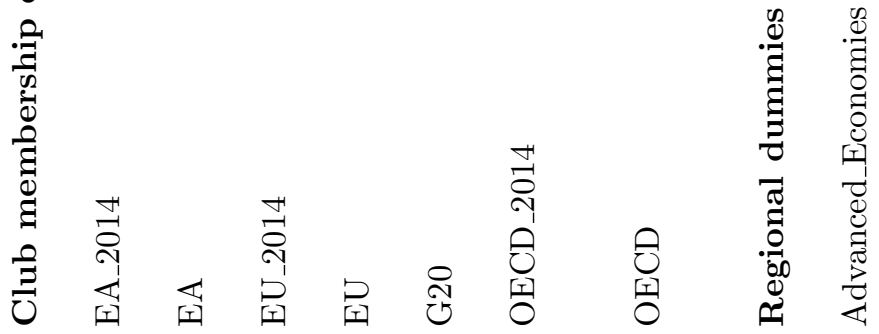




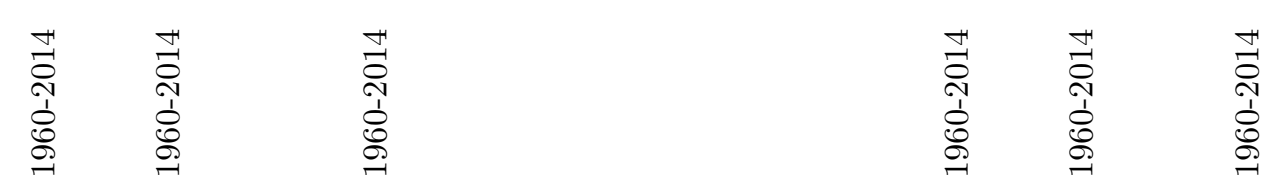

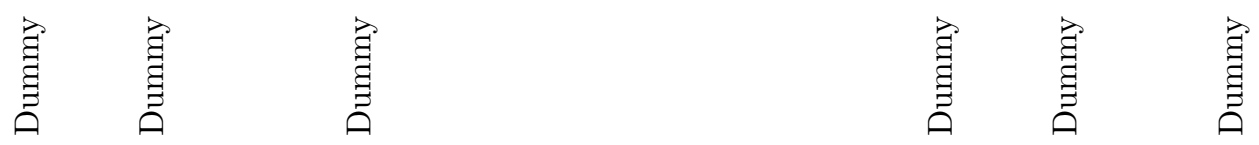

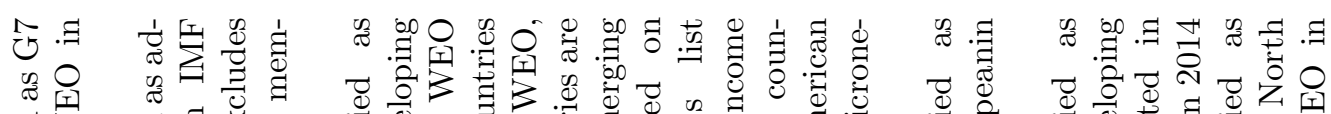

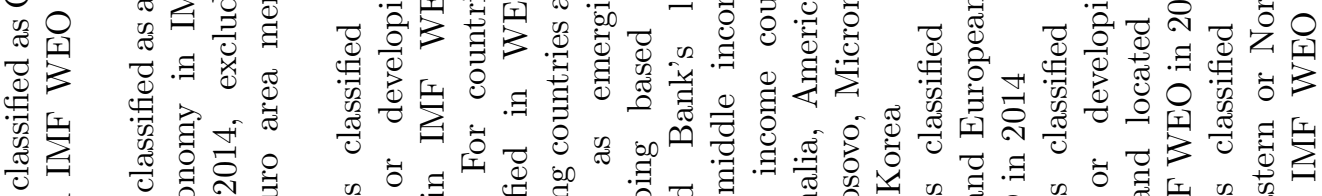

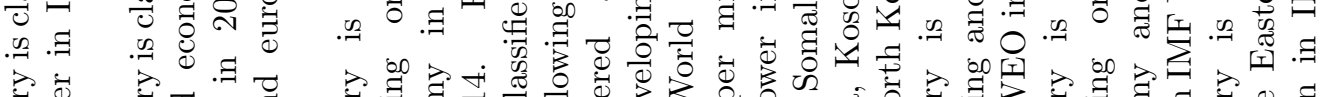

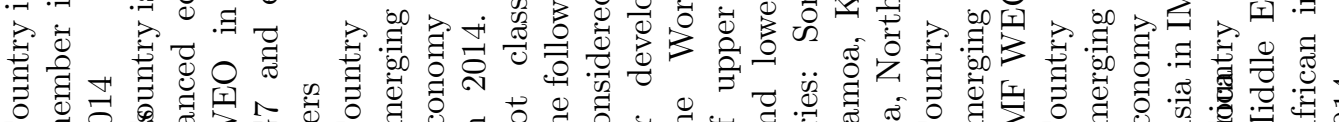

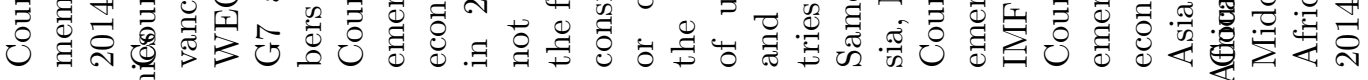

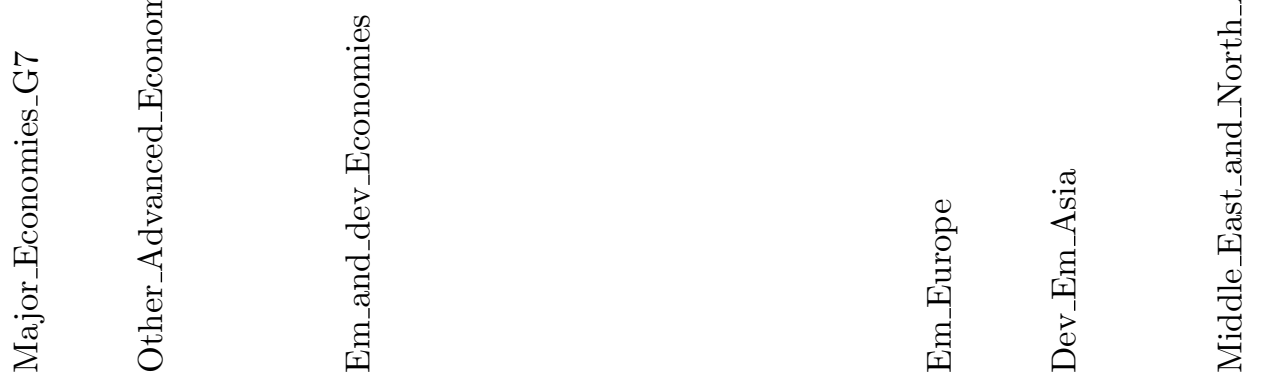




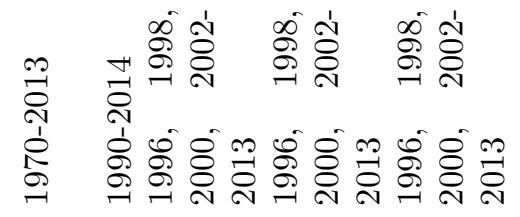

善

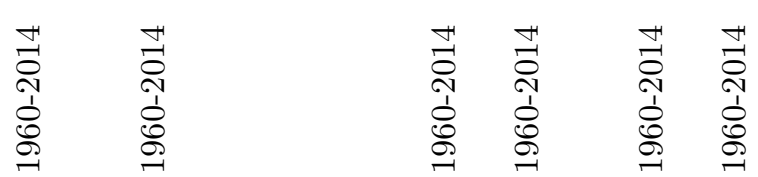

竞

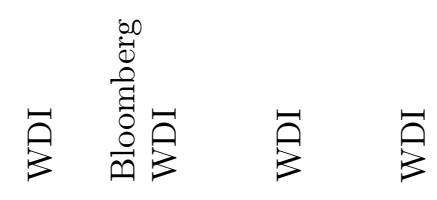

㤩

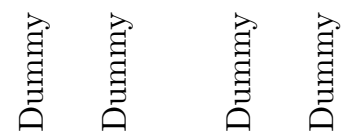

o $\quad$ 离

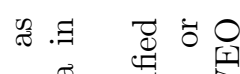

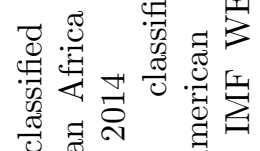

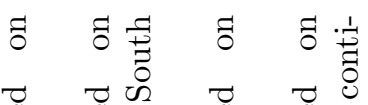

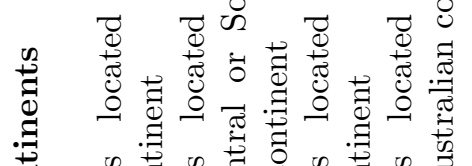

(

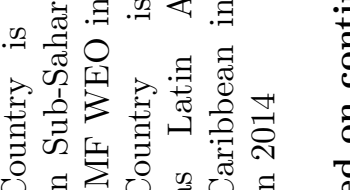

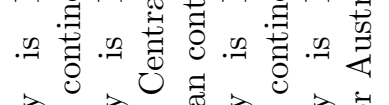

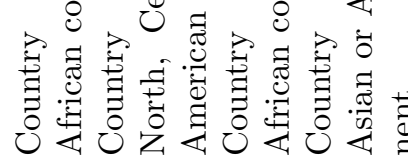

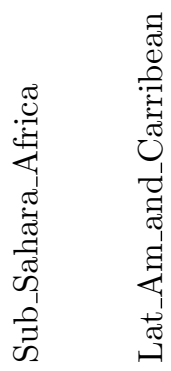

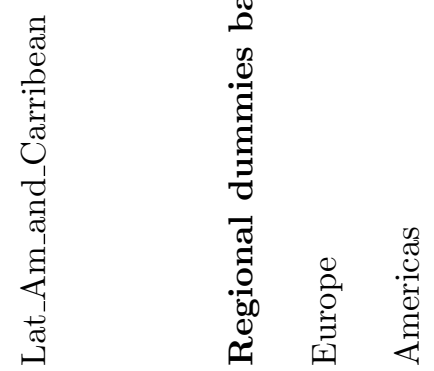

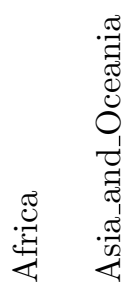

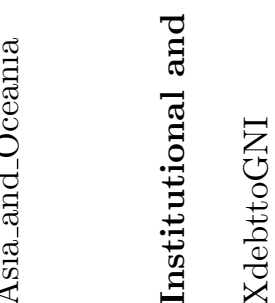

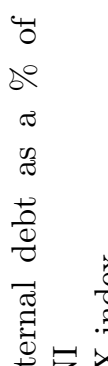

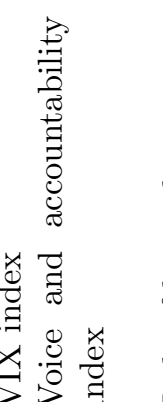

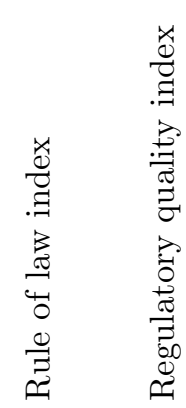

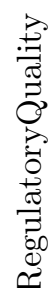




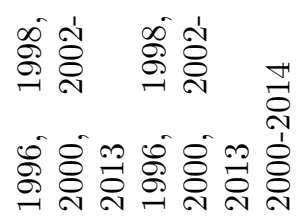

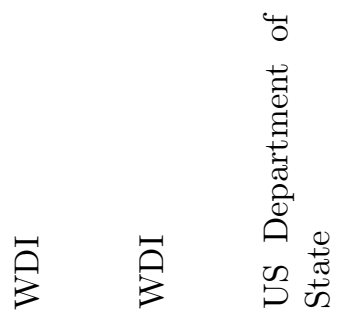

范 荖

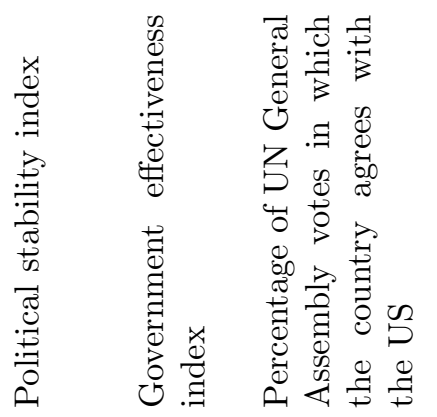

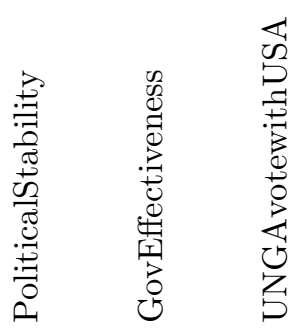


Table 2: IDENTIFICATION OF CAPITAL FLOW EPISODES

\begin{tabular}{lll}
\hline \hline Surge & $\Delta c_{t}^{i}>\left(m_{4}^{\Delta c_{t}^{i}}+2 s d_{4}^{\Delta c_{t}^{i}}\right)$ & A sharp increase in gross capital inflows \\
& for at least 1 year; lasts as long & \\
& as & \\
& $\Delta c_{t}^{i}>\left(m_{4}^{\Delta c_{t}^{i}}+s d_{4}^{\Delta c_{t}^{i}}\right)$ & \\
& during consecutive years & \\
& $\Delta c_{t}^{i}<\left(m_{4}^{\Delta c_{t}^{i}}-2 s d_{4}^{\Delta c_{t}^{i}}\right)$ & \\
& for at least 1 year; lasts as long & \\
& as & \\
& $\Delta c_{t}^{i}<\left(m_{4}^{\Delta c_{t}^{i}}-s d_{4}^{\Delta c_{t}^{i}}\right)$ & \\
& during consecutive years & \\
& & \\
Flight & $\Delta c_{t}^{o}>\left(m_{4}^{\Delta c_{t}^{o}}+2 s d_{4}^{\Delta c_{t}^{o}}\right)$ & A sharp increase in gross capital \\
& for at least 1 year; lasts as long in gross capital inflows \\
& as & outflows \\
& $\Delta c_{t}^{o}>\left(m_{4}^{\Delta c_{t}^{o}}+s d_{4}^{\Delta c_{t}^{o}}\right)$ & \\
& during consecutive years & \\
& $\Delta c_{t}^{o}<\left(m_{4}^{\Delta c_{t}^{o}}-2 s d_{4}^{\Delta c_{t}^{o}}\right.$ & A sharp decrease in gross capital \\
& for at least 1 year; lasts as long & outflows \\
& as & \\
& $\Delta c_{t}^{o}<\left(m_{4}^{\Delta c_{t}^{o}}-s d_{4}^{\Delta c_{t}^{o}}\right)$ & \\
Retrenchmg consecutive years & \\
\hline \hline
\end{tabular}


Table 3: Components of AGgregate GFSN Indices

\begin{tabular}{|c|c|c|c|c|}
\hline Indicator & $\begin{array}{l}\text { Reserves } \\
\text { measure }\end{array}$ & Swap measure & IMF measure & RFA measure \\
\hline GFSN_CARD & Level of reserves & Swap line limit & $\begin{array}{l}\text { Agreed } \\
\text { disbursement }\end{array}$ & Size of RFA loan \\
\hline GFSN_COUNT & $\begin{array}{l}\text { Reserves }>= \\
\text { cross-section av- } \\
\text { erage }\end{array}$ & $\begin{array}{l}\text { Swap line } \\
\text { available }\end{array}$ & $\begin{array}{l}\text { Country has } \\
\text { IMF programme }\end{array}$ & RFA loan used \\
\hline $\begin{array}{l}\text { GFSN_COUNT } \\
\text { _NONPREC }\end{array}$ & - & - & $\begin{array}{l}\text { Country has } \\
\text { non-prec. IMF } \\
\text { programme }\end{array}$ & RFA loan used \\
\hline $\begin{array}{l}\text { GFSN_COUNT } \\
\text { _PREC }\end{array}$ & $\begin{array}{l}\text { Reserves }>= \\
\text { cross-section av- } \\
\text { erage }\end{array}$ & $\begin{array}{l}\text { Swap line } \\
\text { available }\end{array}$ & $\begin{array}{l}\text { Country has } \\
\text { prec. IMF pro- } \\
\text { gramme }\end{array}$ & - \\
\hline $\begin{array}{l}\text { GFSN_COUNT } \\
\text { _IMF1 }\end{array}$ & $\begin{array}{l}\text { Reserves }>= \\
\text { cross-section av- } \\
\text { erage }\end{array}$ & $\begin{array}{l}\text { Swap line } \\
\text { available }\end{array}$ & $\begin{array}{l}\text { Above-average } \\
\text { number of IMF } \\
\text { programmes in } \\
\text { the past }\end{array}$ & RFA member \\
\hline $\begin{array}{l}\text { GFSN_COUNT } \\
\text { _IMF2 }\end{array}$ & $\begin{array}{l}\text { Reserves }>= \\
\text { cross-section av- } \\
\text { erage }\end{array}$ & $\begin{array}{l}\text { Swap line } \\
\text { available }\end{array}$ & $\begin{array}{l}\text { Above-average } \\
\text { IMF quota }\end{array}$ & RFA member \\
\hline GFSN_OVERALL & $\begin{array}{l}\text { Reserves }>= \\
\text { cross-section } \\
\text { average }\end{array}$ & $\begin{array}{l}\text { Unlimited swap } \\
\text { line available }\end{array}$ & $\begin{array}{l}\text { Above-average } \\
\text { IMF quota }\end{array}$ & RFA member \\
\hline
\end{tabular}




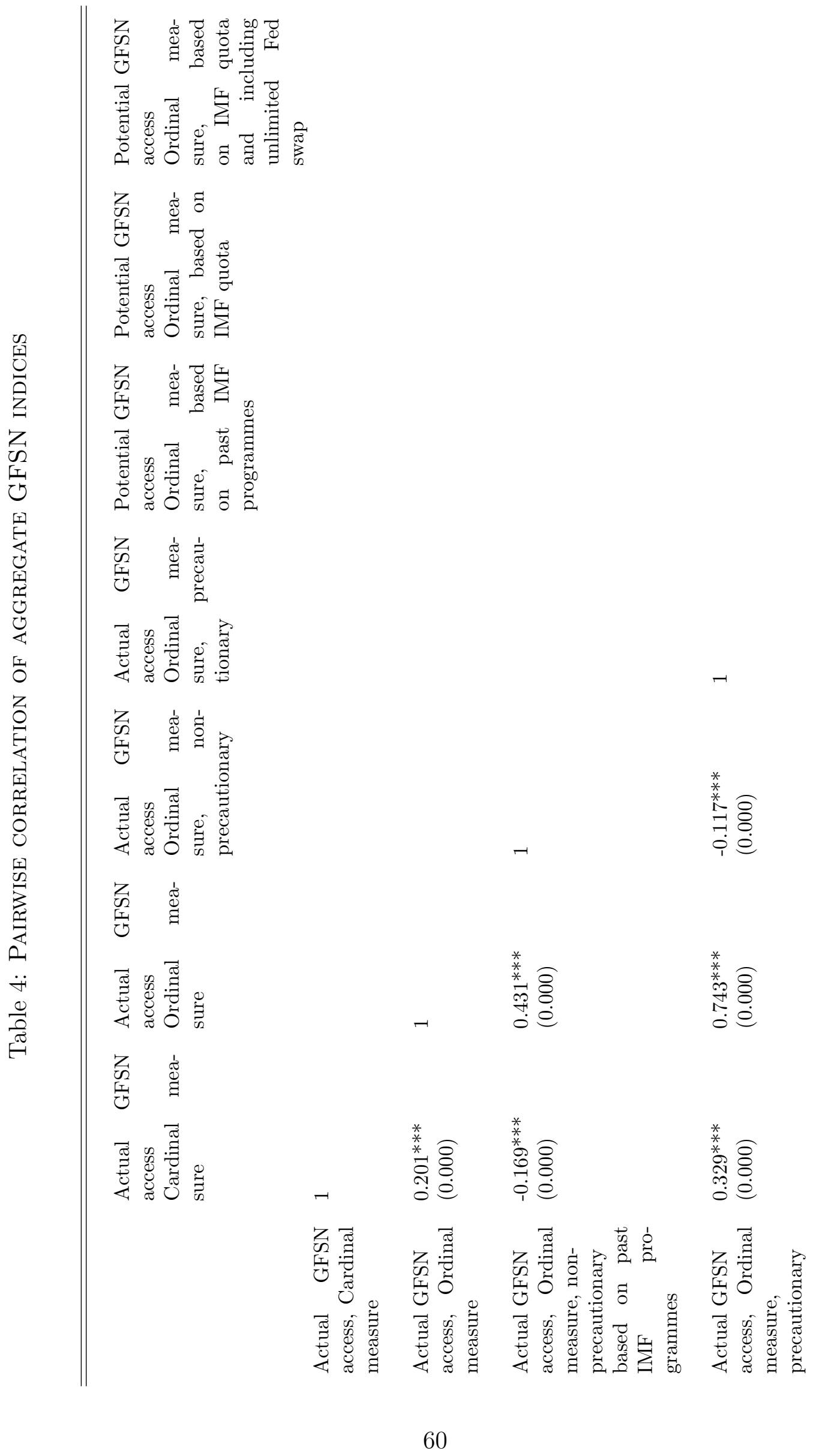




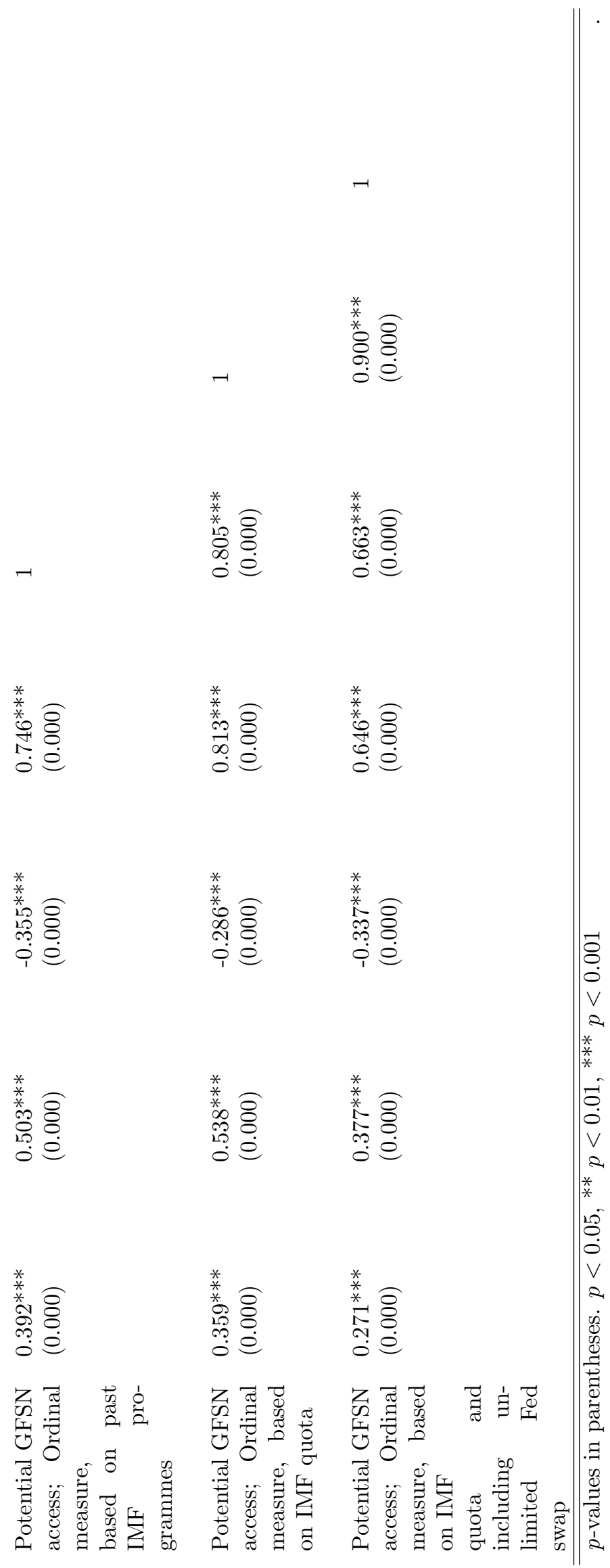


$\therefore$ बे

离营

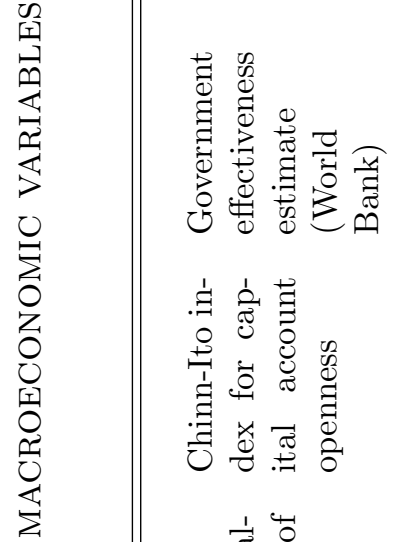

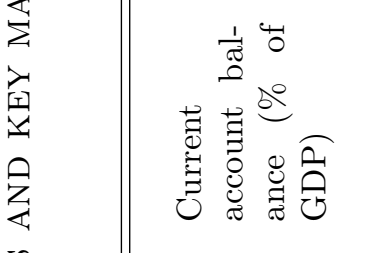

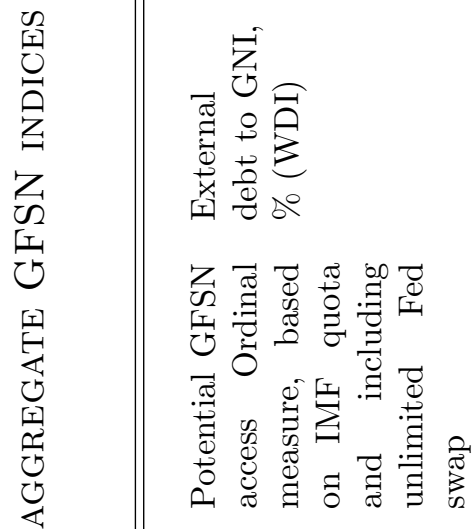

贡望焉

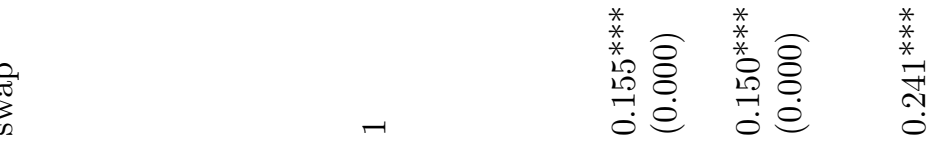

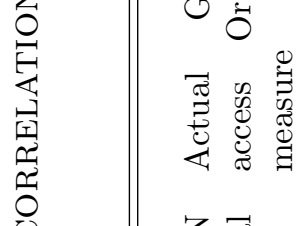

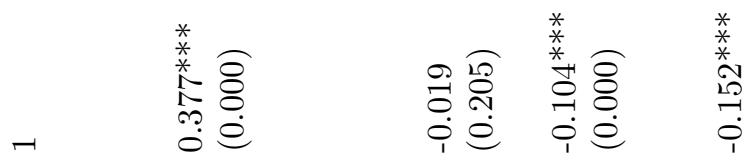

觉袢

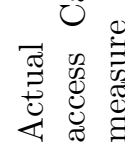

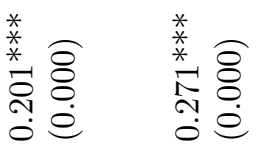

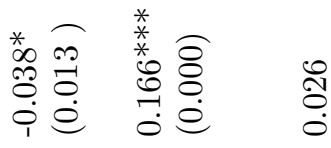

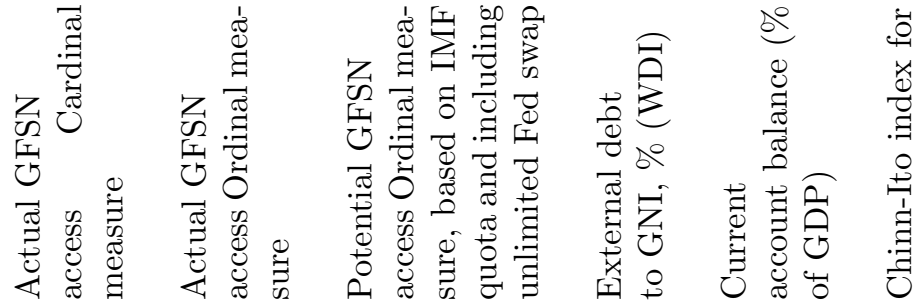




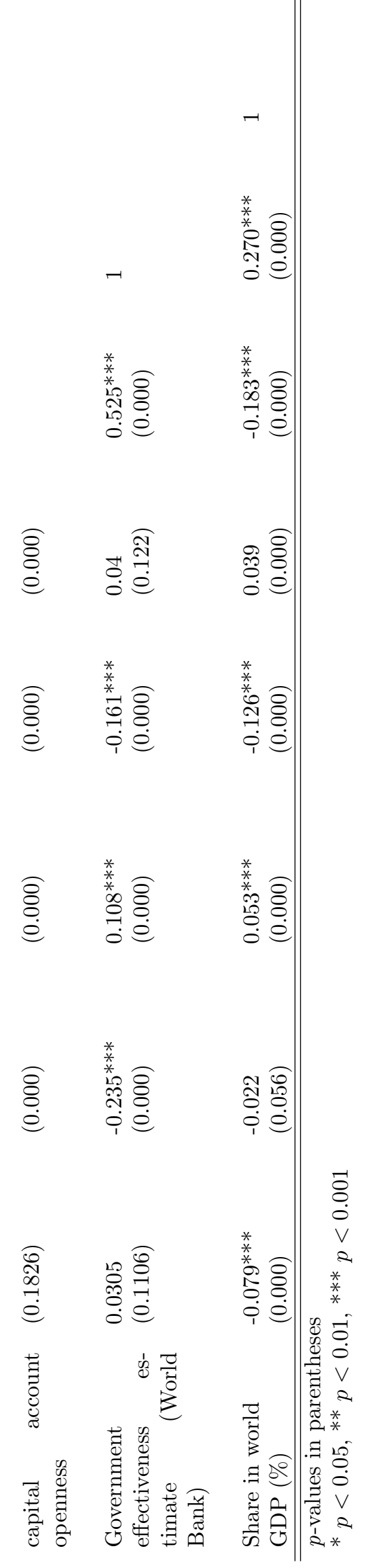


Table 6: PAIRWISE CORRELATION COEFFICIENTS: SUDDEN STOPS

\begin{tabular}{|c|c|c|c|c|c|}
\hline & $\begin{array}{l}\text { Number of } \\
\text { sudden stops }\end{array}$ & $\begin{array}{l}\text { FX reserves } \\
(\% \text { of GDP) }\end{array}$ & $\begin{array}{l}\text { Size of RFA } \\
\text { loan }(\% \text { of } \\
\text { GDP })\end{array}$ & $\begin{array}{l}\text { Number of } \\
\text { IMF pro- } \\
\text { grammes }\end{array}$ & $\begin{array}{l}\text { Limit on } \\
\text { swap line }(\% \\
\text { of GDP) }\end{array}$ \\
\hline $\begin{array}{l}\text { Number of } \\
\text { sudden stops }\end{array}$ & 1 & & & & \\
\hline $\begin{array}{l}\text { FX reserves } \\
(\% \text { of } \mathrm{GDP})\end{array}$ & $\begin{array}{l}-0.0007 \\
(0.942)\end{array}$ & 1 & & & \\
\hline $\begin{array}{l}\text { Size of RFA loan } \\
(\% \text { of GDP })\end{array}$ & $\begin{array}{l}0.166^{* * *} \\
(0.000)\end{array}$ & $\begin{array}{l}-0.033^{*} \\
(0.027)\end{array}$ & 1 & & \\
\hline $\begin{array}{l}\text { Number of } \\
\text { IMF programmes }\end{array}$ & $\begin{array}{l}-0.085^{* * *} \\
(0.000)\end{array}$ & $\begin{array}{l}-0.018 \\
(0.064)\end{array}$ & $\begin{array}{c}-0.037^{*} \\
(0.015)\end{array}$ & 1 & \\
\hline $\begin{array}{l}\text { Limit on swap line } \\
(\% \text { of GDP })\end{array}$ & $\begin{array}{l}0.183^{* * *} \\
(0.000)\end{array}$ & $\begin{array}{l}0.289^{* * *} \\
(0.000)\end{array}$ & $\begin{array}{l}-0.084^{* * *} \\
(0.000)\end{array}$ & $\begin{array}{c}-0.024^{*} \\
(0.016)\end{array}$ & 1 \\
\hline
\end{tabular}


Table 7: Local PROJECTIONS On SUdDEn StOPS - ORdinal GFSN MEASURE

\begin{tabular}{lccccc}
\hline & $(1)$ & $(2)$ & $(3)$ & $(4)$ & $(5)$ \\
& $t$ & $t+1$ & $t+2$ & $t+3$ & $t+4$ \\
\hline \hline \multirow{2}{*}{ Coefficient on the sudden stop in $t\left(\beta_{h}\right)$} & & & \\
GDP $(\log )$ & & & & & \\
& $-0.146^{*}$ & $-0.146^{* *}$ & 0.021 & 0.075 & 0.051 \\
& $(0.066)$ & $(0.016)$ & $(0.049)$ & $(0.073)$ & $(0.062)$ \\
FX $(\log )$ & & & & & \\
& $0.110^{* *}$ & $0.117^{* *}$ & -0.001 & -0.079 & -0.032 \\
Current account balance & $(0.047)$ & $(0.046)$ & $(0.036)$ & $(0.076)$ & $(0.066)$ \\
& & & & & \\
& $\left(1.086^{*}\right.$ & $2.926^{* *}$ & 1.687 & 0.527 & 1.638 \\
Unemployment rate & & $(1.335)$ & $(1.883)$ & $(1.375)$ & $(1.192)$ \\
& $1.063^{*}$ & 0.989 & $-0.827^{*}$ & $-1.660^{* *}$ & -0.27 \\
& $(0.698)$ & $(0.668)$ & $(0.427)$ & $(0.720)$ & $(0.410)$
\end{tabular}

\begin{tabular}{llllll}
$\begin{array}{l}\text { Coefficient on sudden } \\
\text { (GFSN_COUNT) }\left(\theta_{h}\right)\end{array}$ & stop in $t *$ GFSN & coverage & in & $t$ \\
GDP $(\log )$ & & & & & \\
& & & & & \\
& $\left(0.044^{* *}\right.$ & 0.016 & -0.027 & -0.032 & -0.022 \\
FX $(\log )$ & & & & & \\
& $-0.031^{*}$ & -0.021 & 0.011 & 0.025 & 0.015 \\
& $(0.015)$ & $(0.020)$ & $(0.016)$ & $(0.030)$ & $(0.027)$ \\
Current account & -0.440 & -0.561 & -0.025 & -0.554 & -0.622 \\
& $(0.257)$ & $(0.227)$ & $(0.175)$ & $(0.235)$ & $(0.164)$ \\
& & & & & \\
Unemployment rate & -0.307 & -0.026 & $0.293 *$ & $0.530 * *$ & 0.097 \\
& $(0.257)$ & $(0.227)$ & $(0.175)$ & $(0.235)$ & $(0.164)$ \\
\hline \hline
\end{tabular}

Notes: Estimation with FE OLS, including a time trend; standard errors adjusted for clustering. Significance level: ${ }^{* * *}: p<0.01 ;^{* *}: p<0.05 ;^{*}: p<0.1$. Estimation based on GFSN measure GFSN_COUNT. Vector of control variables $z_{i, t+h-1}$ includes GDP, FX, CA, unemployment rate, imports, exports and debt as a share of GDP, the Chinn-Ito measure of capital account openness and the overall restrictions index by Fernàndez et al. (2015), a country's share in world GDP and the VIX index. Respective dependent variables included as first lag. 
Table 8: Local Projections on SUdden stops - CARdinal GFSN MEAsure

\begin{tabular}{|c|c|c|c|c|c|}
\hline & $\begin{array}{c}(1) \\
t\end{array}$ & $\begin{array}{c}(2) \\
t+1 \\
\end{array}$ & $\begin{array}{c}(3) \\
t+2 \\
\end{array}$ & $\begin{array}{c}(4) \\
t+3 \\
\end{array}$ & $\begin{array}{c}(5) \\
t+4 \\
\end{array}$ \\
\hline \multicolumn{6}{|c|}{ Coefficient on the sudden stop in $t\left(\beta_{h}\right)$} \\
\hline GDP (log) & $\begin{array}{c}-0.107^{* *} \\
(0.0256)\end{array}$ & $\begin{array}{c}-0.091^{*} \\
(0.052)\end{array}$ & $\begin{array}{c}0.023 \\
(0.041)\end{array}$ & $\begin{array}{c}0.039 \\
(0.062)\end{array}$ & $\begin{array}{c}0.023 \\
(0.058)\end{array}$ \\
\hline FX $(\log )$ & $\begin{array}{c}0.087^{* *} \\
(0.039)\end{array}$ & $\begin{array}{c}0.089^{*} \\
(0.045)\end{array}$ & $\begin{array}{c}0.001 \\
(0.037)\end{array}$ & $\begin{array}{c}-0.042 \\
(0.065)\end{array}$ & $\begin{array}{c}0.005 \\
(0.053)\end{array}$ \\
\hline Current account & $\begin{array}{c}1.637 \\
(1.371)\end{array}$ & $\begin{array}{c}1.169 \\
(1.257)\end{array}$ & $\begin{array}{c}1.722 \\
(1.552)\end{array}$ & $\begin{array}{c}0.242 \\
(1.164)\end{array}$ & $\begin{array}{c}1.862^{* * *} \\
(0.740)\end{array}$ \\
\hline Unemployment rate & $\begin{array}{c}0.700 \\
(0.607)\end{array}$ & $\begin{array}{c}1.128^{*} \\
(0.653)\end{array}$ & $\begin{array}{l}-0.464 \\
(0.342)\end{array}$ & $\begin{array}{c}-1.048^{*} \\
(0.555)\end{array}$ & $\begin{array}{l}-0.366 \\
(0.273)\end{array}$ \\
\hline \multicolumn{6}{|c|}{$\begin{array}{l}\text { Coefficient on sudden stop in } t * \text { GFSN coverage in } t-1 \text { (GFSN_CARD) } \\
\left(\theta_{h}\right)\end{array}$} \\
\hline GDP (log) & $\begin{array}{c}0.002 \\
(0.001)\end{array}$ & $\begin{array}{r}-0.001^{*} \\
(0.002)\end{array}$ & $\begin{array}{l}-0.002 \\
(0.001)^{*}\end{array}$ & $\begin{array}{l}-0.001 \\
(0.002)\end{array}$ & $\begin{array}{l}-0.001 \\
(0.001)\end{array}$ \\
\hline FX $(\log )$ & $\begin{array}{c}-0.002^{* *} \\
(0.001)\end{array}$ & $\begin{array}{l}-0.001 \\
(0.001)\end{array}$ & $\begin{array}{c}0.001 \\
(0.001)\end{array}$ & $\begin{array}{c}0.001 \\
(0.002)\end{array}$ & $\begin{array}{c}0.000 \\
(0.001)\end{array}$ \\
\hline Current account & $\begin{array}{c}0.007 \\
(0.035)\end{array}$ & $\begin{array}{c}0.019 \\
(0.048)\end{array}$ & $\begin{array}{l}-0.004 \\
(0.047)\end{array}$ & $\begin{array}{c}-0.031 \\
(0.029)\end{array}$ & $\begin{array}{c}-0.061^{* *} \\
(0.029)\end{array}$ \\
\hline Unemployment rate & $\begin{array}{c}-0.011 \\
(0.016)\end{array}$ & $\begin{array}{c}-0.006 \\
(0.016)\end{array}$ & $\begin{array}{c}0.006 \\
(0.009)\end{array}$ & $\begin{array}{c}0.156 \\
(0.014)\end{array}$ & $\begin{array}{c}0.013 \\
(0.009)\end{array}$ \\
\hline
\end{tabular}

Notes: Estimation with FE OLS including a time trend; standard errors adjusted for clustering. Significance level: ${ }^{* * *}: p<0.01{ }^{* *}: p<0.05 ;^{*}: p<0.1$. Estimation based on GFSN measure GFSN_CARD. Vector of control variables $z_{i, t+h-1}$ includes GDP, FX, CA, unemployment rate, imports, exports and debt as a share of GDP, the Chinn-Ito measure of capital account openness and the overall restrictions index by Fernàndez et al. (2015), a country's share in world GDP and the VIX index. Respective dependent variables included as first lag. 
Table 9: Local Projections on SUdDEn stops - Potential GFSN MEASURE

\begin{tabular}{ccccc}
\hline$(1)$ & $(2)$ & $(3)$ & $(4)$ & $(5)$ \\
$t$ & $t+1$ & $t+2$ & $t+3$ & $t+4$ \\
\hline \hline
\end{tabular}

Coefficient on the sudden stop in $t\left(\beta_{h}\right)$

$\begin{array}{lccccc}\text { GDP }(\log ) & -0.117^{* *} & -0.136^{* * *} & -0.002 & 0.049 & 0.046 \\ & (0.054) & (0.048) & (0.042) & (0.056) & (0.046) \\ \text { FX }(\log ) & & & & & \\ & 0.098^{* *} & 0.112^{* * *} & 0.015 & -0.047 & -0.027 \\ \text { Current account } & (0.038) & (0.035) & (0.033) & (0.057) & (0.049) \\ & & & & & \\ \text { Unemployment rate } & 2.794^{*} & 2.236^{*} & 1.491 & 0.197 & 0.942 \\ & (0.761) & (0.928) & (0.887) & (0.673) & (0.438) \\ & 0.941^{*} & 1.178^{*} & -0.366 & -1.083 & -0.233 \\ & (0.550) & (0.610) & (0.319) & (0.551)^{*} & (0.284)\end{array}$

Coefficient of the interaction term between the sudden stop in $t$ and GFSN coverage in $t-1\left(\theta_{h}\right)$

\begin{tabular}{lccccc} 
GDP $(\log )$ & $0.037^{*}$ & 0.015 & -0.034 & -0.035 & -0.040 \\
& $(0.021)$ & $(0.027)$ & $(0.021)$ & $(0.035)$ & $(0.026)$ \\
FX $(\log )$ & & & & & \\
& $-0.035^{* *}$ & -0.026 & 0.007 & 0.021 & 0.034 \\
Current account & $(0.014)$ & $(0.019)$ & $(0.016)$ & $(0.029)$ & $(0.026)$ \\
& & & & & \\
& -0.260 & -0.220 & 0.078 & -0.588 & -0.286 \\
Unemployment rate & $(0.531)$ & $(0.686)$ & $(0.665)$ & $(0.378)$ & $(0.398)$ \\
& -0.336 & -0.125 & 0.087 & 0.266 & 0.020 \\
& $(0.228)$ & $(0.262)$ & $(0.143)$ & $(0.228)$ & $(0.143)$ \\
\hline \hline
\end{tabular}

Notes: Estimation with FE OLS, including a time trend; standard errors adjusted for clustering. Significance level: ${ }^{* * *}: p<0.01 ;^{* *}: p<0.05 ;^{*}: p<0.1$. Estimation based on GFSN measure GFSN_OVERALL. Vector of control variables $z_{i, t+h-1}$ includes GDP, FX, CA, unemployment rate, imports, exports and debt as a share of GDP, the Chinn-Ito measure of capital account openness and the overall restrictions index by Fernàndez et al. (2015), a country's share in world GDP and the VIX index. Respective dependent variables included as first lag. 


\section{Figures}

Figure 1: GROWING SIZE OF RESERVES

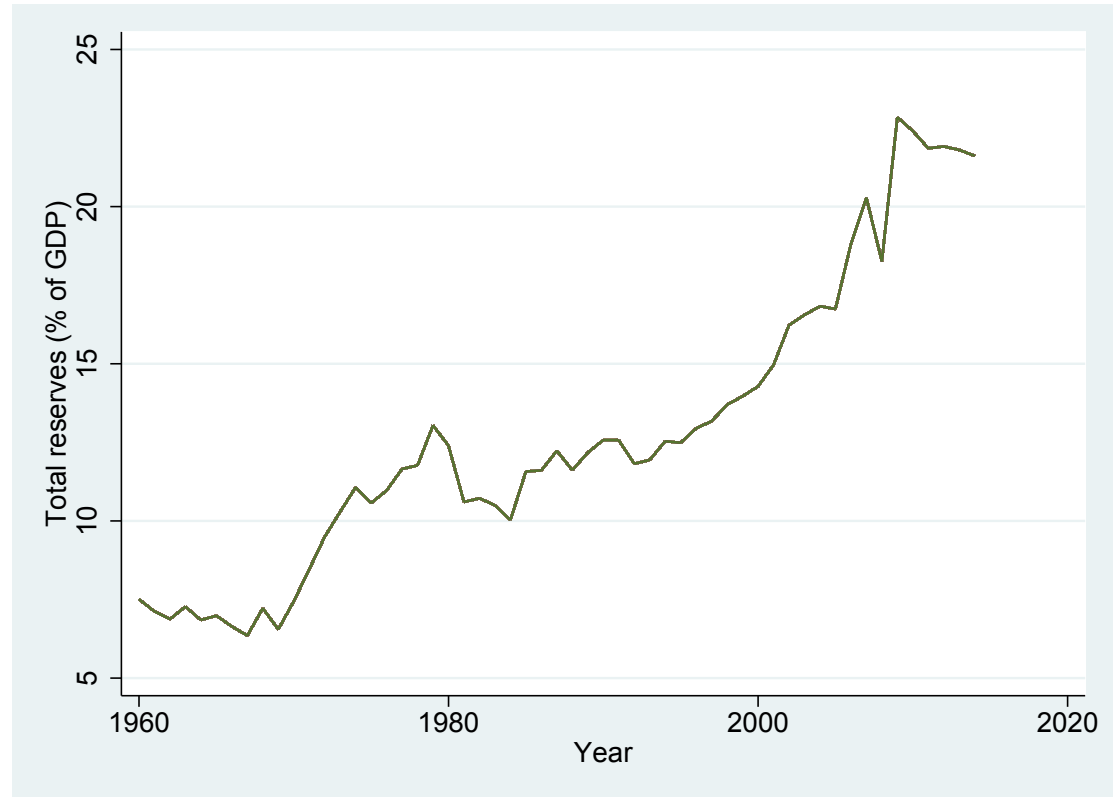

Source: World Bank database, average across countries. 
Figure 2: Growing NETWORK OF CENTRAL BANK SWAP LINES

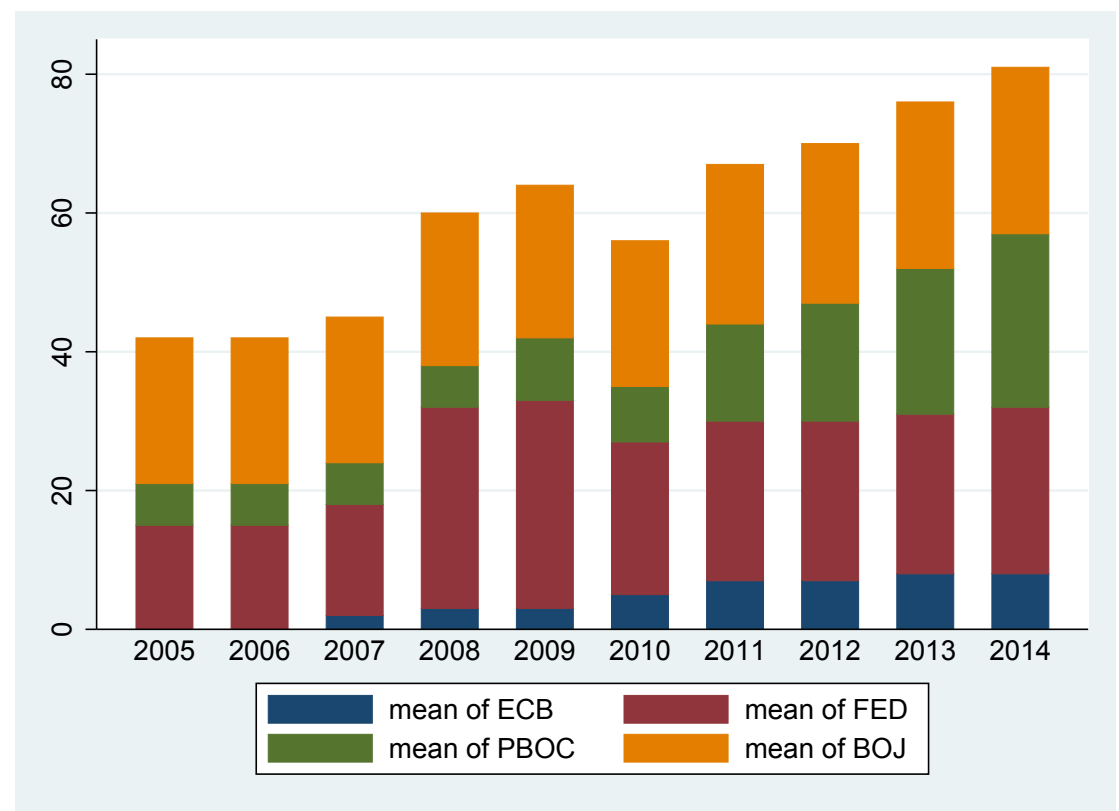

Sources: BoJ, ECB, Federal Reserve, PBoC. The chart indicates the number of swap line partners of the central banks.

Figure 3: THE SWAP LINE NETWORK HAS GLOBAL COVERAGE

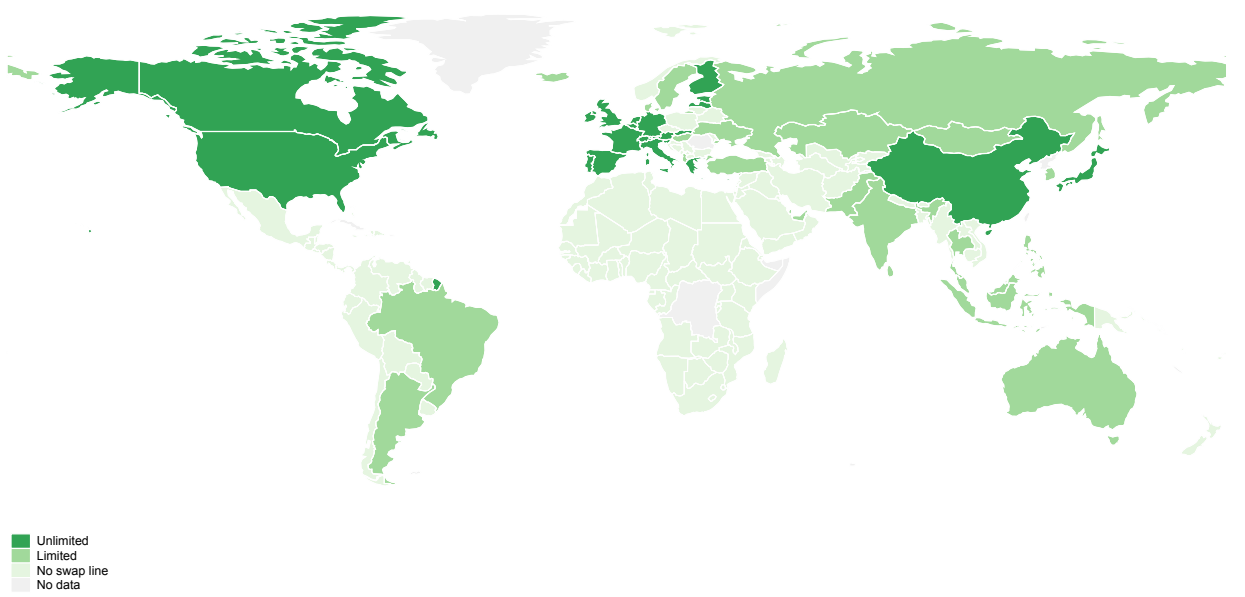

Sources: BoJ, ECB, Federal Reserve, PBoC. Coloured areas indicate countries with a swap line in 2013 from the BoJ, ECB, Federal Reserve or PBoC. Dark green=unlimited swap line; light green=limited swap line. 
Figure 4: USE OF THE GFSN HAS INCREASED

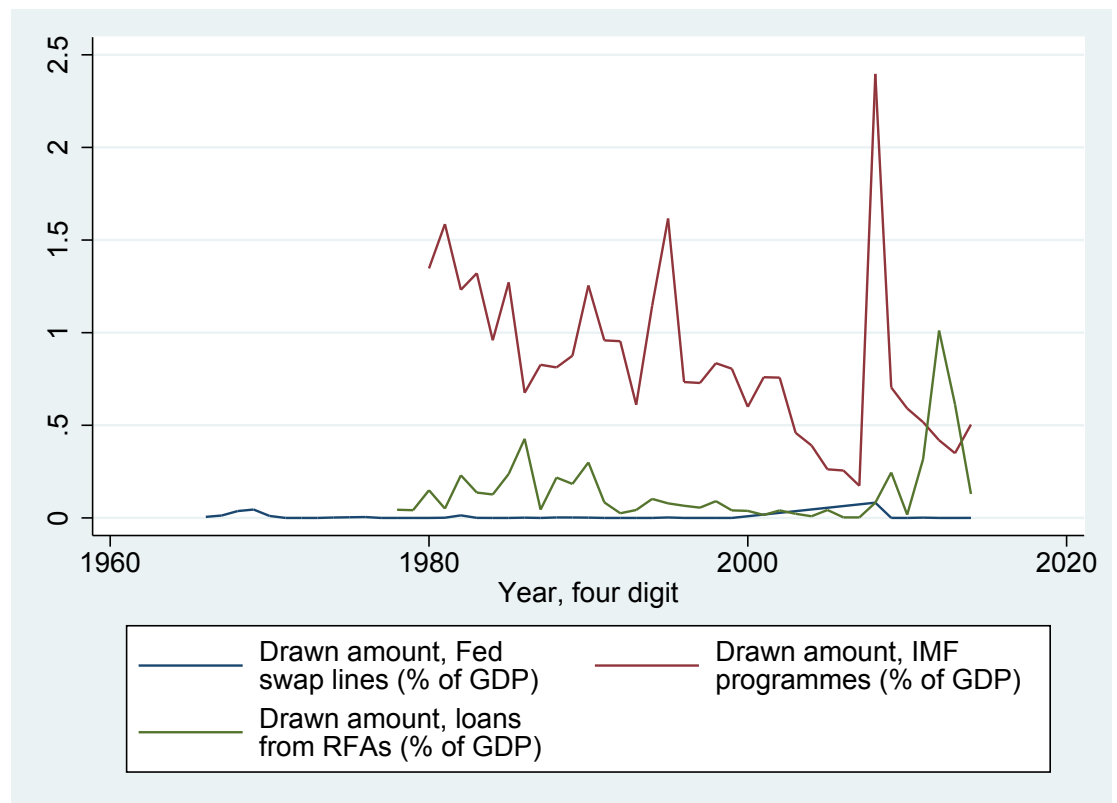

Source: World Bank, RFA websites, Federal Reserve. The chart shows the annual cross-country average.

Figure 5: MEMBERSHIP IN RFAs: 1980 versus 2014
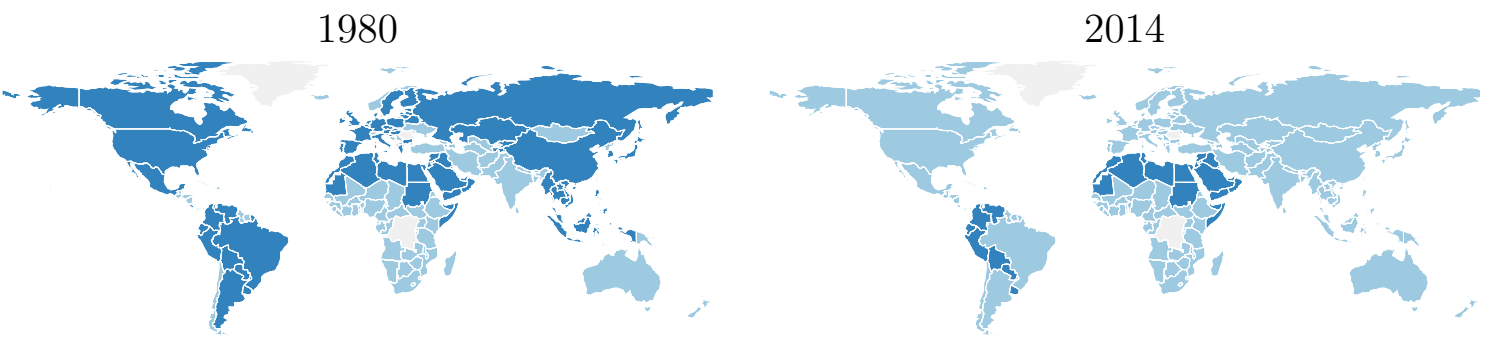

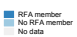

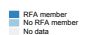

Source: RFA websites. Blue colour indicates membership in a RFA. The chart includes membership in the following RFAs: the Latin American Reserve Fund (FLAR), the Arab Monetary Fund (AMF), the Chiang Mai Initiative Multilateralisation (CMIM), the Contingent Reserve Arrangement (CRA), the European Stability Mechanism (ESM), the European Financial Stabilisation Mechanism (EFSM), the European Financial Stability Facility (EFSF), the Eurasian Fund for Stabilisation and Development (EFSD), the North American Framework Agreement (NAFA) and EU balance of payments assistance. 
Figure 6: Average Duration of SUdDen Stops AND GFSN COVERAGE
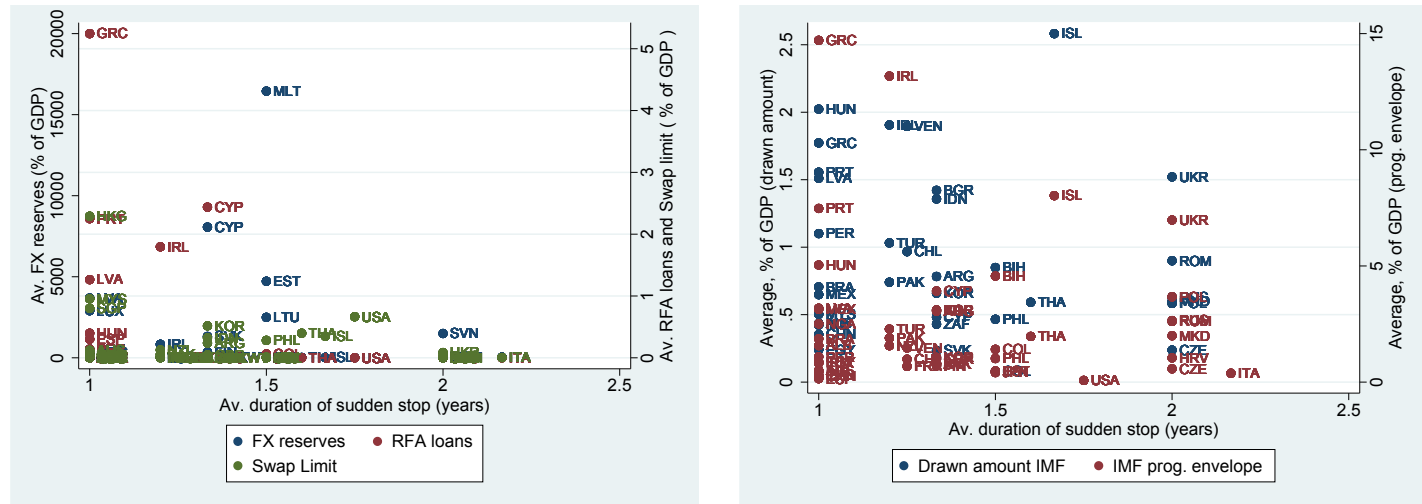

Source: Authors' calculations.

Figure 7: DEVELOPMENTS IN KEY ECONOMIC VARIABLES AROUND SUDDEN STOP PHENOMENA
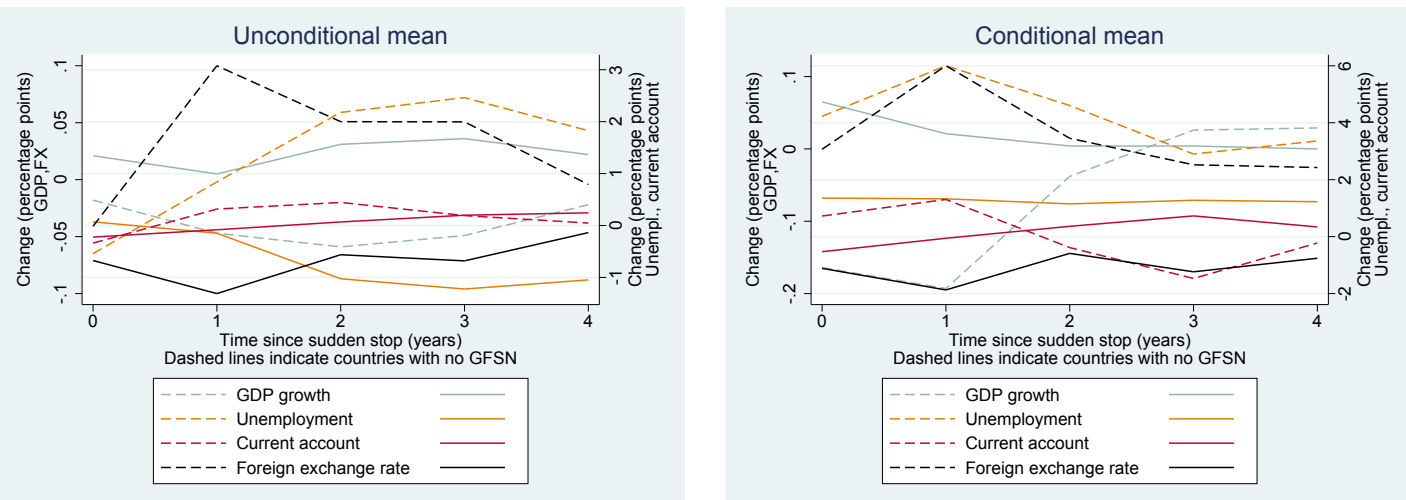

Source: Authors' calculation. Positive changes in FX denote devaluation of currency. 


\section{Appendix B: Details on data related to IMF pro- grammes}

\section{Data sources, availability and consistency}

Any analysis of the GFSN or the usefulness of IMF lending facilities benefits from a clear measure of Fund support to each supported country at each point in time. For the database presented in this paper, four sources for data on IMF lending facilities are used. The primary source is the IMF's MONitoring of Fund Arrangements (MONA) database. It contains all information usually provided in the Memoranda of Economic and Financial Policies (MEFPs) between a country and the IMF, grouped into several variables, which includes information on each condition and associated disbursements by review, including review dates. This makes MONA the most precise source of Fund support. Inter alia, MONA contains information on the amount agreed for a programme and at each review as well as on funding disbursed to a country on a specific date (its 'purchases' of SDRs). The MONA data base is available only for years 1992 to present. The second source of information is the IMF's International Financial Statistics (IFS), which are related to a country's balance of payments (b.o.p.) reporting, and which for years 19802009 also report a country's position with the Fund for Stand-By Arrangements (SBAs), Extended Fund Facilities (EFFs), Enhanced Structural Adjustment Facilities (ESAFs) and Structural Adjustment Facilities (SAFs). For these facilities, the IFS contain information on the agreed amount and on the undrawn balance. The third source of information on IMF programmes is the World Bank's International Debt Statistics, which provides under the heading 'IMF purchases' a sum of total annual drawings on the IMF's General Resources Account (GRA), excluding the reserve tranche. The World Bank data are available from 1966-present. The fourth source of information on IMF programmes is the IMF's record of members' financial position in the Fund, which provides information on agreed programmes and the associated agreed amounts for years 1952-present.

While three of the four data sources provide IMF lending data on an annualised basis, the underlying data recording and aggregation method will shape the aggregated information as programmes may span more than one calendar year. IMF 
programmes typically start when they are needed such that a two-year programme may span up to three calendar years. Only the MONA data base does not provide annualised information, but information by review date. This is related to the fact that disbursements are scheduled upon the agreement of a programme to take place after the completion of a review and hence depend on a successful review, but they may be brought forward or delayed if there is a change in the review date. Moreover, countries may apply for successor arrangements or change the type of arrangement during a year which implies that there may be more than one arrangement during one year. In addition, the size and nature of Fund support may not only change when the type of programme is switched, but also during a programme when waivers are granted or programme targets are amended. Consequently, actual Fund support may significantly differ from agreed Fund support and from drawn Fund support.

The different approaches to reporting and consequences for data aggregation need to be taken into consideration regarding the consistency of the four data sources used to compile information on a country's access to IMF funding. While the MONA database contains information directly drawn from programme documentation, the data on IMF financial transactions are drawn from the IMF Treasury. IFS data, related to international investment position (i.i.p.) / balance of payments (b.o.p.) reporting, and World Bank data are also based on country reporting. As a consequence, MONA provides information for specific dates while the other sources may be aggregated on at least a quarterly basis or follow year-end accounting. This may lead to differences in reporting information annually.

In compiling the information on IMF support for this database, several consistency checks have been applied. These checks have indicated that full consistency is difficult to achieve for years not covered by MONA data. While information on the overall programme envelope is almost fully consistent across all years covered in the database, there are some differences, not only in reporting, regarding disbursed amounts. This may be related to the fact that disbursements per year can be summed or averaged and to the fact that planned disbursements may differ from actual disbursements. In addition, not all programmes or disbursements are covered equally by each data source, even during the times when they overlap. 
To minimise consistency issues, the information in the GFSN database on IMF support is primarily based on IMF MONA data (for years 1992-2014), and only supplemented with IFS or World Bank data where information is not available in MONA. This implies that data on both programme envelope and drawn amounts is sourced from MONA data for years 1992-2014 and supplemented by IFS and World Bank data. Data on programme envelopes for years 1960-1979 are drawn from IMF financial position information and for years 1980-1991 from the IFS. Data on drawn amounts for years 1980-1991 are primarily sourced from the IFS, and supplemented with World Bank data for years 1966-1979 and where IFS data was missing for years 1980-1991. As the differing reporting standards imply that not all programme years may be reliably covered, particularly not for years in which data from MONA are not available, the database provides indicator variables on the data source. 2 indicator variables are provided which take the value 1 if an observation on agreed or drawn amount is taken from the IFS (agreed_fromifs and drawn_fromifs). An additional indicator variable takes the value 1 if an observation on the drawn amount is taken from the World Bank (from_wb). Importantly, while this approach gives a satisfactory record particularly for years 1992-2014, it has to be noted that it does not cover all programmes, as detailed below.

Not all IMF programmes are included in the database. Some programmes are not available in MONA and therefore disbursement information for these programmes, if listed in the database, stems from the IFS and World Bank. These include: Bulgaria (SBA, approved 27 February 2002), Democratic Republic of Congo (PRGF, approved 13 June 2002), Guyana (PRGF, approved 19 September 2002), Macedonia (SBA, approved 30 April 2003), Peru (SBA, approved 1 February 2002), Turkey (SBA, approved 4 February 2002) and all arrangements for Samoa. The programmes for the Republic of Yugoslavia and for Serbia and are also excluded from the database as they cannot be clearly attributed to one specific country at this stage. The SBA (2009) for Dominica is not included either.

Annualised data drawn from the MONA database is the basis for the indicators IMFAgreedTotaltoGDP and IMFDrawtoGDP. Inter alia, MONA contains information on the amount agreed for each programme and on funding disbursed to a country (its 'purchases' of SDRs). To measure access to Fund support, this 
paper focuses on the total programme envelope, the funding which has originally been planned to be disbursed and on the funding which has actually been disbursed. MONA data as provided by the Fund are not organised by year, but by programme and by review. The information on agreed and drawn amounts is compiled from the information on the programme envelope and from the information on planned and actual disbursements during each review. This includes revisions of the total programme envelope during the course of a programme. Annualising the data implies that some disbursements may be listed for years without a corresponding IMF arrangement. Such disbursements are related to revised disbursement schedules of previously agreed programmes. Moreover, if more than one programme took place during a year aggregated amounts may cover more than one programme. A variable (IMFNrofProgrammes) indicates the number of on-going programmes during a year.

For years 1992-2014 MONA data on the programme envelope is only supplemented for 24 country-year observations and for 591 country-year observations on drawn amounts and data on where information on a programme envelope was not provided in MONA. The additional information on the programme envelope only relates to years 1992 and 1993 for which the coverage in MONA is less comprehensive than for following years. ${ }^{28}$ Drawn amounts are supplemented for more years, but mostly for years prior to 2002 for which MONA data is provided in a different format. 29

The information on IMF support in the IFS is provided for programme envelope and undrawn amount, for SBAs, EFFs, ESAFs and SAFs for years 1980-2009. The drawn amount is calculated as the difference between agreed and undrawn amount. It should be noted that the agreed amount provided in the IFS refers to the total programme envelope, but that this information in the IFS is not provided for every year of the programme if no amount was drawn after the year

\footnotetext{
28 These observations include inter alia programmes which have been agreed early in 1992 , such as Guatemala's precautionary SBA which had been agreed in 1992 and expired in 1994, Panama's SBA which had been agreed in 1992 and expired in 1993 and which was not fully drawn, and Jordan's SBA which had been agreed in 1992 and which expired in 1994.

29 The IMF provides MONA data for years 1992-2002 as so-called 'Archived MONA' which on some occasions has different labels from the data from 2002 and a slightly different recording of reviews, which is the information on which the calculation of the drawn amount is based.
} 
of programme approval. Moreover, while the total programme envelope in IFS data largely corresponds to the total programme envelope provided in the MONA data base for years 1992-2009, the figures are not identical for all years. It may be possible that these (rather small) divergences are related to the fact that IFS data on a country's transactions with the IMF stem from its b.o.p. reporting.

The information from the World Bank International Debt statistics provided for drawings from the IMF's GRA can complement the information from MONA and IFS further. World Bank data on IMF support contains longer time series than the IFS. However, since the World Bank data refers to drawings from the GRA, it includes non-concessional financing, and therefore does not report all drawings which are listed on the IMF's website. Hence, the additional information provided by the World Bank data should be considered complementary, but not fully comprehensive information, particularly for years 1966-1980 for which the World Bank is the only source for the variable IMFDrawtoGDP.

Information on the agreed amounts between 1960 and 1980 is added from the IMF website using its Financial Data Query tool. This tool allows listing all programme agreement dates and types, including the agreed amount. For adding this information to the variable IMFAgreedTotaltoGDP, the date of the arrangement is considered the starting year while the expiration date is considered the final year. The amount agreed, i.e. the total programme envelope, is transformed from SDR into USD using year end exchange rates, and then divided by GDP in current USD. Similar to the approach for MONA data, the programme envelope is summed if there was more than one programme per year. While the IMF website also provides information on two subsequent programmes, it does not provide the corresponding arrangement numbers. Hence, for years 1960-1980, arrangement numbers are not included in the data base. However, it is possible to detect a second programme (which in these times were mostly SBAs) if the total programme envelope changes significantly (i.e. not just driven by marginal changes in GDP) from one year to the next. 


\section{Appendix C: Details on measuring private capital flows}

There are two main concepts for recording international capital flows which have been used for the analysis of financial flows and positions. The standard balance of payments (b.o.p.) provides information on capital flows between residents and nonresidents, whereas the recording of the international investment position (i.i.p.) provides information on stocks of financial assets and liabilities. This implies that the researcher interested in (sudden) capital movements, particularly at shorter frequencies, should prefer to look at the flows recorded in the b.o.p.

\section{Private versus public flows}

Both public and private capital flows, which are also the basis for the financial position recorded in the i.i.p., are accounted for in the financial account of the b.o.p. For the context of this paper, it is useful to consider the financial account as being composed of public and private flows (e.g. Bayoumi et al., 2015): Financialaccount $=$ publicflows + privateflows However, both the i.i.p. and the financial account recording of the b.o.p. list assets and liabilities by functional category, which include (i) direct investment, (ii) portfolio investment, (iii) financial derivatives (other than reserves and employee stock options), (iv) other investment, and only for assets (v) reserve assets. Consequently, public flows have to be separated from private flows for these functional categories. For example, according to BPM 6, IMF loans and SDR allocations are recorded under 'other investment', while SDR holdings are recorded as 'reserve assets'.

Consequently, private flows can either be derived separately from these b.o.p. items or calculated as the financial account net of public flows, and the approach in the few papers which have attempted to do so depends on the research question. To show an inverse relationship between public and private capital flows, Dasgupta and Ratha (2000) define FDI flows and all portfolio flows as private, and official flows as all bilateral governmental and multilateral flows other than those related to the IMF. Milesi-Ferretti and Tille (2011) select those items of the b.o.p. where a bank is involved in the transaction to measure financial integration. 
By contrast, Bayoumi et al. (2015) aim to single out public capital flows. They sum reserves and net portfolio investment and other investment for central bank and general government, making adjustments for countries with e.g. large pension funds or sovereign this wealth funds. Alfaro et al. (2014) focus on private flows, acknowledging the difficulty of differentiating between public and private issuers and holders of debt securities. Particularly for 'debt securities' which are recorded under 'portfolio investment' (b.o.p. item 3.2), it is difficult to distinguish between public and private issuers and holders of debt securities. For this reason, Alfaro et al. (2014) combine IMF b.o.p. data with the World Bank's Global Development Finance database, which contains this information for developing countries, and consequently focus their analysis on developing countries. The approach to approximating private sector capital flows based on b.o.p. statistics is similar to Alfaro et al. (2014) and Lane and Milesi-Ferretti (2001). In particular, this paper also counts errors and omissions, which denote the accounting difference between inflows and outflows, as unrecorded capital outflows such that they are added as part of private debt assets. However, the approach differs in a main respect in that this paper looks at gross instead of net flows.

In addition, some assumptions are needed as b.o.p. statistics are not bilateral. Consider the depiction of capital inflows and capital outflows in Figure C.1 . A proper identification of private capital inflows and outflows requires data from both the creditor and the debtor side. From the b.o.p. statistics it can be inferred whether the flow to or from the domestic economy is to or from the public or the private sector, but not the source or destination sector of the foreign economy. The source or destination sector in the foreign economy can be private or public. This leads to the four types of bilateral flows depicted in Figure C.1 . Consider inflows to the domestic economy first. As the source sector is not known, all flows which are recorded in the domestic private sector are treated as private and all flows which are recorded in the domestic public sector are treated as public. As long as it can be assumes that foreign public capital flows which are eventually targeted at the private sector, such as foreign aid, are first channelled via the public sector in the domestic economy, the measure of private flows largely excludes those flows which should be considered public. A similar logic can be applied to outflows by 
considering all outflows from the private sector as private and all outflows from the public sector as public.

Figure C.0 : IDENTIFICATiOn OF PRIVATE CAPitAl INFLOWS AND OUTFLOWS
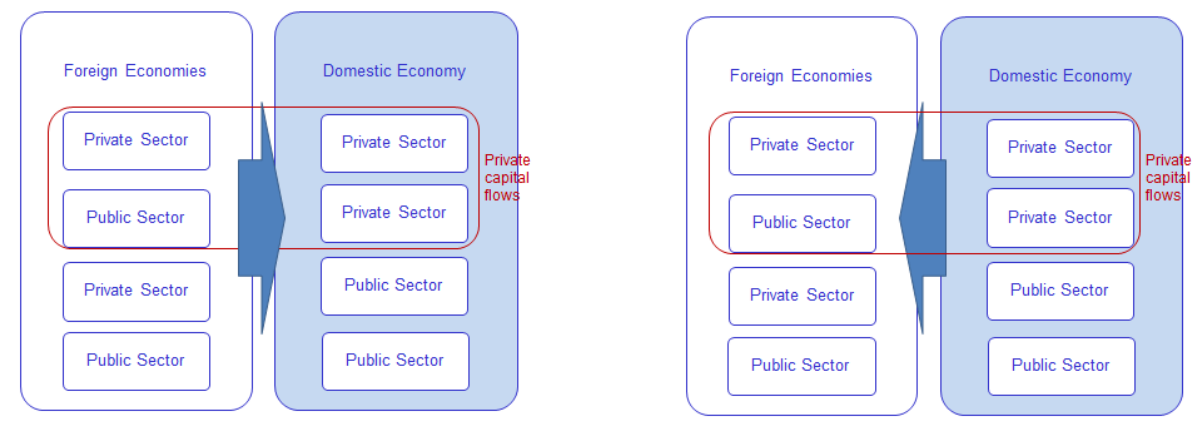

Inflows defined as (private and public) flows from foreign investors to the domestic private sector. Outflows defined as flows from private agents resident in domestic country, investing in (public or private) assets abroad.

\section{Inflows versus outflows}

While most earlier studies have focused on net capital inflows, more recent studies have looked at gross outflows and gross inflows separately to better gauge foreign and domestic triggers of capital flows. It is important to stress, as already noted by Forbes and Warnock (2012), that "gross inflows is the net of foreign purchases and foreign sales of domestic assets, while gross outflows is the net of domestic residents' purchases of foreign assets and domestic residents' sales of foreign assets". In other words, gross inflows effectively measure net financial transactions by non-residents and gross outflows measure net financial transactions by residents. Consequently, net inflows/outflows denote the difference between domestic and foreign net flows. Looking at net flows would not allow a distinction to be made between changes in foreign and domestic flows.

As the new edition of the IMF's Balance of Payments Manual (BPM6) was introduced in 2012, with effect on data series from 2005, differences between BPM5 and BPM6 are also reflected in the data. The dataset covers the period 19702015. This means that b.o.p. data from 2005 onwards accounted for according to 
BPM6 are included in the dataset. For the financial account, which is the source of the data on capital flows, changes are minor. First, "reverse investment" in "direct investment" was reclassified, which does not affect the composition of private capital flows since this paper assumes that all direct investment is by definition private. In addition to some changes in the accounting of portfolio investment, BPM6 switched the sign for gross outflows. While the database contains the data accounted for under BPM6 for years after 2005, the data are included according to the BPM5 signing convention, i.e. similar to earlier research outflows are denoted with a negative sign.

In contrast to Forbes and Warnock (2012), this approach cannot distinguish between foreign and domestic investors. However, this paper does not focus on the behaviour of investors. To gauge the adequacy of the GFSN during past capital flow episodes, it is important to adequately capture private flows, but not the type of investor. Moreover, residency-based capital flow data can be heavily distorted by the use of tax havens or low-tax areas.

While the capital flow data in the database are annualised, they are available quarterly. When only focusing on the behaviour of capital flows, data at a higher frequency than annual is useful owing to the high volatility of capital flows particularly around crises. Moreover, capital flow episodes may not span more than one year. Consequently, particularly for analysing capital flow episodes, using at least quarterly data should be preferable. However, data for two of the four elements of the GFSN (harmonised reserves data by country and RFA access) are not available quarterly. Therefore, the database includes annual data also for capital flows, but note that the methodology could in principle also be applied to quarterly data.

In addition, a concern should be noted which led Alfaro et al. (2014) to focus their paper on developing economies only. The distinction between private and public entities in 'portfolio investment' and 'other investment' is not available for all IMF-reporting countries for longer time series. Particularly during the 1970s and 1980s, separate data for public and private entities are not available for many countries. Moreover, the fact that information is missing for those years for some countries may not be random and could be related to the degree of financial integration of a country or to its exchange rate regime. Despite these data issues, 
the consistency of accounting of b.o.p. data and availability for most countries makes it a valuable source at least for analysing episodes since the mid-1990s and the interaction between the GFSN and private capital flows.

Data coverage for b.o.p. capital flows is limited particularly for years earlier than the 1990s and for many developing economies. Corresponding to the size of the economies, the size of capital flows differs across countries. This implies that for some emerging and developing economies in the sample, hardly any capital flows are recorded. Moreover, as capital flows were generally smaller during the 1970s and 1980s, there are fewer non-missing observations for those years. In addition, since b.o.p. reporting is voluntary for some items, non-random non-reporting by some countries cannot be ruled out. To deal with large numbers of missing data and zeros particularly for developing countries and for years prior to 1990, the sample is restricted for the analysis of sudden stops to the $80 \%$ largest economies or 72 countries in total. Although this is a reduced and possibly non-randomly restricted sample, it contains the non-negligible capital flows. Moreover, since this paper treats errors and omissions as unrecorded capital outflows, this may help to to address at least part of the bias resulting from "non-zero zeros" in the data. 